Working Paper/Document de travail 2014-36

\title{
Global Inflation Dynamics in the Post-Crisis Period: What Explains the Twin Puzzle?
}

by Christian Friedrich 
Bank of Canada Working Paper 2014-36

August 2014

\title{
Global Inflation Dynamics in the Post-Crisis Period: What Explains the Twin Puzzle?
}

by

\section{Christian Friedrich}

\author{
International Economic Analysis Department \\ Bank of Canada \\ Ottawa, Ontario, Canada K1A 0G9 \\ cfriedrich@bankofcanada.ca
}

Bank of Canada working papers are theoretical or empirical works-in-progress on subjects in economics and finance. The views expressed in this paper are those of the author. No responsibility for them should be attributed to the Bank of Canada. 


\section{Acknowledgements}

I would like to thank, without implicating, Michael Ehrmann, Benoit Mojon, Filippo Ferroni, Robert Lavigne, Rose Cunningham, Mark Kruger, Michael Francis, Danilo Leiva-Leon for valuable comments on the paper and Bryce Shelton for excellent assistance in the data collection process. I would also like to thank all seminar participants at the Banque de France, the Bank of Canada, the Graduate Institute Geneva and all conference participants at the 6th NAFTA Central Banks Conference on the North American Economy: Outlook and Challenges for Economic Policy. 


\begin{abstract}
Inflation dynamics in advanced countries have produced two consecutive puzzles during the years after the global financial crisis. The first puzzle emerged when inflation rates over the period 2009-11 were consistently higher than expected, although economic slack in advanced countries reached its highest level in recent history. The second puzzle - still present today - was initially observed in 2012, when inflation rates in advanced countries were weakening rapidly despite the ongoing economic recovery. This paper specifies a global Phillips curve for headline inflation using inflation expectations by professional forecasters and a measure of economic slack at the global level over the period 1995q1-2013q3. Phillips curve data points in the period after the global financial crisis show a significantly different but consistent pattern compared to data points in the period before or during the crisis. In the next step, potential explanatory variables at the global level are assessed regarding their ability to improve the in-sample fit of the global Phillips curve. The analysis yields three main findings. First, the standard determinants can still explain a sizable share of global inflation dynamics. Second, household inflation expectations are an important addition to the global Phillips curve. And third, the fiscal policy stance helps explain global inflation dynamics. When taking all three findings into account, it is possible to closely replicate global inflation dynamics over the post-crisis period.
\end{abstract}

JEL classification: E31, E5, F41

Bank classification: Inflation and prices; International topics; Fiscal policy

\title{
Résumé
}

La dynamique de l'inflation au sein des pays avancés a donné lieu à deux énigmes, qui se sont succédé après la crise financière mondiale. La première apparaît au moment où, de 2009 à 2011, les taux d'inflation étaient systématiquement plus élevés que prévu tandis que le niveau des capacités excédentaires atteignait, de mémoire récente, un sommet. La seconde énigme persiste à ce jour: malgré la reprise, l'inflation connaît un affaiblissement rapide pour la première fois en 2012. Dans son étude, l'auteur spécifie tout d'abord une courbe de Phillips mondiale de l'inflation nominale en s'appuyant sur les anticipations d'inflation de prévisionnistes professionnels, ainsi qu'une mesure des capacités excédentaires à l'échelle internationale pour la période allant du $1^{\mathrm{er}}$ trimestre 1995 au $3^{\mathrm{e}}$ trimestre 2013. Après la crise, les points de données de la courbe présentent une forme homogène sensiblement différente de la forme épousée avant ou pendant la crise. L'auteur évalue ensuite l'aptitude de plusieurs variables explicatives à améliorer l'adéquation statistique sur l'échantillon pour la spécification choisie de la courbe de Phillips. De son analyse se dégagent trois conclusions importantes. 1) Les déterminants habituels permettent encore d'interpréter une bonne partie de la dynamique de l'inflation à l'échelle internationale. 2) Les anticipations d'inflation des ménages sont un apport important à la courbe de Phillips mondiale. 3) L'orientation de la politique 
budgétaire aide à expliquer le comportement de l'inflation dans le monde. La prise en compte de ces trois observations rend possible une reproduction plus fidèle de la dynamique de l'inflation dans l'après-crise.

Classification JEL : E31, E5, F41

Classification de la Banque : Inflation et prix; Questions internationales; Politique budgétaire 


\section{Introduction}

Inflation dynamics in advanced countries have been largely puzzling over the recent past. While inflation rates fell sharply during the global financial crisis and thus behaved as expected, their subsequent post-crisis evolution is much harder to align with economic theory. In fact, two distinct puzzles have emerged. The first puzzle is defined by the observation that inflation rates over the period 2009-2011 were consistently higher than expected, even though economic slack in advanced countries was at its highest level in recent history. The second puzzle emerged from 2012 onwards, when inflation rates in many advanced countries were weakening rapidly despite the ongoing economic recovery.

The first puzzle was initially raised by Williams (2010) in the context of the United States and later expanded to advanced countries in general by WEO (2013). The puzzle concerns the fact that inflation rates have remained very stable following the financial crisis - despite rising levels of unemployment. The key explanatory factors cited in WEO (2013) were stable inflation expectations arising from successfully established inflation-targeting regimes and a long-term decline in the slope of the Phillips curve, i.e., an increasingly weaker sensitivity of inflation to economic slack. The main conclusion of the analysis was that as long as central bank independence was maintained, inflation would evolve around the inflation target.

The second puzzle emerged more recently. During 2012, inflation rates in advanced countries suddenly started falling and have remained substantially below target since. In light of these developments, the IMF has recently issued a warning about the risk of global deflation. ${ }^{1}$ Although most advanced economies still face substantial amounts of economic slack (especially in Europe), it is specifically puzzling why the phenomenon of falling inflation rates occurs at a time when economic slack in many countries is dissipating gradually.

In this paper, I contribute to the literature by reconciling the two puzzles at the international level and examining a broad set of common explanations for both. I start with the specification of a global Phillips curve that explains the dynamics of headline inflation using inflation expectations and a measure of economic slack at the global level over the 1995q1-2013q3 period. It turns out that all the Phillips curve data points during the post-crisis period, defined as the time after $2009 \mathrm{q} 4$, show a consistent but significantly different pattern than data points before or during the crisis period. In the next step, a variety of potential explanatory variables are assessed in terms of their ability to improve the in-sample fit of the Phillips curve. The analysis yields three main findings. First, the standard determinants can explain a sizable share of global inflation dynamics. Second, household inflation expectations are an important addition to the global Phillips curve. Moreover, household inflation expectations appear to be more volatile than inflation expectations by professional forecasters and most likely are a proxy for energy and food price dynamics. And third, the government budget balance helps predict inflation dynamics as well. When all three findings are taken into account, it is possible to closely replicate global inflation dynamics over the post-crisis period.

While this paper explicitly deals with global inflation dynamics in the post-crisis period, it is not the first one to examine global inflation. Although only a few papers specify a global Phillips curve explicitly, there is a large body of academic literature that incorporates international elements in domestic Phillips curves (see Eickmeier and Pijenburg (2013) and references cited therein). The typical paper in this literature uses a standard Phillips curve framework and augments it with international variables, such as import-price inflation and a global measure of weighted (e.g., by GDP, Purchasing Power Parity (PPP), or trade) output gaps/unit labor costs.

\footnotetext{
${ }^{1}$ See Lagarde (2014).
} 
Although several authors find a statistically significant impact of these global determinants on domestic inflation rates, the findings are often only marginally significant and usually not very robust to the sample selection. ${ }^{2}$

Papers that study global inflation dynamics more explicitly are Ciccarelli and Mojon (2005), Hakkio (2009), Monacelli and Sala (2009), and Mumtaz and Surico (2012). ${ }^{3}$ The findings of this smaller body of literature indicate that common components of industrial production, unemployment rates, nominal wages, short- and long-term interest rates, the yield curve, and money aggregates may be important determinants. Longer-term trends, such as sectoral trade openness, have also been associated with the common elements of inflation. However, none of the above papers discusses inflation dynamics in the post-crisis years.

The remainder of the paper is organized as follows. Section 2 defines the two inflation puzzles and characterizes global inflation dynamics. Section 3 contains the core of the paper and consists of three subsections. The first sets up a global Phillips curve and explains that standard determinants are not able to sufficiently account for global inflation dynamics in the post-crisis period. A second subsection discusses a list of variables that could potentially explain the weak post-crisis fit, and a third subsection identifies those variables from the list that yield the best statistical fit. Section 4 then provides an interpretation of the findings and examines their robustness. Finally, Section 5 concludes.

\section{Characterizing Global Inflation Dynamics}

\subsection{Defining the Two Inflation Puzzles}

The first inflation puzzle was initially raised in the U.S. context. As pointed out in the introductions of Ball and Mazumder (2011) and Gordon (2013), the first reference to a "missing deflation puzzle" dates back to Williams (2010), who mentioned in a public speech that, "based on the experience of past severe recessions," he would have expected "inflation to fall by twice as much as it has". Subsequently, several authors took up the puzzle notion and tried to provide an empirical explanation for its occurrence - most of them used a version of the U.S. Phillips curve as the underlying tool. Ball and Mazumder (2011) provide two modifications of the Phillips curve. First, the authors measure core inflation with the weighted median of consumer price inflation across industries, and second, they allow the slope of the Phillips curve to change with the level and variance of inflation. Murphy (2014) discusses a similar line of arguments and suggests that the time-varying slope of the Phillips curve is driven by sticky-price and sticky-information approaches to price adjustments. By including a measure of uncertainty about regional economic conditions, Murphy argues that the recent path of inflation is explained well. A different approach is taken by Gordon (2013) who uses the "triangle model" from the early 1980s to explain away the missing deflation puzzle for the United States. The triangle model expresses current U.S. inflation with backward-looking inflation expectations, a measure of economic slack to capture demand-side developments and a measure of energy-price shocks to account for supply-side dynamics. When the model is estimated from the early 1960s to 1996, it predicts the U.S. inflation rate in $2013 \mathrm{q} 1$ within 0.5 percentage points - without changing the

\footnotetext{
${ }^{2}$ In a very recent paper, Medel et al. (2014) study the information content of global inflation dynamics for the prediction of national inflation rates in 31 countries. Their findings indicate that, especially in recent years, there is predictive content contained in the international inflation measure, but its impact on national inflation rates is very heterogeneous.

${ }^{3}$ Table A1 in the Appendix shows a more detailed description of these papers.
} 
slope of the Phillips curve over time. Gordon also argues that the predictions improve when the (total) unemployment rate is replaced by an explicit measure for short-term unemployment. Finally, Coibion and Gorodnichenko (2013) discuss the absence of disinflation dynamics in the United States over the years 2009-2011. By using household inflation expectations as a measure of inflation expectations in the Phillips curve, the authors manage to re-establish the Phillips curve relationship for the United States since the 1960s.

The theoretical literature has also discussed potential explanations for the first puzzle. The performance of DSGE models in describing inflation dynamics over the global financial crisis and the early post-crisis period has been criticized by Hall (2011) and King and Watson (2012). Del Negro et al. (2014) challenge these critiques by including financial frictions in a standard DSGE model. The resulting model predicts a sharp contradiction in economic activity, along with a modest and protracted decline in inflation following the period of financial stress at the end of 2008. In addition, Gilchrist et al. (2013) provide evidence for a channel leading from firm balance sheets to inflation dynamics. The authors demonstrate that firms with "weak" balance sheets increase their prices significantly in order to generate required revenues, and firms with strong balance sheets lower their prices in order to maintain their customer base. This finding helps explain inflation dynamics in the United States during the crisis itself, as well as during the early post-crisis period. Finally, Christiano et al. (2014) examine the dynamics of a broad set of economic variables in the United States over the crisis and the post-crisis period. The authors identify four shocks that can describe the features of the data well: a consumption wedge to proxy the zero lower bound, a financial wedge to describe credit market frictions, a technology shock that captures the decline of total factor productivity, and a government consumption shock. The authors conclude that the fall in total factor productivity and the rise in the cost of working capital were important factors that kept U.S. inflation high over the crisis.

The generalization of the first puzzle to the international level was then undertaken in WEO (2013). Here, it was observed that inflation rates in advanced countries remained very stable following the financial crisis despite continuously rising unemployment rates. The key explanatory factors cited were stable inflation expectations arising from successfully established inflationtargeting regimes and a long-term decline in the slope of the Phillips curve, i.e., an increasingly weaker sensitivity of inflation to economic slack. The main conclusion of the chapter is that as long as central bank independence is maintained, inflation will evolve around the target.

Figure 1 documents the presence of the first puzzle for a broad set of advanced countries. The bars indicate the deviation of quarterly headline inflation - measured on a year-on-year basis - from the mean value of the implicit or explicit inflation target of the associated central bank. The blue bars describe the deviation of the average inflation rate over the period 2009q42011q4. It turns out that all countries, with the exception of Switzerland, Japan and Ireland, have exhibited positive or only slightly negative deviations from the target during the first part of the post-crisis period. Figure 1 also shows that at the beginning of the first puzzle period (i.e., in 2009), annual real GDP growth across all sample countries amounted to $3.58 \%$. Hence, above-target inflation rates occurred at a time when economic growth was at its lowest level in recent history and one would rather expect deflationary pressures to occur.

The second puzzle emerged more recently. From 2012 onwards, inflation rates in the same set of advanced countries suddenly started falling and have remained substantially below target since. This development is indicated by the red bars that show the deviation of average inflation from target for the period 2012q1-2013q3. It turns out that most countries have experienced a clearly negative deviation over the second part of the post-crisis period. Although most ad- 


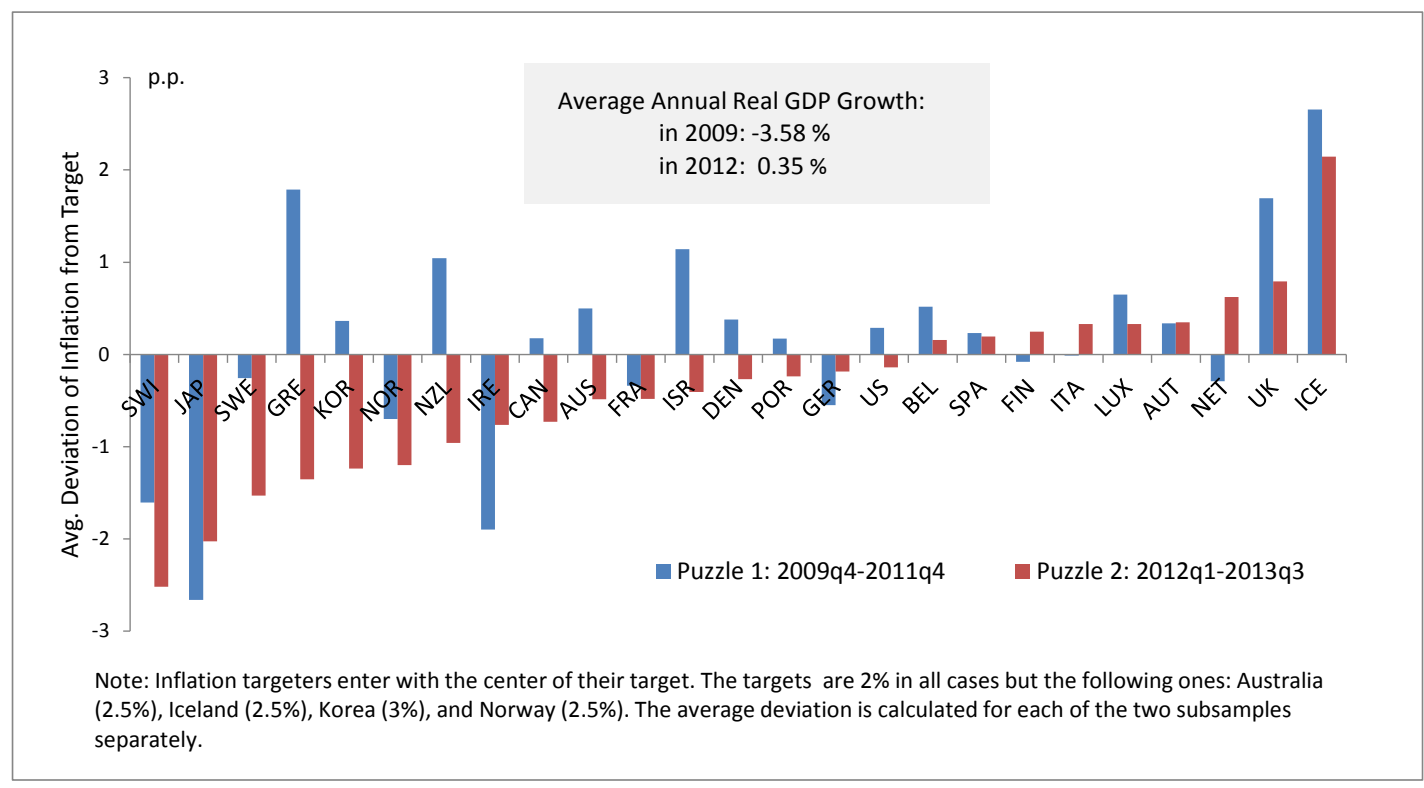

vanced economies still face substantial amounts of economic slack (especially in Europe), it is specifically puzzling why the phenomenon of falling inflation rates occurs at a time when the economic recovery had set in and economic slack is gradually dissipating in a large number of countries. Figure 1 shows that at the beginning of the second puzzle period (i.e., in 2012), annual real GDP growth across all sample countries amounted to 0.35\%. Although highly discussed in policy circles, this puzzle has not yet received much attention in the academic literature. The most closely related papers are Svensson (2013) and Ferroni and Mojon (2014). Svensson (2013) describes a similar experience for the case in Sweden, where inflation rates have been below target since 1997. He argues that keeping inflation rates below target for an extended period of time results in a 0.8 percentage point higher unemployment rate in Sweden over the period 1997-2011. Ferroni and Mojon (2014) examine the predictive content of global inflation for domestic inflation with a sample ranging until 2013. Using a variety of potential forecasting models, the authors find that this is indeed the case. In the next step, the authors try to identify the underlying forces at both the domestic and the global levels by specifying a VAR with sign restrictions that identify two domestic (supply and demand) and two global shocks (commodity prices and world demand). The authors specifically find that global supply-side factors, e.g., commodity prices, are most likely not the main driver of inflation dynamics after 2009. Instead, the authors argue that falling inflation rates in 2008-2009, and during the second puzzle period, are caused by demand shocks - with relative contributions of global and domestic shocks varying by country and time.

Finally, to sum up the findings from the literature and the evidence from Figure 1, it can be seen that both inflation puzzles appear in a broad set of advanced countries and seem to be even stronger for countries other than the United States. Therefore, the next subsection combines the information contained in national inflation rates to construct a "global" inflation rate. 


\subsection{Constructing Measures of Global Inflation}

"Global" inflation dynamics in this paper are based on national inflation data from 25 advanced countries over the period from $1995 \mathrm{q} 1$ to $2013 \mathrm{q} 3 .{ }^{4}$ National inflation rates are obtained by computing year-on-year growth rates of the individual Consumer Price Index (CPI) for each country. The data are obtained from the OECD and come in quarterly frequency. Global inflation rates are shown separately for headline and core inflation, where core inflation is defined as headline inflation purged of food and energy prices. Largely based on Ciccarelli and Mojon (2005), I use the following three methods to identify global inflation:

- A static factor model: The first approach here is the standard approach in the literature. It relies on the first common factor of national inflation rates. The underlying (static) factor model can be written as:

$$
X_{i, t}=\Lambda_{k, i} \times F_{k, t}+U_{i, t}
$$

Equation (1) expresses national inflation rates $\left(X_{i, t}\right)$ in terms of a set of orthogonal variables, the common factors $\left(F_{k, t}\right)$, with $k=1,2, \ldots, K$. I extract the resulting variable that captures the largest common variation, the first common factor $F_{1, t}$. The factor model also produces factor loadings $\Lambda_{k, i}$, which range from 0 to 1 , and quantify the importance of the first common factor for each country. Finally, $U_{i, t}$ represents the country-specific or idiosyncratic part of the variation in $X_{i, t}$, which cannot be explained by the first common factor. National inflation rates are standardized by subtracting their individual mean and dividing by their standard deviation before entering the factor model.

- An unweighted average: The second approach is based on the unweighted arithmetic mean of all national inflation rates. For comparison purposes with the factor model, the resulting global inflation series is standardized as well.

- A PPP weighted average: Finally, the third approach is based on a weighted arithmetic mean of national inflation rates, where the weights constitute world PPP shares (normalized to 1 among all sample countries) obtained from the WEO database. Again, the resulting global inflation series is standardized by subtracting the mean and dividing by its standard deviation.

Figure 2 shows the results. The global inflation rates obtained using any of the three approaches are very similar. The following observations emerge: First, headline inflation is more volatile than core inflation (note the different scales in the two plots), especially during the actual crisis period. Second - in line with the first puzzle - the period 2009-2011 shows a sustained upward movement in both inflation concepts. Third - in line with the second puzzle - more recently, all measures of global inflation show a clear downward trend.

The remainder of this paper deals with the specification of a global Phillips curve based on global headline inflation and the factor approach as the aggregation technique. ${ }^{5}$ In order to explain global inflation dynamics with global determinants, all potential explanatory variables

\footnotetext{
${ }^{4}$ I hereby follow the convention of the literature to use the "global" terminology but keeping the focus on advanced countries only (see Ciccarelli and Mojon (2005) for example). The sample countries correspond to the ones presented in Figure 1 and comprise Australia, Austria, Belgium, Canada, Denmark, Finland, France, Germany, Greece, Iceland, Ireland, Israel, Italy, Japan, Korea, Luxembourg, Netherlands, New Zealand, Norway, Portugal, Spain, Sweden, Switzerland, the United Kingdom and the United States.

${ }^{5}$ The robustness of the results to alternative aggregation techniques is examined in Section 4.2.
} 
Figure 2: Global Headline (left) and Core (right) Inflation
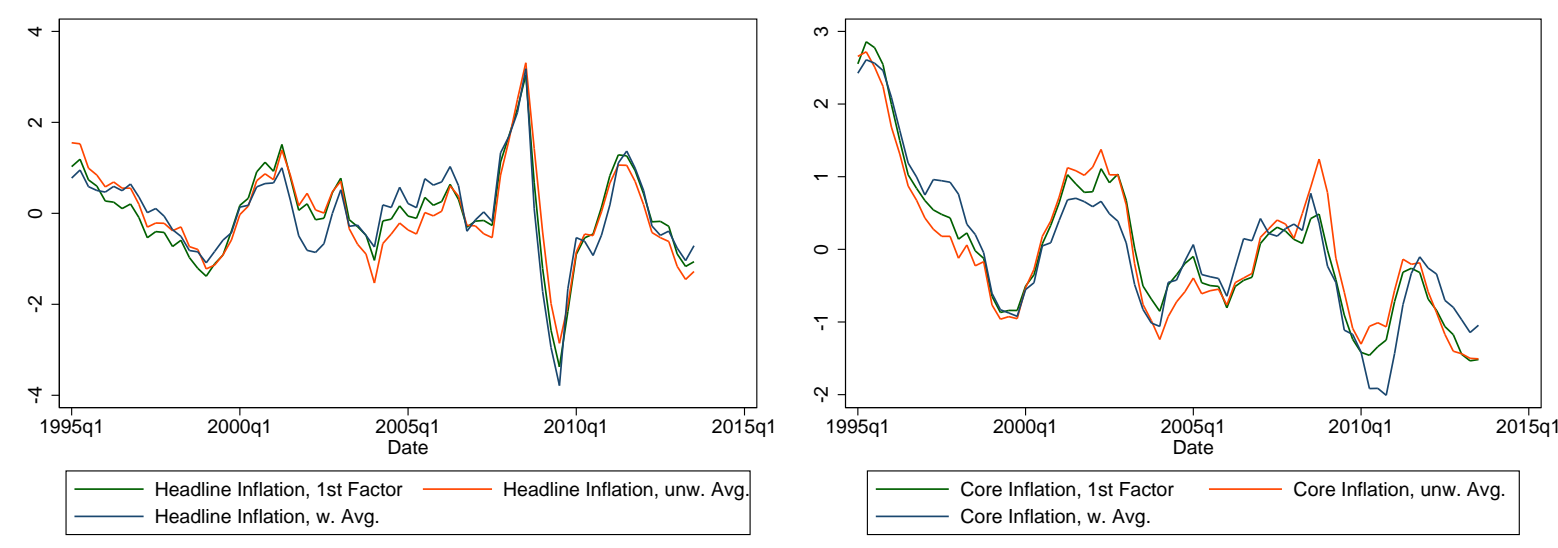

are aggregated from the national to the global level using the same methods as shown above. However, not all potential explanatory variables are available for the full set of sample countries and, with only a very few exceptions, I include only those national variables in the aggregation process that cover the entire sample period. ${ }^{6}$

\section{Specifying a Global Phillips Curve}

The goal of this section is to specify a global Phillips curve and specifically examine the impact of the crisis on its structure. The first subsection presents the shape of the standard Phillips curve before, during and after the crisis and discusses the relationship between the previously identified puzzles. The second subsection presents a large set of potential explanations for the puzzles and introduces a strategy to test for the most likely one(s). Finally, the third subsection discusses the outcome of the tests and specifies an augmented global Phillips curve.

\subsection{The Global Phillips Curve with Standard Determinants}

Following the identification of a global inflation rate in Section 2.2, this subsection aims to explain global inflation using standard determinants from the literature. In order to specify a global Phillips curve for global headline inflation, I largely follow the steps of Coibion and Gorodnichenko (2013) who specify a Phillips curve in the U.S. context. First, I calculate a measure of global "surprise" inflation that is obtained by subtracting global inflation expectations from the previously obtained global headline inflation series based on the first common factor. The global measure of inflation expectations is derived in the exact same way and is based on national series of inflation expectations by professional forecasters for the next calendar year, provided by Consensus Economics. Second, as a measure of economic slack, I calculate a global unemployment rate - again based on the first factor of national unemployment rates. Finally, I plot both variables in a scatter plot with the inflation surprise measure on the vertical and the measure of economic slack on the horizontal axis.

\footnotetext{
${ }^{6}$ Appendix Table A2 presents the exact country composition that underlies each of the global determinants.
} 
Figure 3: The Global Phillips Curve I

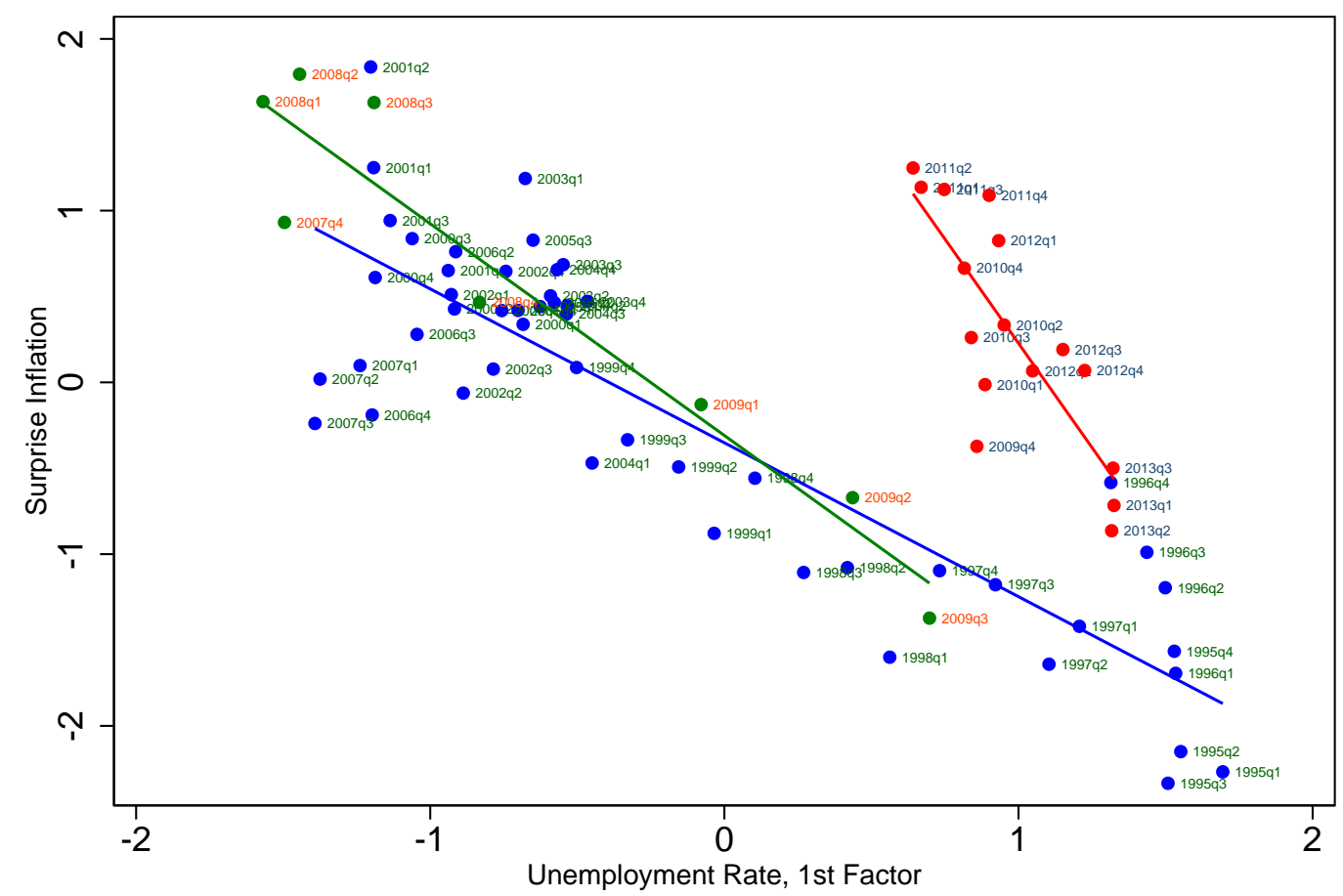

Note: Surprise Inflation = Difference between the 1st factor of headline inflation and the 1st factor of inflation expectations by professional forecasters for the next calendar year.

Figure 4: The Global Phillips Curve II

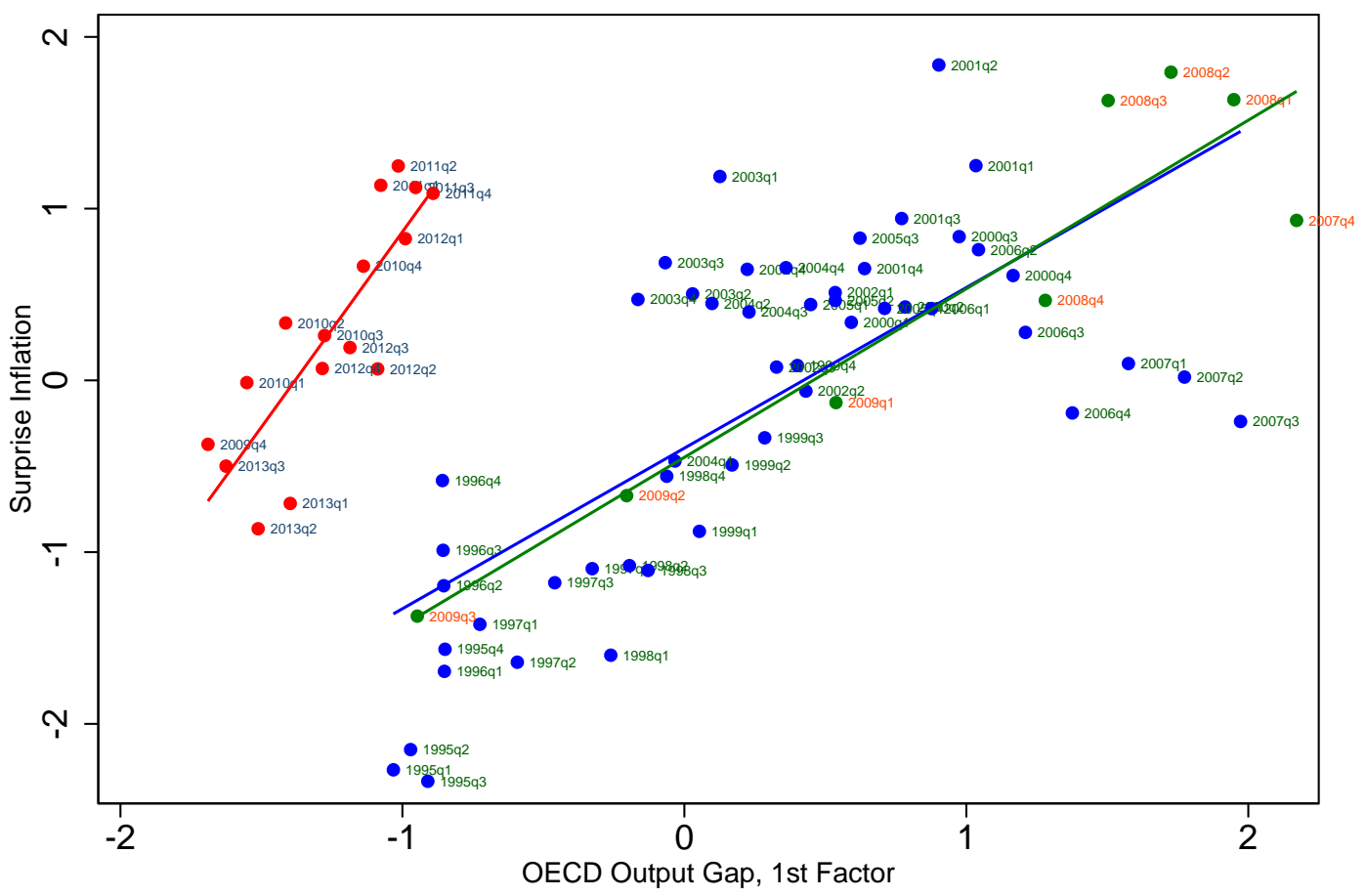

Note: Surprise Inflation $=$ Difference between the 1 st factor of headline inflation and the 1 st factor of inflation expectations by professional forecasters for the next calendar year. 
Based on Figure 3, which shows the results, we can make the following observations:

- First, there is a negative long-run relationship between the two variables during the precrisis period from 1995q1 to 2007q3 (blue line).

- Second, the relationship in the crisis period is fairly similar to the pre-crisis period between 2007q4 and 2009q3 (green line).

- And third, most importantly, the entire post-crisis period, 2009q4-2013q3, shows a significantly different, but consistent, pattern with a steeper slope and a higher intercept term (red line).

The third observation in particular requires a more detailed discussion. Evidence so far has suggested that there are two distinct puzzles at work, one with inflation rates for the period 2009-2011 that are too high and one with inflation rates from 2012 onwards that are too low. However, Figure 3 now reveals that surprise inflation in the entire post-crisis period is consistently more sensitive to changes in economic slack and consistently higher for reasons unrelated to economic slack. Hence, the two puzzles discussed so far can be combined into a single one, which I henceforth term the "Twin Puzzle." Using the unemployment rate as a measure of economic slack has the advantage that data are available at a quarterly frequency. However, since the Phillips curve is mostly specified using an output gap, Figure 4 shows the same relationship using the output gap as the measure of economic slack. While the result confirms the findings in Figure 3 (this time with a prior for a positive slope), the output gap measure has a major drawback. As output gap data for most of the sample countries are available only at annual frequency, the data have to be linearly interpolated to a quarterly frequency. Hence, the observations align more closely around the regression lines, suggesting an even better fit.

Next, we can use the above findings to specify an econometric model for global inflation. The starting point is a simple Phillips curve equation that corresponds to Figure 3. By moving inflation expectations to the right-hand side and assigning the coefficient $\beta$, global headline inflation $\left(\pi_{t}\right)$ is expressed in Equation (2) in terms of global inflation expectations $\left(\pi_{t}^{e}\right)$, and the global unemployment rate $\left(\right.$ unemp $\left._{t}\right)$. Finally, $\varepsilon_{t}$ represents an error term.

$$
\pi_{t}=\alpha+\beta \pi_{t}^{e}+\gamma \text { unemp } p_{t}+\varepsilon_{t}
$$

Specification 1 in Table 1 shows the estimated coefficients of the baseline specification, and Figure 5 illustrates the resulting in-sample fit. As already expected from observing Figure 3 , the standard Phillips curve relationship - containing inflation expectations by professional forecasters (PFC) and the unemployment rate - does not do very well in predicting inflation during the post-crisis period. When examining Figure 5 more closely, however, it turns out that the in-sample prediction does a fairly good job in capturing the higher-frequency dynamics during this period. The only problem seems to be a level and a scaling difference from around 2009 onwards. Equation (3) therefore introduces a Post-Crisis Dummy $\left(D p c_{t}\right)$ that takes on the value of 1 during the period 2009q4-2013q3 and 0 elsewhere:

$$
\pi_{t}=\alpha+\beta \pi_{t}^{e}+\gamma u n e m p_{t}+\psi D p c_{t}+\delta \pi_{t}^{e} \times D p c_{t}+\theta u n e m p_{t} \times D p c_{t}+\varepsilon_{t}
$$


Table 1: The Baseline Specification With and Without Post-Crisis Dummy

\begin{tabular}{lccccc}
\hline $\begin{array}{l}\text { Dependent Variable: } \\
\text { Headline Inflation }\end{array}$ & $(1)$ & $(2)$ & $(3)$ & $(4)$ & $(5)$ \\
\hline \hline Unemployment Rate & $-0.54^{* * *}$ & $-0.64^{* * *}$ & $-0.96^{* * *}$ & $-0.95^{* * *}$ & $-0.93^{* * *}$ \\
& $(0.00)$ & 0 & $(0.00)$ & $(0.00)$ & $(0.00)$ \\
Inflation Expectations by PFC, next year & $0.71^{* * *}$ & 1.00 & $1.01^{* * *}$ & 1.00 & $0.97^{* * *}$ \\
& $(0.00)$ & $()$. & $(0.00)$ & $()$. & $(0.00)$ \\
Post-Crisis Dummy & & & $2.99^{* * *}$ & $2.98^{* * *}$ & $3.32^{* * *}$ \\
& & & $(0.00)$ & $(0.00)$ & $(0.00)$ \\
Unemployment Rate x Post-Crisis Dummy & & & $-1.47^{* * *}$ & $-1.48^{* * *}$ & $-1.54^{* * *}$ \\
& & & $(0.00)$ & $(0.00)$ & $(0.00)$ \\
Infl. Exp. By PFC x Post-Crisis Dummy & & & & & $0.68^{* * *}$ \\
& & & & & $(0.00)$ \\
\hline \hline Observations & 75 & 75 & 75 & 75 & 75 \\
R-squared & 0.52 & & 0.78 & & \\
\hline
\end{tabular}

Note: P-Values in parentheses. Constant not reported. The stars indicate significance levels (also in all subsequent tables): $* * * p<0.01, * * p<0.05, * p<0.1$.

Figure 5: In-Sample Fit using the Standard Phillips Curve Relationship

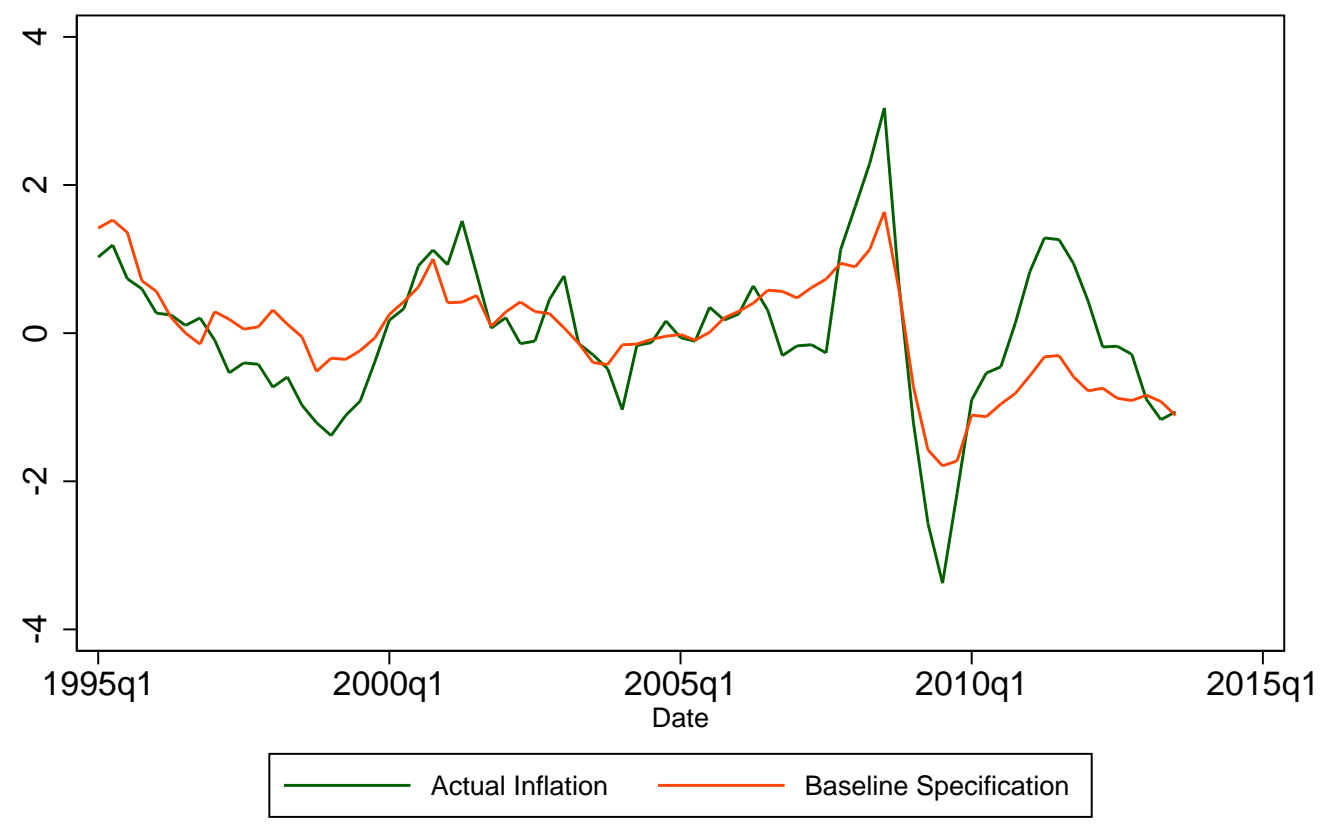

Note: Actual Inflation = 1st factor of headline inflation. Baseline Specification = In-sample fit for the standard global Phillips curve specification, containing the unemployment rate and inflation expectations by professional forecasters.

Equation (3) is written in the most general way. By also interacting the post-crisis dummy with all the other variables in the equation, it allows the effect of unemployment and inflation expectations to differ during the post-crisis period and thus to account for the scaling discrepancy noted in Figure 5. Specification 5 in Table 1 indicates that inflation is more sensitive to inflation expectations by professional forecasters and to the measure of economic slack during the postcrisis period. However, Specifications 3 and 5 also show that the difference between adding and excluding the interaction of the post-crisis dummy with inflation expectations is fairly small. In addition, the in-sample prediction based on Specification 5 is presented in Figure 6. Also, it is 


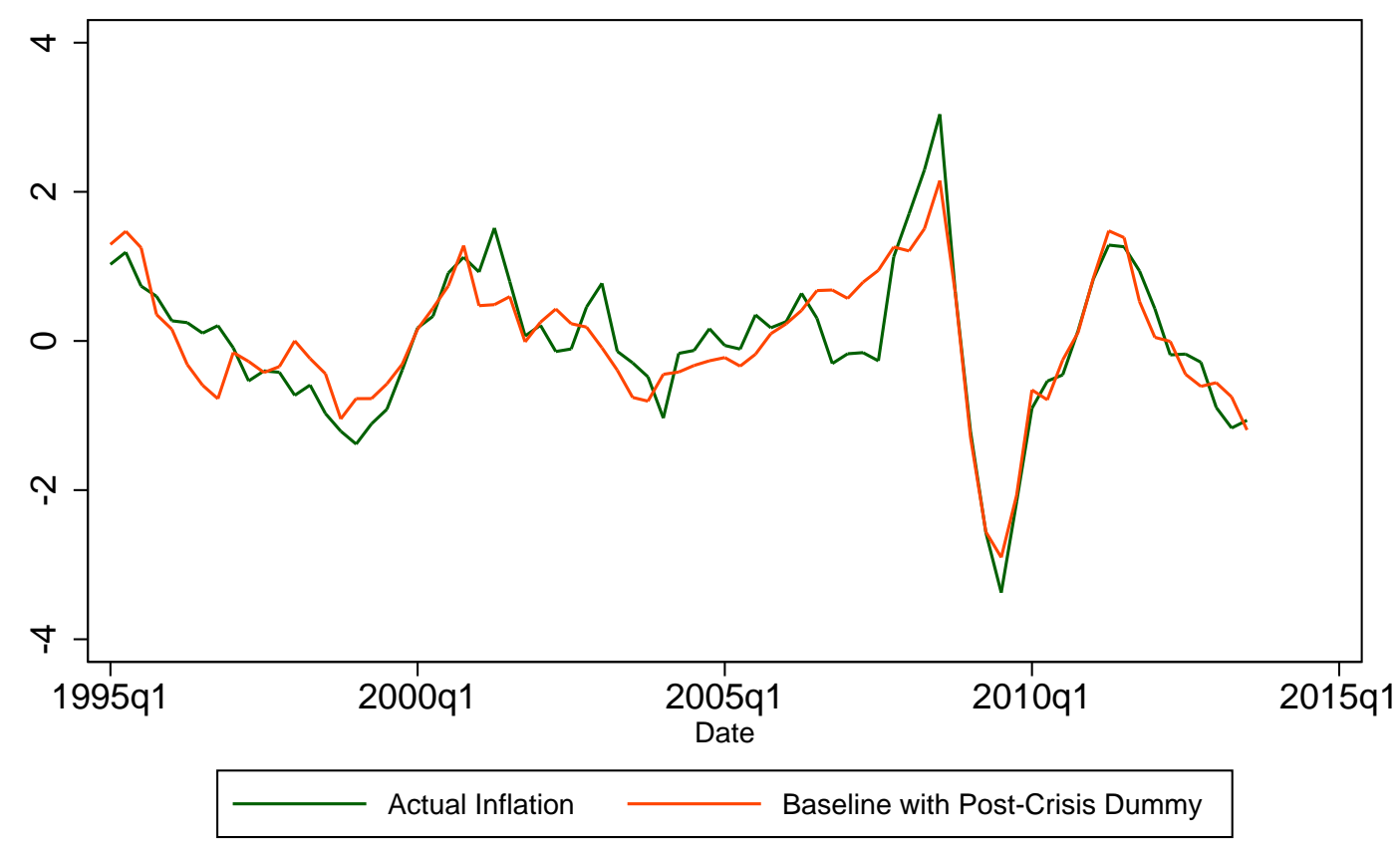

Note: Actual Inflation = 1st factor of headline inflation. Baseline Specification = In-sample fit for the standard global Phillips curve specification, containing the unemployment rate and inflation expectations by professional forecasters. Post-Crisis Dummy = Level and interaction terms of a dummy taking on the value of 1 over $2009 q 4-2013 q 3$.

confirmed here that adding and interacting the post-crisis dummy with the standard Phillips curve determinants remarkably improves the in-sample fit over the post-crisis period. Finally, Specifications 2 and 4 in Table 1 show that the results are fairly similar when constraining the coefficient on inflation expectations, $\beta$, to be equal to 1 (as was implicitly the case in Figure 3). Especially when looking at Specification 3, it turns out that inflation expectations receive a coefficient close to 1 , even in the unconstrained case.

Before moving on and testing which variable(s) could be underlying the post-crisis dummy, it is helpful to conduct a historical decomposition for the determinants contained in Specification 5. The contributions of the individual determinants are calculated by combining the estimated coefficients with the values of the underlying variables at each point in time. Figure 7 shows the result. Inflation expectations by professional forecasters played the most important role in the second half of the 1990s. The introduction of inflation targeting made agents and, hence, also professional forecasters revise their inflation expectations downward. On the other hand, global inflation dynamics in the 2000s were mostly driven by contributions of the unemployment rate. The crisis itself was then characterized by falling inflation expectations, while unemployment had not fully reacted yet. However, this changes significantly in the post-crisis period. Whereas inflation expectations by professional forecasters play a key role from mid-2009 to 2011, most of the post-crisis period is driven by a different variable. The high importance of the interaction term between the crisis dummy and the unemployment rate suggests that the effect is closely related to economic slack - however, it could also proxy for crisis-related dynamics in other variables. Finally, Figure 7 shows that the post-crisis dummy has shifted inflation in the post-crisis period up by a significant amount. 
Figure 7: Contributions of Individual Determinants - Post-Crisis Dummy

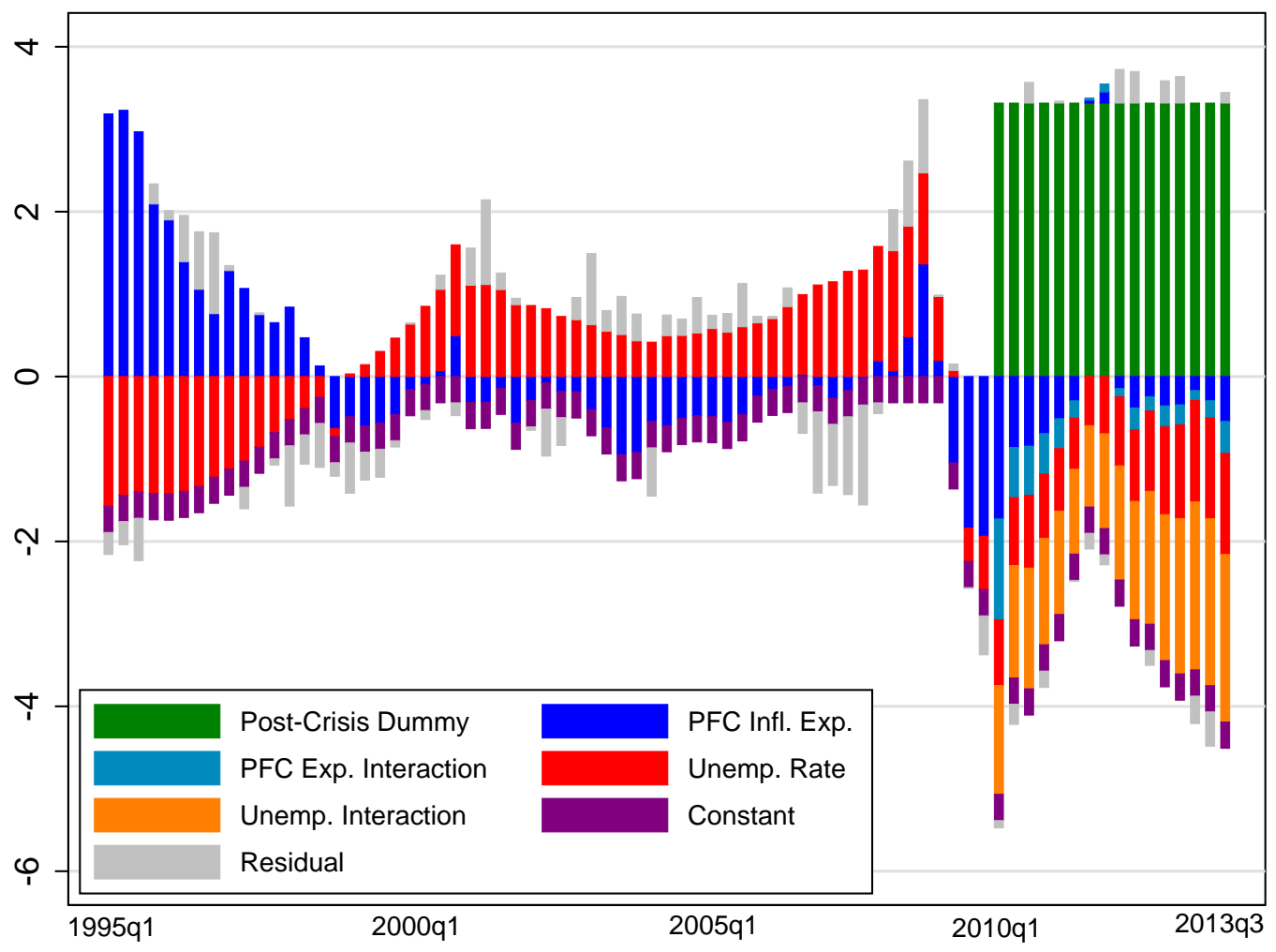

\subsection{Potential Explanatory Variables to Augment the Global Phillips Curve}

The previous subsection has shown that adding a post-crisis dummy to the standard Phillips curve specification significantly improves the fit during the entire period. The goal of this subsection is to give an economic meaning to the post-crisis dummy and to determine if it potentially proxies for another variable. Since the crisis and the post-crisis periods brought a substantial number of structural changes, the list of potential explanatory variables is long. In order to structure the analysis, I group them in the following five categories: additional measures of inflation expectations, additional measures of economic slack, policies and policy uncertainty, commodity prices, and financial variables. Table 2 shows all candidate variables and their placement into the categories. ${ }^{7}$

(i) Additional Measures of Inflation Expectations: Inflation expectations differ primarily along the following two dimensions:

- forecasting entity (i.e., surveys among professional forecasters, surveys among households, or expectations calculated from financial market data); and

- forecasting horizon (e.g., next calendar year or 1, 5, 10 years ahead). In general, we expect that inflation expectations generated by professional forecasters over the longer term are closer to central bank targets, and that inflation expectations by households over the short term are more affected by current inflation rates.

\footnotetext{
${ }^{7}$ Summary statistics are shown in Table A 3 in the Appendix.
} 
The role of household inflation expectations is of particular interest in the context of the global Phillips curve. Coibion and Gorodnichenko (2013) suggest that household inflation expectations are good proxies for inflation forecasts by small firms. The authors argue that using these expectations yields a stable Phillips curve relationship for the United States and therefore solves the first part of the post-crisis puzzle (i.e., inflation dynamics during 2009-2011). Unfortunately, there is no internationally consistent series for inflation expectations by households. I therefore use data from two different sources and treat each of them as separate variables. ${ }^{8}$ Expectations by households appear to be more volatile, especially in the United States, and are also more elevated compared with inflation expectations by professional forecasters - even more so during the post-crisis period.

(ii) Additional Measures of Economic Slack: Owing to the annual frequency of international output gap measures, this paper relies primarily on the unemployment rate as the measure of economic slack in the Phillips curve. Under certain assumptions, output gaps and unemployment gaps can be used interchangeably. However, in the presence of a jobless recovery or prolonged periods of slack, traditionally measured output gaps may not align well with unemployment gaps. Further, additional measures of economic slack, such as labor compensation measures or unit labor costs, might become more important in times of crises.

(iii) Policies and Policy Uncertainty: The global financial crisis was followed by an unprecedented amount of fiscal and monetary easing, possibly raising uncertainty.

- Fiscal Policy: In this paper, fiscal policy is represented by the variable Net Lending/Borrowing of the General Government in \% of GDP, henceforth referred to as the "government budget balance." Economic theory suggests that fiscal policy affects inflation dynamics through the measure of economic slack. However, in the presence of a deep and prolonged recession, this standard relationship could change, and large government budget deficits could have an additional direct effect on inflation, over and above the unemployment rate/output gap measure.

- Unconventional Monetary Policy: The adoption of unconventional monetary policies could lead to price increases, not only in asset markets but also in goods markets.

- Inflation Expectation Uncertainty: Inflation expectations from professional forecasters usually refer to the next calendar year. One could therefore expect an improvement in the forecasts towards the end of the year.

(iv) Commodity Prices: Although the previous literature has shown that inflation expectations, especially by households, are highly correlated with commodity-price dynamics (with a lag), the additional inclusion of energy and food prices in the Phillips curve might improve the fit - even more so when inflation expectations are focused on the long term.

(v) Financial Variables: A number of theoretical papers discuss the impact of financial frictions (e.g., Christiano et al., 2014; Del Negro et al., 2014) and firm balance sheets (e.g.,

\footnotetext{
${ }^{8}$ Inflation expectations by U.S. households are from the Michigan Survey of Consumers and are based on the question: "By about what percent per year do you expect prices to go up or down, on the average, during the next 12 months?" Inflation expectations by European households are provided by the OECD for 11 countries in our sample and are based on the question: "By comparison with the past 12 months, how do you expect that consumer prices will develop in the next 12 months?" Possible answers range from "increase more rapidly" to "fall" in five steps and are converted into an overall index.
} 
Table 2: Description of Potential Explanatory Variables

Inflation Expectations

Professional Forecasters, next calendar year

1 Headline Inflation, backwardlooking

2 Core Inflation, backward-looking Consensus Economics OECD, BoC Calculations $\mathrm{OECD}, \mathrm{BOC}$

Calculations

US Households, 1 year-ahead Average of core inflation over the last 4 quarters

Surveys of

Inflation expectations by US households based on the question: "By what percent do you expect prices to go up, on the average, during the next 12 months?"

4 US Households, 5+ years-ahead Inflation expectations by US households based on the question: "By about what percent per year do you expect prices to go up or down, on the average, during the next 5 to 10 years?"

5 European Households, 1 yearahead

Index for inflation expectations by European households based on the

Consumers, Univ. of

Michigan

Surveys of

Consumers, Univ. of

Michigan

question "By comparison with the past 12 months, how do you expect that

OECD

consumer prices will develop in the next 12 months?" Possible answers range from "increase more rapidly" to "fall" in 5 steps.

6 Professional Forecasters, 5 calendar years from now

Inflation Expectations by Professional Forecasters in 5 Years

Consensus

Economics

Consensus

Inflation Expectations by Professional Forecasters in 10 Years

Economics

calendar years from now

Difference between yields of inflation-indexed bonds and non-indexed bonds

Bloomberg, BoC

Calculations

years

Difference between yields of inflation-indexed bonds and non-indexed bonds

Bloomberg, BoC

Calculations

Measures of Economcic Slack

$\begin{array}{ll}\text { BL } & \text { Unemployment Rate } \\ 10 & \text { Output Gap } \\ 11 & \text { Unemployment Gap } \\ 12 & \text { Real GDP Gap } \\ 13 & \text { Industry Production Gap } \\ & \\ 14 & \text { Industry Production Growth } \\ 15 & \text { Unit Labor Cost Growth } \\ 16 & \text { Labor Compensation Growth }\end{array}$

The unemployment rate in percent

Interpolated quarterly values of annual output gap estimates from the OECD

OECD

OECD

Cyclical component of the unemployment rate, obtained using an HP filter

OECD, BoC Calc

Cyclical component of a real GDP index, obtained using an HP filter

Cyclical component of an industry production index, obtained using an HP

filter

OECD, BoC Calc

OECD, BoC Calc.

YoY growth rate of an industry production index

OECD

YoY growth rate of an index of unit labor costs

OECD

YoY growth rate of an index of labor compensation

OECD

Policies and Policy Uncertainty

17 Gov. Budget Balance
18 Inflation Expectations Uncertainty

General government net lending/borrowing in \% of GDP, interpolated to

IMF

arterly frequency

Growth of QE quantities in \% of GDP; in levels for Figure 7C, in growth rates

for the empirical analysis.

Dahlhaus, Hess,

Standard deviation across the individual mean forecasts/inflation Reza (2014)

expectations by professional forecasters in the next calendar year (first

Consensus

variable in the list)

Economics

Commodity Prices

\begin{tabular}{llll}
\hline 20 & Oil Price & YoY growth rate of Brent Index. & Intercontinental \\
& & & Exchange \\
21 & Energy Prices & YoY growth rate of energy prices & IMF \\
22 & Food Prices & YoY growth rate of food prices & IMF
\end{tabular}

Financial Variables

\begin{tabular}{|c|c|c|c|}
\hline 23 & Financial Market Uncertainty & VIX Index & $\begin{array}{l}\text { Chicago Board } \\
\text { Options Exchange } \\
\text { (CBOE) }\end{array}$ \\
\hline 24 & Credit Growth & YoY growth rate of credit to private non-fianncial sector in $\%$ of GDP & BIS \\
\hline 25 & Stockmarket Growth & YoY growth rate of the MSCI World index & Bloomberg \\
\hline 26 & Real Estate Price Growth & YoY growth rate of a real estate index (res. property, all dwellings) & BIS \\
\hline
\end{tabular}

BL = Baseline Specification 
Gilchrist et al., 2013) on output and inflation dynamics during the global financial crisis. In addition, Borio et al. (2013) have recently shown empirically that accounting for cyclical financial variables can improve the estimation of potential output and the output gap. Hence, financial variables could indeed be important drivers of inflation dynamics. I therefore examine the role of stock market prices, real estate prices and private credit in helping to predict global inflation. In addition, the VIX index is also tested, since uncertainty about financial developments could be an important driver of global inflation dynamics.

\subsection{What Explains the Twin Puzzle at the Global Level?}

To better understand the shift in inflation dynamics, I begin by estimating the baseline specification, which contains the unemployment rate and inflation expectations from professional forecasters for the next calendar year (results were shown in Specification 1 of Table 1). I then re-estimate the model with the addition of each of the 26 potential explanatory variables listed in Table 2 to optimally match the structural shift during the post-crisis period observed in Figure 3. The corresponding functional form for the analysis is given by Equation (4):

$$
\pi_{t}=\alpha+\beta \pi_{t}^{e}+\gamma u n e m p_{t}+\psi \operatorname{Var} X_{t}+\delta \pi_{t}^{e} \times \operatorname{Var} X_{t}+\theta u n e m p_{t} \times \operatorname{Var} X_{t}+\varepsilon_{t}
$$

where $\operatorname{Var} X_{t}$ is the variable to be tested as a potential determinant that could be responsible for the post-crisis level and slope shift. Hence, each candidate variable is included as it is, as an interaction term with the unemployment rate and as an interaction term with the expectations by professional forecasters. The resulting specifications are evaluated using the (lowest) Mean Squared Error (MSE) for the following four intervals: ${ }^{9}$

- the entire sample period (1995q1-2013q3);

- the entire post-crisis period (2009q4-2013q3);

- the period of the first puzzle (2009q4-2011q4); and

- the period of the second puzzle (2012q1-2013q3).

Table 3 shows the results. The potential explanatory variables are ordered according to the MSEs of their underlying specifications over the entire sample period from the lowest to the highest. ${ }^{10}$ The variable with the lowest MSE of all the candidate variables is the measure of inflation expectations by European households over the next 12 months (MSE of 0.50). Interestingly, this variable is followed by a measure of inflation expectations by U.S. households over the same time frame (MSE of 0.55). The variables that follow this selection in turn are the growth rates of real estate prices (MSE of 0.56), as well as the growth rates of food and energy prices (both have an MSE of 0.57 ).

\footnotetext{
${ }^{9}$ As some of the intervals are very short, the MSE is calculated without a degree of freedom adjustment. This overstates the MSE in absolute terms but it does not affect its ordering as in all cases the same number of variables is included in the regression

${ }^{10}$ In the remainder of this section, the MSE associated with each variable refers to the MSE of the underlying specification including this variable; i.e., the baseline specification plus the variable under examination.
} 
Table 3: Potential Explanatory Variables Ordered by Mean Squared Error

Variable added

1995q1-2013q3 2009q4-2013q3 2009q4-2011q4 2012q1-2013q3

Infl. Exp. European Households, 1 year-ahead

$\begin{array}{llll}0.50 & 0.43 & 0.52 & 0.29 \\ 0.55 & 0.68 & 0.78 & 0.52\end{array}$

Infl. Exp. US Households, 1 year-ahead

$0.55-0.68$

Real Estate Price Growth

Growth Rate of Food Prices

$\begin{array}{llll}0.56 & 0.79 & 0.89 & 0.63 \\ 0.57 & 0.76 & 0.76 & 0.76\end{array}$

Growth Rate of Energy Prices

Real GDP Gap

Industry Production Gap

Growth Rate of Oil Price

Government Budget Balance

Unit Labor Cost Growth

Infl. Exp. for Core Inflation, backward-looking

Industry Production Growth

Output Gap

Credit Growth

Stock Market Growth

QE-Quantities

Infl. Exp. by Professional Forecasters, 5 years from now

Labor Compensation Growth

Infl. Exp. by Financial Markets, over the next 5 years

Infl. Exp. by US Households, 5+ years-ahead

Infl. Exp. by Professional Forecasters, 10 years from now

Financial Market Uncertainty

Unemployment Gap

Inflation Expectations Uncertainty

Infl. Exp. for Headline Inflation, backward-looking

Infl. Exp. by Financial Markets, over the next $10+$ years

$\begin{array}{llll}0.57 & 0.75 & 0.80 & 0.67\end{array}$

$\begin{array}{llll}0.57 & 0.75 & 0.80 & 0.67 \\ 0.58 & 0.60 & 0.75 & 0.31\end{array}$

$\begin{array}{llll}0.58 & 0.60 & 0.70 & 0.42\end{array}$

$\begin{array}{llll}0.59 & 0.77 & 0.83 & 0.70\end{array}$

$\begin{array}{llll}0.60 & 0.78 & 0.83 & 0.70\end{array}$

$\begin{array}{llll}0.60 & 0.87 & 1.03 & 0.60\end{array}$

$\begin{array}{llll}0.60 & 0.73 & 0.72 & 0.74\end{array}$

$\begin{array}{llll}0.60 & 0.77 & 0.93 & 0.50\end{array}$

$\begin{array}{llll}0.60 & 0.90 & 1.04 & 0.66\end{array}$

$\begin{array}{llll}0.60 & 0.83 & 1.02 & 0.48\end{array}$

$\begin{array}{llll}0.60 & 0.87 & 1.08 & 0.51\end{array}$

$\begin{array}{llll}0.62 & 0.84 & 1.00 & 0.51\end{array}$

$\begin{array}{llll}0.63 & 0.80 & 0.90 & 0.66\end{array}$

$\begin{array}{llll}0.63 & 0.75 & 0.89 & 0.51\end{array}$

$\begin{array}{llll}0.64 & 0.75 & 0.93 & 0.42\end{array}$

$\begin{array}{llll}0.64 & 0.73 & 0.89 & 0.44\end{array}$

$\begin{array}{llll}0.64 & 0.83 & 0.98 & 0.59\end{array}$

$\begin{array}{llll}0.65 & 0.88 & 1.06 & 0.56\end{array}$

$\begin{array}{llll}0.65 & 0.84 & 1.01 & 0.53\end{array}$

$\begin{array}{llll}0.65 & 0.90 & 1.07 & 0.62\end{array}$

$\begin{array}{llll}0.66 & 0.90 & 1.10 & 0.55\end{array}$

$\begin{array}{llll}0.66 & 0.85 & 1.01 & 0.58\end{array}$

Memorandum

Baseline 0.69

0.93

1.11

0.62

Table 4: Derivation of the Augmented Baseline Specification

\begin{tabular}{lcccc}
\hline $\begin{array}{l}\text { Dependent Variable: } \\
\text { Headline Inflation }\end{array}$ & $(1)$ & $(2)$ & $(3)$ & $(4)$ \\
\hline \hline Unemployment Rate & $-0.37^{* * *}$ & $-0.33^{* * *}$ & $-0.91^{* * *}$ & $-0.75^{* * *}$ \\
& $(0.00)$ & $(0.00)$ & $(0.00)$ & $(0.00)$ \\
Inflation Expectations by PFC, next year & $0.30^{* * *}$ & $0.34^{* * *}$ & $0.51^{* * *}$ & $0.47^{* * *}$ \\
& $(0.00)$ & $(0.00)$ & $(0.00)$ & $(0.00)$ \\
Inflation Expectations by HH, 12 months & $0.64^{* * *}$ & $0.58^{* * *}$ & $0.54^{* * *}$ & $0.49^{* * *}$ \\
& $(0.00)$ & $(0.00)$ & $(0.00)$ & $(0.00)$ \\
Unemp. Rate x Infl. Exp. by HH & 0.12 & & & \\
& $(0.12)$ & & & \\
Infl. Exp. By PFCx Infl. Exp. by HH & 0.07 & & & \\
& $(0.23)$ & & & \\
Budget Bal. in \% of GDP & & & $(0.00)$ & $(0.00)$ \\
& & & & $0.70^{* * *}$ \\
GR of World Energy Prices & & & & $(0.00)$ \\
\hline Observations & 75 & & & 75 \\
R-squared & 0.75 & 0.74 & 0.82 & 0.86 \\
\hline
\end{tabular}

Note: P-Values in Parentheses. Constant not reported. 
When looking at the (entire) post-crisis period, the MSE-reducing effect of household inflation expectations becomes even more pronounced. Over the entire post-crisis sample, inflation expectations by European households reach an MSE of 0.43, while the next variables, two measures of economic slack, reach an MSE of 0.6. The effect clearly originates from the first part of the post-crisis period: while European household inflation expectations have an MSE of 0.52 here, the next variable reaches an MSE of 0.70 during 2009q4 and 2011q4. U.S. household inflation expectations show a slightly higher MSE but still score fourth highest among all the potential explanatory variables in the entire crisis period (MSE of 0.68), as well as sixth highest (MSE of 0.78) in the first part of the post-crisis period. European household inflation expectations still dominate the list of potential explanatory variables in the second part of the post-crisis period (MSE of 0.29); however, the difference with respect to the next candidate variable becomes smaller (the real GDP gap with an MSE of 0.31). Given their high but relatively constant trajectory, U.S. household inflation expectations over the next 12 months have a higher MSE now and score relatively lower among all potential explanatory variables (MSE of 0.52). Interestingly, the measure of U.S. household inflation expectations 5 years ahead turns out to be better during this period. It ranks fifth among all the candidate variables and reaches an MSE of 0.44 .

Specifications 1 and 2 in Table 4 present the results after European household inflation expectations have been added to the baseline specification. There are two ways in which European household expectations can be included in the specification. First, by adding the two interaction terms as originally shown in Equation (4) and represented by Specification 1. Since it turns out that abstracting from both interaction terms yields only a marginally lower fit, the second approach, as shown in Specification 2, is to add only the level term to the baseline specification.

Figure 8 plots the corresponding in-sample fit and indicates that there is only a small difference between the two approaches. Finally, the figure also includes actual global inflation for comparison. Although the two models that include household expectations show a similar insample fit, they are less precise around the peak of global inflation during the post-crisis period. The next section will therefore examine whether there is another variable that can account for the higher inflation trajectory during the period in question.

In addition to European household inflation expectations, Figure A1 in the Appendix replicates the analysis for U.S. household inflation expectations - the variable that had the secondlowest MSE in Table 3 (see Specifications 1 and 2 in Appendix Table A4 for details). As expected from the MSE, the in-sample fit of U.S. household inflation expectations is lower. Although the in-sample prediction mirrors the spike in inflation rates during the post-crisis period, there still seems to be a scaling difference. In addition, U.S. household inflation expectations have remained largely constant over the post-crisis period, yielding an overprediction of inflation rates at the end of the period.

The analysis so far has shown that household inflation expectations, and especially the measure based on household inflation expectations from 11 European countries, improve the in-sample fit of global inflation significantly. This was the case for both the specification with interaction terms and the specification without interaction terms. When comparing the insample predictions with the global inflation series in Figure 8, however, it turned out that the curves containing household inflation expectations have some difficulties in tracking global inflation around its peak in mid-2011. 
Figure 8: European Household Inflation Expectations added to the Baseline Specification

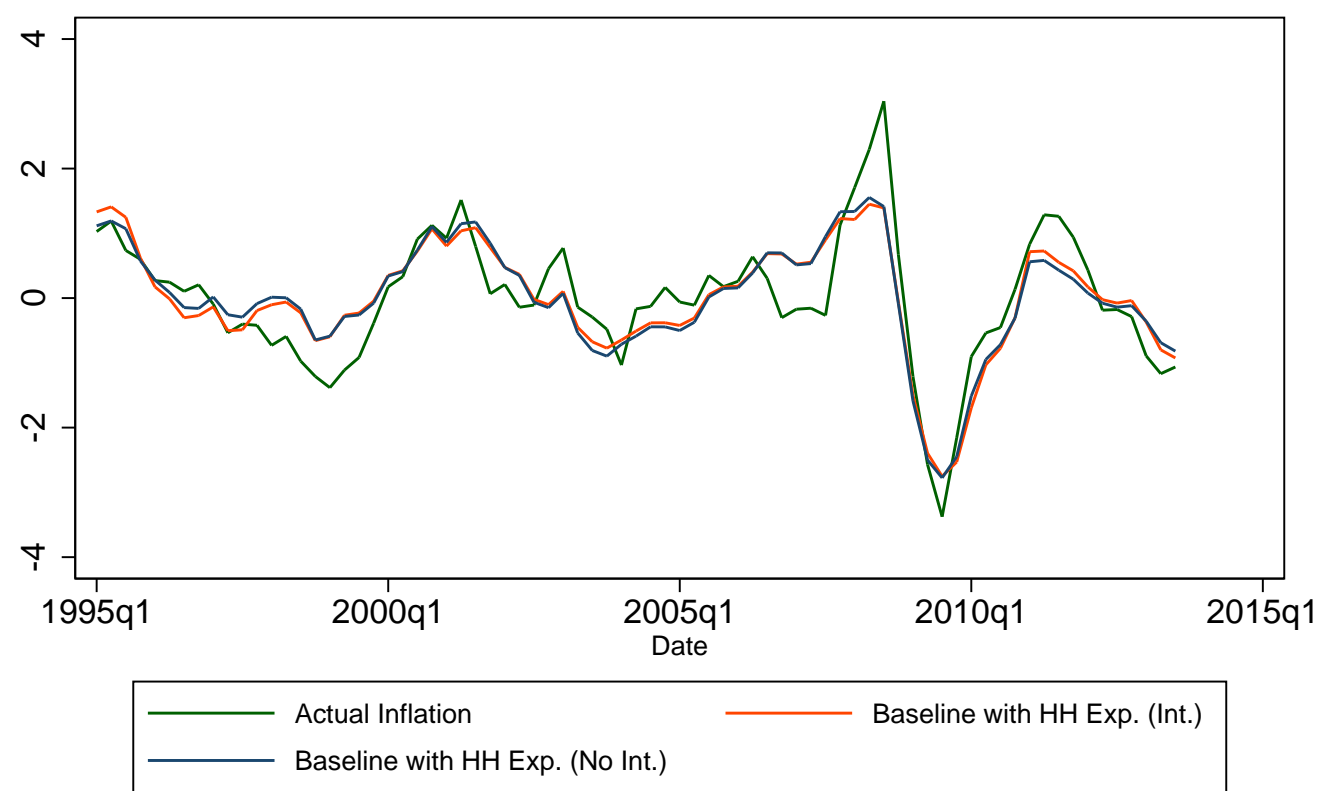

Note: Actual Inflation = 1st factor of headline inflation. Baseline Specification = In-sample fit for the standard global Phillips curve specification, containing the unemployment rate and inflation expectations by professional forecasters. HH Exp. = 1st factor of inflation expectations by households over the next 12 months. Int. = Interaction terms between HH Exp. and the two standard determinants.

Figure 9: Comparing the Best Specification with the Post-Crisis Dummy

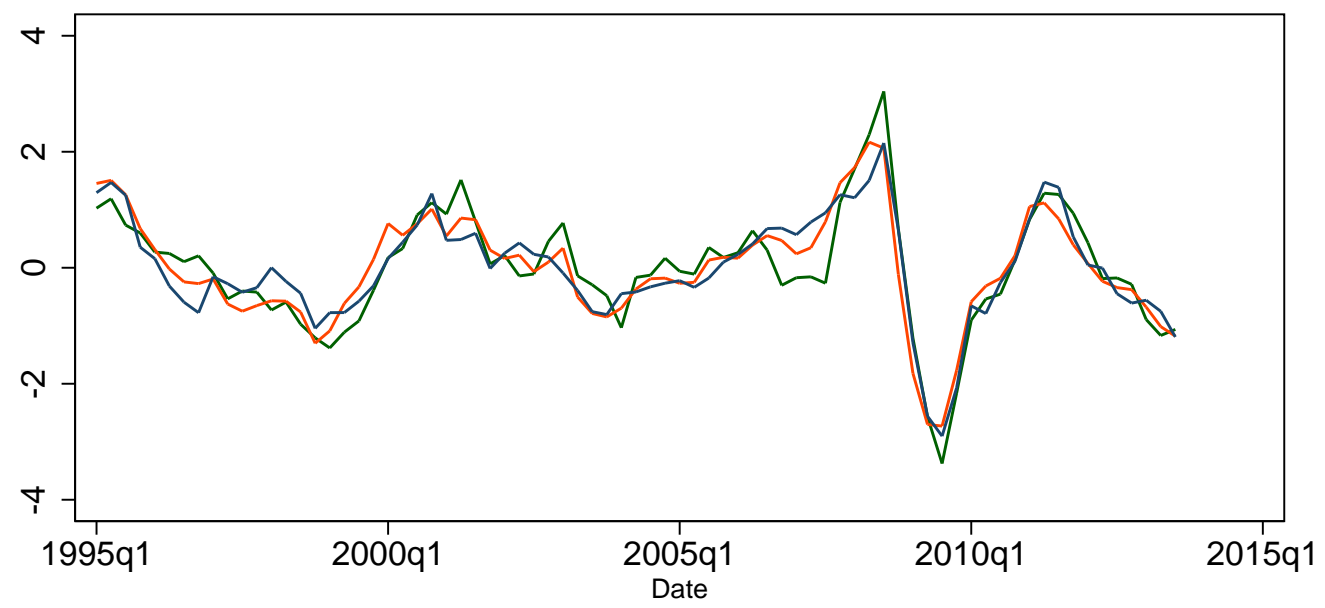

Actual Inflation

Augmented Baseline Specification

Baseline with Post-Crisis Dummy

Note: Actual Inflation = 1st factor of headline inflation. Augmented Baseline Specification = In-sample fit for the standard global Phillips curve specification, containing the unemployment rate and inflation expectations by professional forecasters, plus the following three variables: household inflation expectations, the budget balance in percent of GDP and energy price growth - all global and without interactions. Post-Crisis Dummy = Level and interaction terms of a dummy taking on the value of 1 over 2009q4-2013q3. 
Table 5: Adding a Second Variable Conditional on Household Expectations

Variable added

1995q1-2013q3 2009q4-2013q3 2009q4-2011q4 2012q1-2013q3

Government Budget Balance

$\begin{array}{llll}0.42 & 0.27 & 0.32 & 0.20 \\ 0.44 & 0.34 & 0.38 & 0.28\end{array}$

Growth Rate of Energy Prices

Growth Rate of Oil Price

$0.45 \quad 0.35$

0.28

Growth Rate of Food Prices

Infl. Exp. US Households, 1 year-ahead

$0.46 \quad 0.42$

0.28

$0.47 \quad 0.45$

$0.48 \quad 0.40$

Infl. Exp. by Professional Forecasters, 5 years from now

0.49

0.49

Inflation Expectations Uncertainty

QE-Quantities

Stock Market Growth

Infl. Exp. by Financial Markets, over the next 5 years

Unemployment Gap

Real GDP Gap

Financial Market Uncertainty

Infl. Exp. by US Households, 5+ years-ahead

Infl. Exp. by Professional Forecasters, 10 years from now

Industry Production Gap

Labor Compensation Growth

Infl. Exp. by Financial Markets, over the next 10+ years

Unit Labor Cost Growth

Industry Production Growth

Infl. Exp. for Headline Inflation, backward-looking

Credit Growth

Real Estate Price Growth

Infl. Exp. for Core Inflation, backward-looking

0.50

0.50

0.50

0.50

0.50

0.50

0.51

0.51

0.51

0.51

0.51

0.51

0.51

0.52

0.52

0.52

0.52

0.40
0.44

0.43

0.40

$\begin{array}{lll}0.40 & 0.48 & 0.27\end{array}$

$\begin{array}{lll}0.46 & 0.51 & 0.36\end{array}$

$\begin{array}{lll}0.46 & 0.51 & 0.36 \\ 0.48 & 0.58 & 0.31\end{array}$

$\begin{array}{lll}0.45 & 0.53 & 0.33\end{array}$

$\begin{array}{lll}0.45 & 0.53 & 0.33 \\ 0.40 & 0.49 & 0.25\end{array}$

$\begin{array}{lll}0.46 & 0.54 & 0.32\end{array}$

$\begin{array}{lll}0.46 & 0.54 & 0.32 \\ 0.42 & 0.50 & 0.29\end{array}$

$\begin{array}{lll}0.43 & 0.51 & 0.31\end{array}$

$\begin{array}{lll}0.43 & 0.51 & 0.31 \\ 0.47 & 0.52 & 0.38\end{array}$

$\begin{array}{lll}0.48 & 0.56 & 0.34\end{array}$

$\begin{array}{lll}0.47 & 0.53 & 0.37\end{array}$

$\begin{array}{lll}0.44 & 0.52 & 0.31\end{array}$

$\begin{array}{lll}0.48 & 0.56 & 0.34\end{array}$

$\begin{array}{lll}0.45 & 0.54 & 0.31\end{array}$

$\begin{array}{lll}0.49 & 0.59 & 0.33\end{array}$

$\begin{array}{lll}0.46 & 0.54 & 0.32\end{array}$

$\begin{array}{lll}0.46 & 0.54 & 0.32 \\ 0.46 & 0.54 & 0.33\end{array}$

$\begin{array}{lll}0.45 & 0.52 & 0.36\end{array}$

Table 6: Adding a Third Variable Conditional on Household Expectations and the Budget Balance

Variable added

1995q1-2013q3 2009q4-2013q3 2009q4-2011q4 2012q1-2013q3

\begin{tabular}{|c|c|c|c|c|}
\hline Growth Rate of Energy Prices & 0.38 & 0.27 & 0.32 & 0.19 \\
\hline Growth Rate of Oil Price & 0.39 & 0.28 & 0.32 & 0.20 \\
\hline Credit Growth & 0.39 & 0.29 & 0.32 & 0.24 \\
\hline Infl. Exp. for Headline Inflation, backward-looking & 0.39 & 0.23 & 0.24 & 0.21 \\
\hline Infl. Exp. by Professional Forecasters, 5 years from now & 0.39 & 0.31 & 0.33 & 0.28 \\
\hline Real Estate Price Growth & 0.40 & 0.28 & 0.31 & 0.23 \\
\hline Infl. Exp. for Core Inflation, backward-looking & 0.40 & 0.28 & 0.32 & 0.23 \\
\hline Infl. Exp. US Households, 1 year-ahead & 0.40 & 0.27 & 0.30 & 0.21 \\
\hline Infl. Exp. by Professional Forecasters, 10 years from now & 0.41 & 0.28 & 0.30 & 0.26 \\
\hline Output Gap & 0.42 & 0.28 & 0.33 & 0.21 \\
\hline Real GDP Gap & 0.42 & 0.28 & 0.31 & 0.23 \\
\hline Stock Market Growth & 0.42 & 0.26 & 0.30 & 0.19 \\
\hline Growth Rate of Food Prices & 0.42 & 0.30 & 0.34 & 0.24 \\
\hline Infl. Exp. by Financial Markets, over the next $10+$ years & 0.42 & 0.26 & 0.30 & 0.20 \\
\hline Unemployment Gap & 0.42 & 0.28 & 0.33 & 0.22 \\
\hline Financial Market Uncertainty & 0.42 & 0.25 & 0.29 & 0.20 \\
\hline Infl. Exp. by Financial Markets, over the next 5 years & 0.42 & 0.26 & 0.30 & 0.19 \\
\hline Unit Labor Cost Growth & 0.42 & 0.25 & 0.29 & 0.19 \\
\hline QE-Quantities & 0.42 & 0.26 & 0.30 & 0.19 \\
\hline Labor Compensation Growth & 0.42 & 0.28 & 0.34 & 0.19 \\
\hline Infl. Exp. by US Households, 5+ years-ahead & 0.42 & 0.26 & 0.30 & 0.19 \\
\hline Inflation Expectations Uncertainty & 0.42 & 0.28 & 0.33 & 0.20 \\
\hline Industry Production Growth & 0.42 & 0.26 & 0.31 & 0.19 \\
\hline Industry Production Gap & 0.42 & 0.27 & 0.32 & 0.20 \\
\hline
\end{tabular}

Since this suggests that another variable may be a relevant driver of global inflation dynamics as well, the set of candidate variables is examined a second time - this time conditional on the baseline specification and European household inflation expectations. Since Figure 8 indicated 
that there was only a small difference between the specifications with and without interaction terms, the interaction terms are dropped for simplicity. Table 5 shows the results. The variable that has the lowest MSE in all four samples is the government budget balance. While its MSE in the full sample (0.42) is only slightly lower than for the next best variable (energy prices, MSE of 0.44 ), the differences in the post-crisis period (0.27 vs. 0.34 ) and in its subsamples become larger. Figure A2 in the Appendix shows the resulting in-sample fit improvement once the government budget balance is added to the specification (for the coefficients, see Specification 3 in Table 4). Interestingly, the new setup closes the remaining gap between actual inflation and the in-sample prediction in 2011 to a large extent.

Finally, the same exercise is repeated a third time - now conditional on the variables from the baseline specification, European household inflation expectations and the government budget balance. Table 6 presents the results. The variable that has the lowest MSEs in the overall sample is energy-price growth. However, the difference in the MSE between energy-price growth and the remaining explanatory variables becomes fairly small now ( 0.01 to the second variable, oil-price growth, and 0.04 to the last one, the industry production gap). Although energy-price growth is still among the best explanatory variables in the second part of the post-crisis period, it is not among the variables with the lowest MSE in the first part of the post-crisis period. This also shows up when examining the in-sample fit including energy-price growth in Figure A2. There is only a marginal difference between the in-sample prediction for the version with and without energy-price growth (for coefficients, see Specifications 3 and 4 in Table 4).

Altogether, the analysis has shown that there is no need to evaluate additional candidate variables since the baseline specification plus household inflation expectations, the government budget balance and energy-price growth are able to explain an overwhelming share of global inflation dynamics over the period 1995q1-2013q3 and especially during the post-crisis period 2009q4-2013q3. This can also be seen in Figure 9, where the last specification is compared against the post-crisis dummy and actual global headline inflation. As expected, all three curves align very well - especially in the post-crisis period.

This subsection has identified a set of three variables - household inflation expectations, the government budget balance and energy-price growth - that, once added to the baseline specification, can explain the dynamics of global headline inflation very well. However, the analysis so far was quite agnostic about the potential channels through which these variables could work and also about the extent to which they capture similar dynamics. The next section will examine these questions in more detail, assess the robustness of the results and, additionally, repeat the analysis for selected countries at the individual country level.

\section{Discussion of Findings and Robustness}

\subsection{Discussion of Findings}

The last section has delivered a set of variables that, when added to the standard Phillips curve specification, significantly improve the in-sample prediction of global headline inflation especially during the post-crisis period. This section discusses the economic rationale behind these variables and links them to the two puzzles - unexpectedly high inflation rates over the 2009-2011 period and unexpectedly low inflation rates from 2012 onwards - that were presented in the introduction. As a starting point, Figure 10 shows the historical decomposition for the 
extended set of determinants over time, analogously to Figure 7. The following three results emerge:

1. The two standard determinants in the baseline specification - the unemployment rate and inflation expectations by professional forecasters - are important determinants of global inflation dynamics, even after additional variables are included.

2. Household inflation expectations are a key addition to the baseline specification. They mimic the dynamics of inflation expectations by professional forecasters but are significantly more volatile - especially during the (post)-crisis period. Conditional on household inflation expectations, the contribution of energy-price inflation is fairly small.

3. The government budget balance helps to improve the in-sample fit of headline inflation. Although the contribution of the budget balance is larger in the (post)-crisis period, its impact is visible in the pre-crisis period as well.

In the remainder of this subsection, I discuss all three results in more detail.

Figure 10: Contributions of Individual Determinants - Augmented Baseline

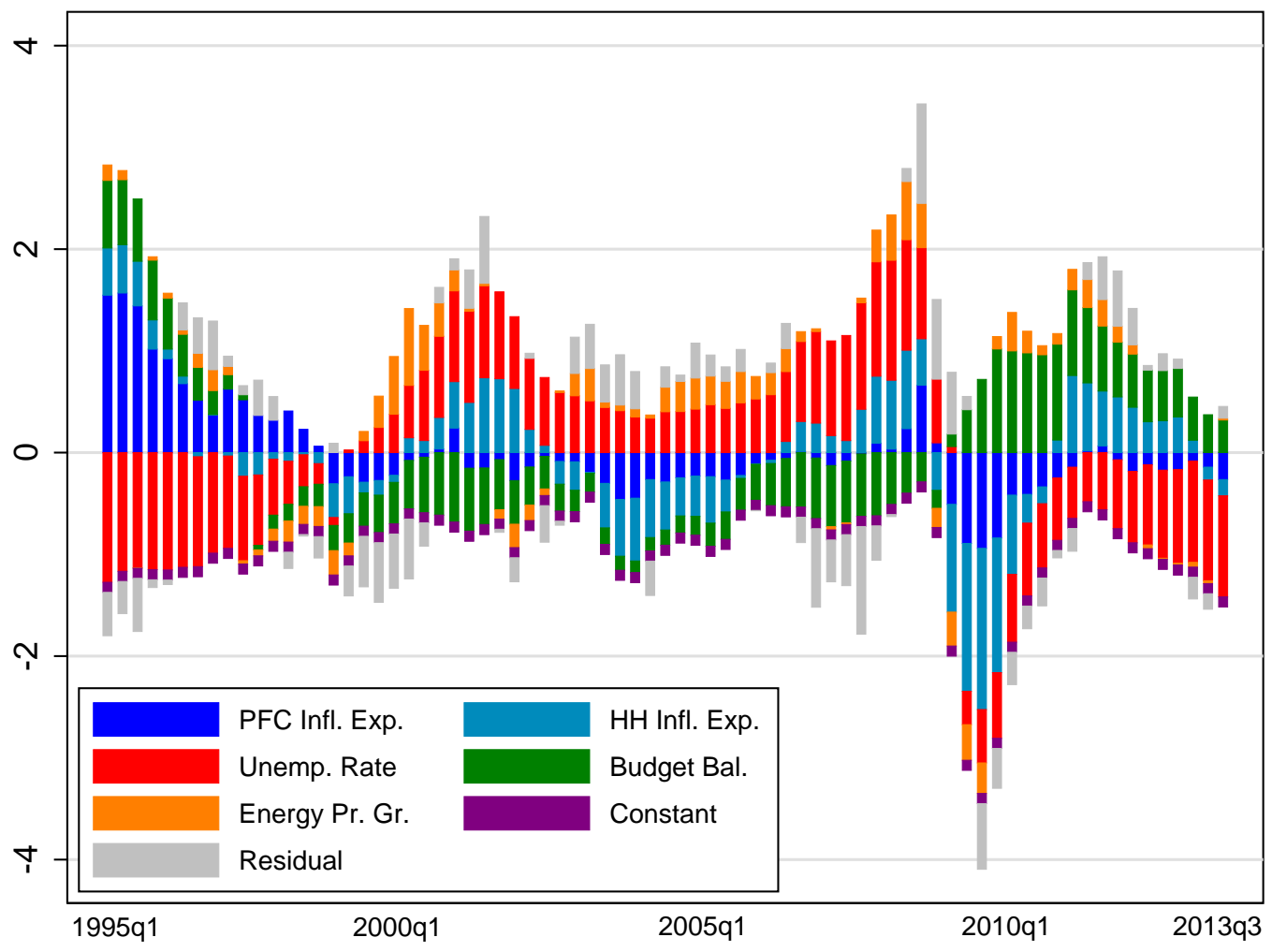

The first result suggests that the two standard determinants in Figure 10 are highly relevant and confirms the earlier observation that when a post-crisis dummy (and two interaction terms) are added to the baseline specification, the unemployment rate and inflation expectations by professional forecasters for the next calendar year are key drivers of global inflation dynamics over the entire sample period. It is also reassuring to see that the contributions of both variables do not change significantly once the post-crisis dummy is removed and additional variables are 
included in the specification. This can be seen when comparing their dynamics in Figure 7 and Figure 10. ${ }^{11}$ Finally, I examine the importance of both standard determinants for the in-sample fit, since one could be worried that after adding the new variables - such as household inflation expectations, the budget balance or energy-price growth - to the specification, the standard determinants could become irrelevant. However, Specifications 3 and 4 in Table A4 and Figure A3 in the Appendix show that this is not the case. Figure A3 contains the augmented baseline specification from the main text (as shown in Figure 9), as well as the same specification excluding either one of the two standard determinants. It turns out that when either of the two standard determinants are excluded, the in-sample prediction becomes worse. This is especially the case at the more recent end of the sample period, where inflation dynamics would be overpredicted otherwise.

The second result can be split up into three distinct observations. The first is that household inflation expectations are an important addition to the global Phillips curve. This finding is highly in line with Coibion and Gorodnichenko (2013), who have shown that replacing inflation expectations by professional forecasters with inflation expectations by households restores the Phillips curve for the United States until at least 2011. ${ }^{12}$

Second, both inflation expectations by professional forecasters and inflation expectations by households exhibit very similar high-frequency movements. Their correlation coefficient amounts to 0.50 over the entire sample period and to 0.90 in the post-crisis period (see also Figure A4 in the Appendix). However, both series differ significantly in their amplitudes - with household inflation expectations being more volatile from 1999 onwards. The corresponding standard deviations amount to 1.14 (0.51) for inflation expectations by professional forecasters (by households) over the 1995q1-1998q4 period and 0.53 (1.10) over the 1999q1-2013q3 period. This observation also helps us to understand why the post-crisis dummy and its interactions - which essentially increase the amplitude - are so successful in explaining global inflation dynamics over the post-crisis period. More specifically, in Figure 7, there seems to be a mapping of the interaction term between inflation expectations by professional forecasters and the post-crisis dummy to the household inflation expectations variable in Figure 10 over the post-crisis period.

And third, one of the potential reasons for the higher volatility of household inflation expectations could be related to their strong dependence on volatile oil and energy prices. The literature examining the formation of household inflation expectations has pointed out that household inflation expectations are highly responsive to gasoline price changes (e.g., for the United States: Coibion and Gorodnichenko, 2013; Ehrmann et al., 2014). Figure 11 therefore plots household inflation expectations against energy-price growth, oil-price growth and food-price growth.

Although all four series show similar high-frequency dynamics, their timing and amplitudes differ over time. While energy and oil prices lead the expectation series by around 1 year over most of the sample, the four series appear to be almost synchronized during the crisis period, where household inflation expectations followed the commodity-price series with a much shorter lag.

\footnotetext{
${ }^{11}$ Another notable feature of the two standard variables in both figures seems to be that there is a positive correlation at the beginning of the sample (until about 1999) and a negative correlation thereafter. Subsequently, the correlation coefficient over the period $1995 \mathrm{q} 1$ to $1998 \mathrm{q} 4$ amounts to 0.84 , and takes on a value of -0.43 from 1999q1-2013q3.

${ }^{12}$ There is an important difference between the results of Coibion and Gorodnichenko (2013) and this paper. Coibion and Gorodnichenko replace inflation expectations by professional forecasters with inflation expectations by households. However, the first result in the previous paragraph has shown that inflation expectations by professional forecasters are still an important driver of inflation dynamics at the global level.
} 
Figure 11: Household Inflation Expectations and Commodity Prices

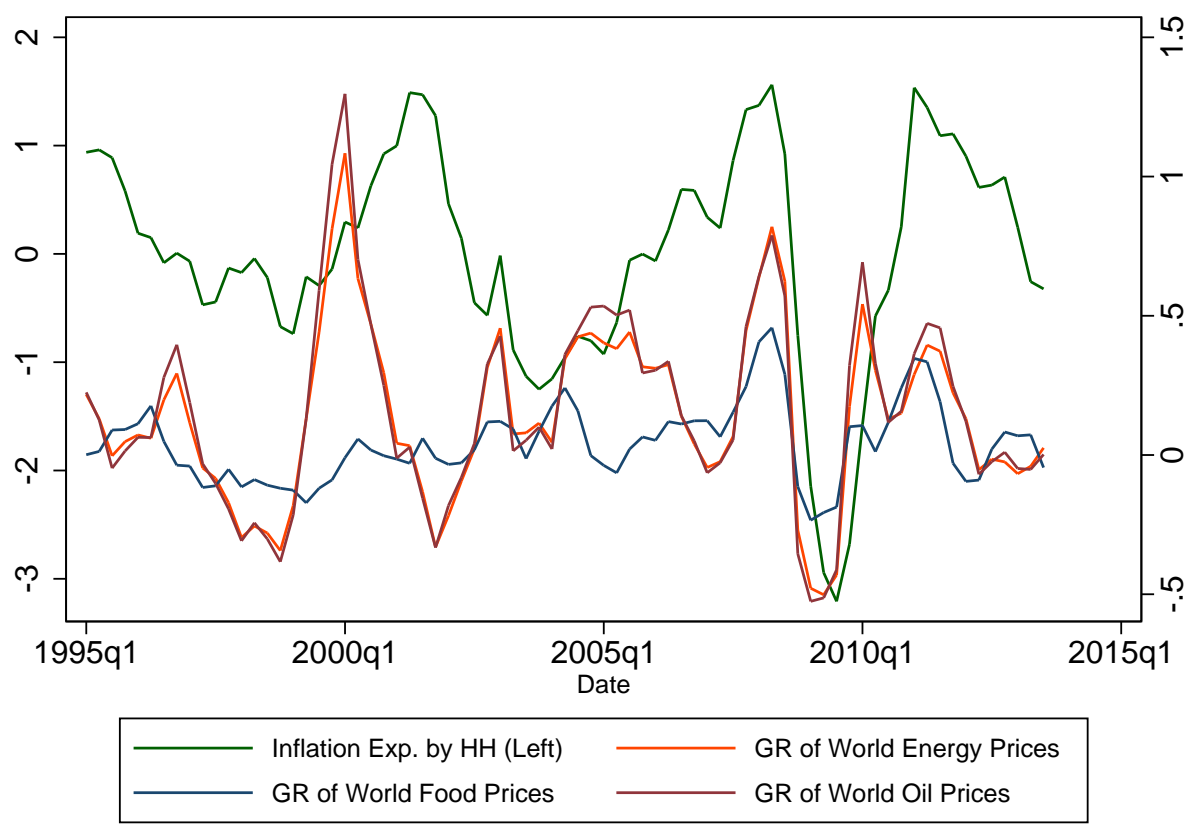

Note: $\mathrm{HH}=$ Households.

Table 7: Correlations between Household Inflation Expectations and Commodity Prices

\begin{tabular}{lrrr} 
Variable/Period & Pre-Crisis & Crisis & Post-Crisis \\
\hline \hline & & & \\
Contemporaneous & & & \\
\hline Energy-Price Growth & $-\mathbf{0 . 1 1}$ & $\mathbf{0 . 9 5}$ & $-\mathbf{0 . 0 8}$ \\
Oil-Price Growth & $-\mathbf{0 . 1 3}$ & $\mathbf{0 . 9 4}$ & $-\mathbf{0 . 1 7}$ \\
Food-Price Growth & $\mathbf{0 . 0 7}$ & $\mathbf{0 . 9 4}$ & $\mathbf{0 . 1 9}$ \\
& & & \\
Lagged by 1 quarter & & & \\
\hline Energy-Price Growth & 0.04 & $\mathbf{0 . 8 2}$ & $\mathbf{0 . 4 8}$ \\
Oil-Price Growth & 0.02 & $\mathbf{0 . 8 3}$ & $\mathbf{0 . 3 7}$ \\
Food-Price Growth & 0.01 & $\mathbf{0 . 8 8}$ & $\mathbf{0 . 5 5}$ \\
& & & \\
Lagged by 2 quarters & & & \\
\hline Energy-Price Growth & 0.16 & 0.39 & 0.69 \\
Oil-Price Growth & 0.14 & 0.44 & 0.61 \\
Food-Price Growth & -0.07 & 0.52 & 0.67 \\
& & & \\
Lagged by 3 quarters & & & \\
\hline Energy-Price Growth & 0.29 & -0.30 & $\mathbf{0 . 7 9}$ \\
Oil-Price Growth & 0.27 & -0.23 & $\mathbf{0 . 7 4}$ \\
Food-Price Growth & -0.14 & -0.10 & $\mathbf{0 . 6 7}$
\end{tabular}

\begin{tabular}{|c|c|c|c|}
\hline Variable/Period & Pre-Crisis & Crisis & Post-Crisis \\
\hline \multicolumn{4}{|l|}{ Lagged by 4 quarters } \\
\hline Energy-Price Growth & 0.38 & -0.97 & 0.79 \\
\hline Oil-Price Growth & 0.38 & -0.96 & 0.80 \\
\hline Food-Price Growth & -0.17 & -0.91 & 0.64 \\
\hline \multicolumn{4}{|l|}{ Lagged by 5 quarters } \\
\hline Energy-Price Growth & 0.43 & -0.92 & 0.20 \\
\hline Oil-Price Growth & 0.44 & -0.92 & 0.31 \\
\hline Food-Price Growth & -0.17 & -0.92 & 0.21 \\
\hline \multicolumn{4}{|l|}{ Lagged by 6 quarters } \\
\hline Energy-Price Growth & 0.42 & -0.59 & -0.34 \\
\hline Oil-Price Growth & 0.44 & -0.57 & -0.22 \\
\hline Food-Price Growth & -0.20 & -0.73 & -0.29 \\
\hline \multicolumn{4}{|l|}{ Lagged by 7 quarters } \\
\hline Energy-Price Growth & 0.34 & 0.07 & -0.56 \\
\hline Oil-Price Growth & 0.37 & 0.08 & -0.47 \\
\hline Food-Price Growth & -0.28 & -0.56 & -0.56 \\
\hline
\end{tabular}

Bold figures are discussed in the text.

Regarding the amplitude, it can be observed that, especially in the first part of the sample, movements in food and energy prices do not translate 1 to 1 into movements in household expectations, while the amplitudes seem to be more aligned over the crisis period. Examining the correlation coefficients of the three commodity-price series with household inflation expectations 
Figure 12: The Contribution of Food and Energy Prices over Time - Excluding Inflation Expectations by Households

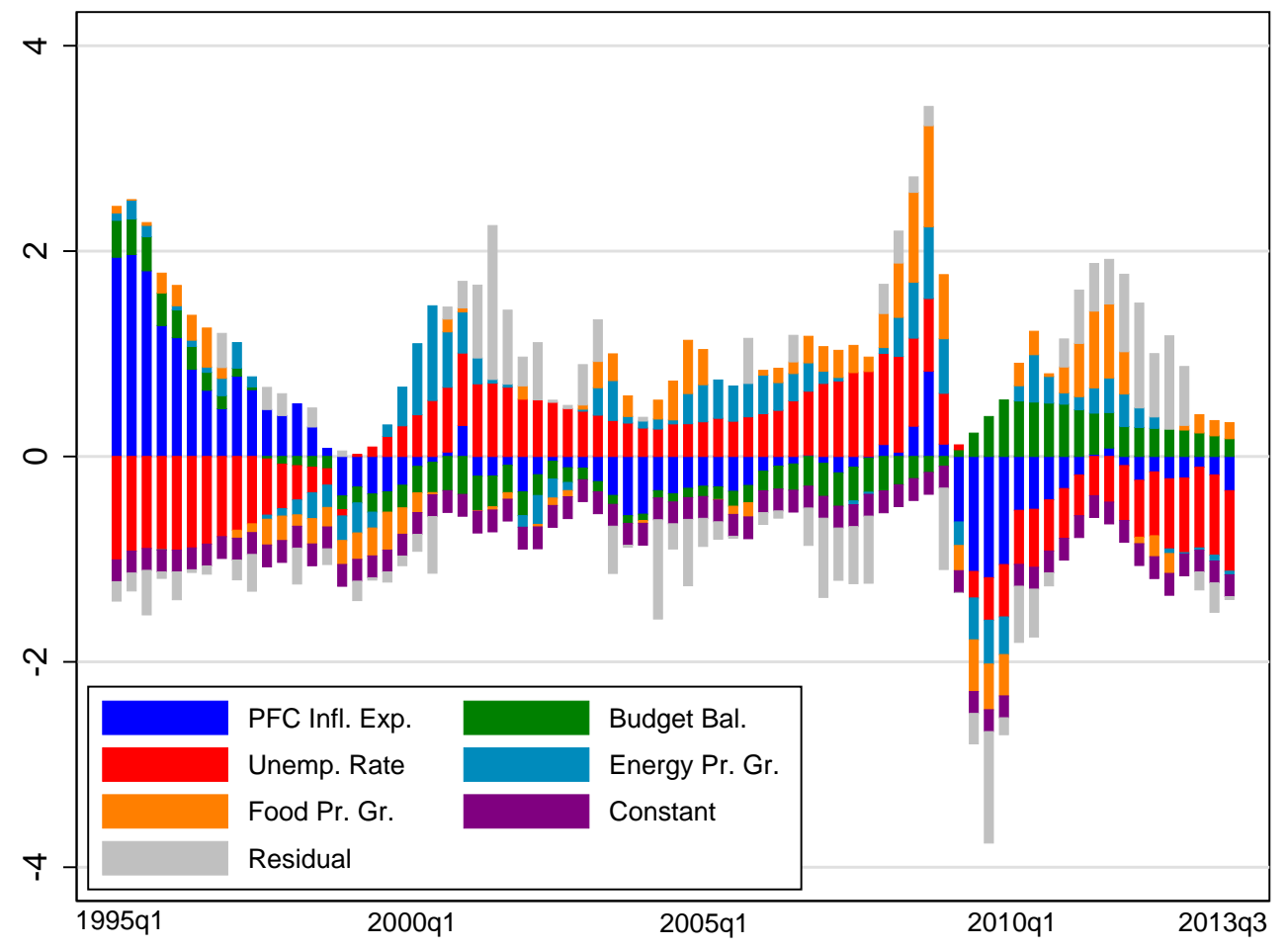

over time yields a similar picture. Table 7 presents the evidence. The three commodity-price series have very high contemporaneous correlations with household inflation expectations during the crisis period (2007q4-2009q3). However, the contemporaneous correlation during the rest of the sample is fairly low. Increasing the lag for the three commodity-price series shows that the highest correlation coefficient is obtained for a lag of around 5-6 quarters in the pre-crisis period (with food prices being an exception) and for a lag of around 3-4 quarters in the post-crisis period. Nevertheless, as noted above, a one-quarter lag in both the crisis and post-crisis periods already produces a clearly positive correlation coefficient.

A factor that could be responsible for the changing correlation dynamics between household inflation expectations and commodity prices is exchange rates. Although it is not possible to examine the role of exchange rates in a global Phillips curve, bilateral movements between the U.S. dollar - the currency in which most commodities are priced - and national currencies can make the pass-through of global commodity-price changes to national inflation expectations appear to be time-dependent. Hence, taken together, the evidence so far suggests that household inflation expectations also incorporate energy- and food-price dynamics at the global level, but the functional form of this process is unknown and seems to vary over time.

To examine the total contribution of food and energy prices to global headline inflation over time, the specification underlying Figure 10 is re-estimated, excluding inflation expectations by households but including the first lag of energy and food prices. ${ }^{13}$ Figure 12 shows the result. ${ }^{14}$ There indeed seems to be a larger role for energy and food prices in such a setup. Both series

\footnotetext{
${ }^{13}$ Once the first lags of both variables are included, their contemporaneous coefficients become insignificant. Hence, this specification contains only the first lags.

${ }^{14}$ The estimated coefficients are shown in Specification 5 in Table A4, and the resulting in-sample fit is plotted in Figure A5 in the Appendix.
} 
pushed up inflation rates in the years prior to the crisis, exerted negative pressure during the crisis period and contributed to higher inflation rates in the first part of the post-crisis period. However, the impact near the recent end of the period seems to be neutral. It should also be noted that the residual is higher when household inflation expectations are not included in the specification.

The third result is probably the most unexpected one in light of the standard Phillips curve framework. Although the presence of large government budget deficits could trigger fears about inflation, ${ }^{15}$ one would expect those fears to materialize through inflation expectations by either professional forecasters or households. Figure A6 in the Appendix plots the two types of inflation expectations together with the government budget balance over time. However, it turns out that inflation expectations and the budget balance move in opposite directions - the behavior that we would expect from economic theory - only at the very beginning of the sample (until 1999) and at the most recent end (after 2011). This implies that, on average, household inflation expectations are not capturing the dynamics and related fears arising from public debt.

Therefore, the more likely justification for the presence of the government budget balance in the Phillips curve is a time-varying relationship between the fiscal policy stance and the measure of economic slack in the Phillips curve. In general, one would expect a constant relationship between the government budget balance and the measure of economic slack - here, the unemployment rate - over time. Figure 13 plots this relationship. It turns out that both variables are highly negatively correlated and show a very symmetric pattern until the onset of the crisis. During the financial crisis, however, this symmetric relationship seems to have broken down: the unemployment rate rises substantially with the onset of the financial crisis in 2007-2008, reaches a small plateau in 2010 and rises again with the onset of the European debt crisis in 2011. Driven by government bailout and stimulus packages, increasing social security expenditures and collapsing tax returns, the government budget balance deteriorates substantially with the onset of the financial crisis in 2007-2008. Although, the dynamics of the deteriorating government budget balance closely mirror those of the rising unemployment rate at the onset of the crisis, the government budget balance deteriorates at a greater rate until 2010 and outpaces the unemployment rate at this time. Subsequently, the correlation even turns positive when the newly implemented austerity policies improve the budget balance significantly, while the unemployment rate levels out and picks up, owing to European developments. Two potential effects are consistent with the observed evidence:

The first is a level effect. Changing levels of government expenditures (and tax rebates) could have had an impact on inflation dynamics over and above those of social security payments. Notably, financial sector support packages and economic stimulus packages were introduced by various governments throughout the crisis. While the former might have stabilized credit-driven demand on a broad basis, the latter were often intended to stabilize demand in selected markets. By subsidizing the purchase of new cars, for example, the prices of cars were artificially elevated for an extended period. Figure 14 shows the associated price dynamics for new cars around the introduction dates of the so-called "Car-Scrappage Premiums" in selected European countries. It is evident that car prices were more stable or even increased during the periods in which the car-scrappage premiums were in place. Given that the category "motor vehicles" in the ECB's Harmonized CPI accounts for $4.4 \%$ of the weights in the euro area over the years 2006-2009,

\footnotetext{
${ }^{15}$ Aizenman and Marion (2011) conclude that "eroding the [U.S.] debt through inflation is not farfetched." And an unexpected inflation rate at the level of $6 \%$ could reduce the debt-to-GDP ratio in the United States by up to $20 \%$ within 4 years.
} 
Figure 13: The Global Unemployment Rate and the Global Government Budget Balance

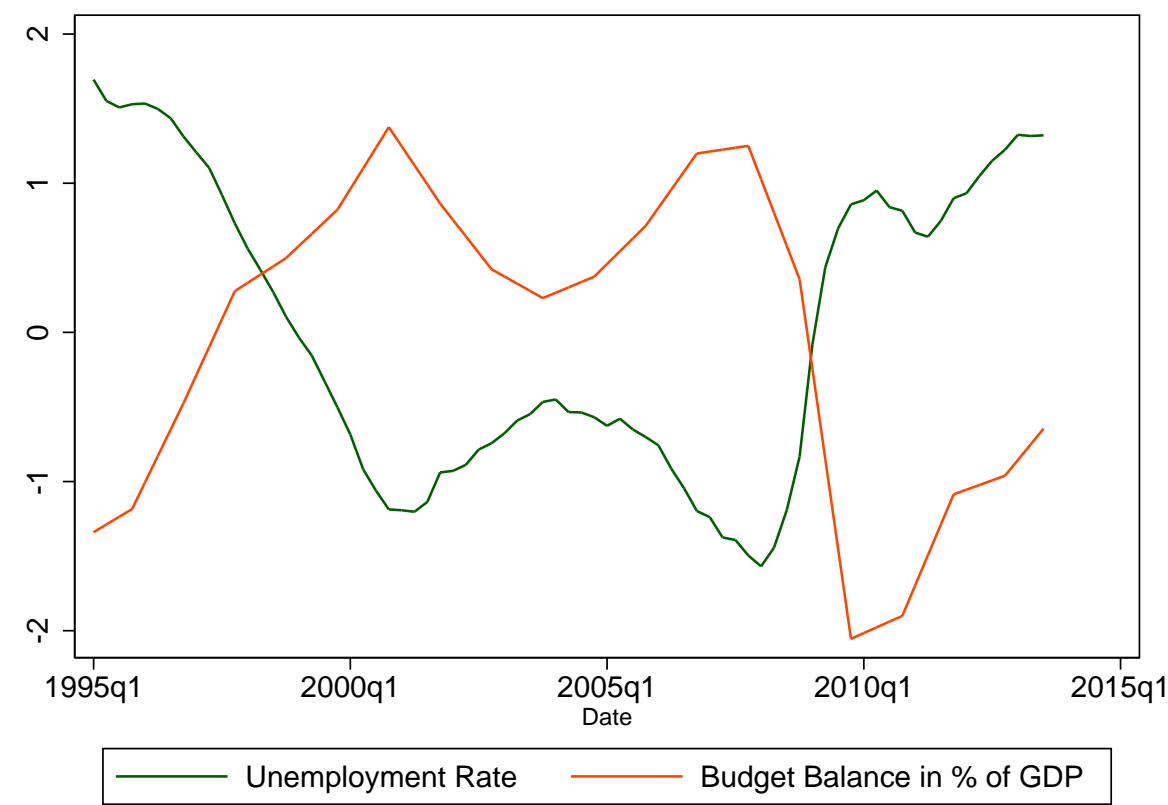

Figure 14: Car-Price Dynamics During the Presence of "Car-Scrappage Premiums" in Europe
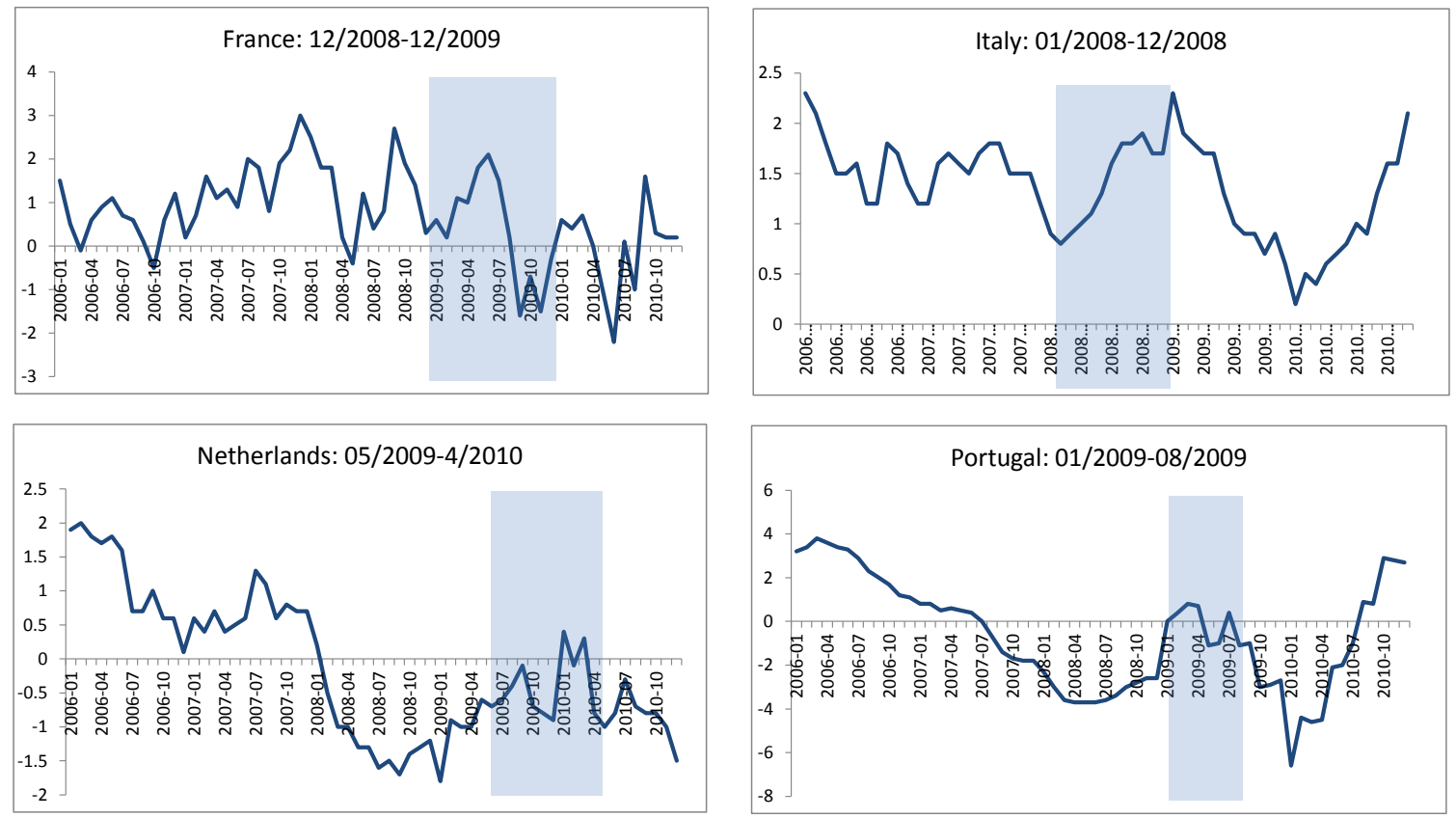

Note: The blue line represents year-on-year price changes in the category "Motor Vehicles" in the national series of the Harmonised CPI, Breakdown by Purpose of Consumption provided by the European Central Bank (ECB). The shaded areas indicate the presence of the first car-scrappage program in each country after January 2008. The introduction and ending dates for all programs are taken from Leheyda and Verboven (2013).

one could imagine a significant impact on overall inflation during this period. In Portugal, the country with the highest share in this category, weights even reach an average weight of $9.0 \%$ 
over this period, making the impact even larger. Besides the market for new cars, governments intervened in markets for housing improvements that have a significant weight in the Harmonized CPI as well.

The second is a composition effect. Returning to Figure 13, it turns out that there is a second channel that could be relevant as well. While sharply rising rates of short-term unemployment at the onset of the crisis caused social security payments to skyrocket, the subsequent transition of short-term to long-term unemployment might have reduced the amount of government expenditures required for a given level of unemployment significantly. At the same time, faced with the lower income and the need for adjustment, households could have changed their behaviour, which might have resulted in weaker demand (and thus prices) in a variety of markets that are characterized by inelastic demand in the short term: e.g., cancellation/downsizing of communication services or cutting down on tourism and leisure expenses.

To sum up, the important role of fiscal policies for inflation dynamics found in this paper lines up well with the findings of two other recent papers in the literature. First, the results align nicely with the explanation given in Ferroni and Mojon (2014), who suggest that the recent low-inflation environment is mainly driven by negative demand shocks. In addition, the authors speculate that negative demand shocks can possibly be explained by a reduction of government consumption in the United States. Second, Christiano et al. (2014) find that the government spending shock in their New Keynesian model describes inflation behavior well over the post-crisis period. Although the authors argue that government spending is not the main explanation behind the dynamics of inflation during the crisis, the expansionary fiscal policy created by the American Recovery and Reinvestment Act from 2009 onwards, and the fiscal contraction starting from 2011, seem to closely match U.S. inflation dynamics in the post-crisis period - especially until 2012. Taken together, my paper adds to the literature by showing that there is indeed empirical evidence for a direct relationship between fiscal policies and inflation dynamics on the global level.

\subsection{Additional Robustness Checks}

This part of the robustness section extends the analysis along four dimensions. First, I replicate the key specifications from the main text for alternative global aggregation techniques. Second, I use the same set of sample countries to construct the global variables. Third, I replicate the key specifications at the individual country level for 10 countries for which all relevant data are available. And fourth, I vary the estimation sample.

\subsubsection{Varying the Definition of Global Inflation Rates}

This subsection examines the robustness of the findings to alternative definitions of the global inflation rate. Section 2.2 introduced three different aggregation techniques to obtain global aggregates for both inflation and its determinants. Besides the technique based on the static factor model that was used in the main text, both a weighted and an unweighted average of national inflation rates have been used to construct the series in Figure 2. I therefore replicate the key specifications for the two alternative measures of global headline inflation as well. This also implies the recalculation of all the global determinants using exactly the same method. Table A5 and Figures A7, A8, and A9 in the Appendix show the results. Figure A7 corresponds to the results in the main text and is presented for comparison purposes only. Figure A8 presents the same specifications using (standardized) unweighted averages for both headline inflation rates and their determinants. When comparing the two figures, it turns out that both yield very 
similar results, reinforcing the findings in the main text. Finally, Figure A9 presents the same analysis with a (standardized) PPP-weighted average. In this case, the in-sample fit is somewhat lower than for the other global inflation measures, but the specification containing household inflation expectations, the government budget balance and energy-price growth in addition to the standard variables still does significantly better than the baseline specification. It should also be kept in mind that the weighting process can produce unintuitive results in the presence of missing data: while the measure of headline inflation will give a high weight to the U.S. inflation rate, the measure of European household inflation expectations will be based entirely on European countries and, hence, will lead to a worse fit by definition. However, to investigate this concern further, the next subsection (4.2.2) examines the impact of missing data in greater detail, while subsection 4.2 .3 repeats part of the analysis for selected countries at the individual level.

\subsubsection{Keeping the Country Sample Constant}

This exercise requires that the country sample for each variable is identical. This way, it can be ensured that the results are not driven by spurious correlations that arise from explaining a global inflation rate using a broad set of national inflation rates with global determinants based on a much more limited country sample. I therefore restrict the sample of countries to those that have all the variables available for each year in the sample period. ${ }^{16}$ It should be noted, however, that the new sample is very much focused on European countries, of which three were severely affected by the European debt crisis. Hence, regional factors might affect also the results. This somewhat reduces the external validity of the results of this subsection.

Tables A6 and A7 in the Appendix show the estimated coefficients when the key specifications of the analysis are replicated with the constant country sample. The results are summarized in Figure A10 and Figure A11. Figure A10 shows the in-sample fit for the baseline specification itself, for the baseline specification plus household inflation expectations, as well as for the augmented baseline specification, which includes the government budget balance and energyprice growth. It turns out that the individual specifications closely mirror the ones from the main text. Finally, Figure A11 shows the contributions of all the variables included in the augmented baseline specification over time. Here, the pattern is very similar to the one shown in Figure 10 in the main text.

\subsubsection{Replicating the Analysis at the Individual Country Level}

This subsection examines how the global results translate to the individual country level. Therefore, the augmented baseline specification - containing inflation expectations by professional forecasters and households, the unemployment rate, the budget balance and the growth rate of energy prices - is estimated for all 10 countries that have data available for all the variables at the country level. ${ }^{17}$ It should be noted, however, that U.S. household inflation expectations are from a different source than those of the European countries and that energy-price growth remains the same variable in all cases. Figures A12-A14 show the results.

In each case, the green line indicates the actual inflation rate at the country level, the red line indicates the in-sample fit using the baseline specification (inflation expectations by

\footnotetext{
${ }^{16}$ The sample now consists of Austria, Belgium, Denmark, France, Germany, Italy, Portugal, Spain, and the United Kingdom.

${ }^{17}$ The countries are Austria, Belgium, Denmark, France, Germany, Italy, Portugal, Spain, the United Kingdom, and the United States.
} 
professional forecasters and the unemployment rate) and the blue indicates the in-sample fit of the augmented baseline specification. Hence, the closer the blue line lies to the green line (and the further away it is from the red line), the better the augmented Phillips curve specification does (relative to the standard Phillips curve specification). Altogether, three distinct groups of countries emerge. The first and largest group mirrors the pattern of the global analysis: the benchmark specification (red line) produces a rather poor in-sample fit, while the augmented baseline specification (blue line) yields a very good fit - especially in the post-crisis period. In descending order of their fit, this group of countries consists of Portugal, Spain, Austria, France and the United Kingdom. A second group of countries, comprising Belgium and Italy, is characterized by an already good in-sample fit for the standard Phillips curve specification. And, finally, there is a third group of countries that see an improvement in their in-sample fit over the whole sample but not as good a fit at the end of the sample period. Countries in this group are the United States, Germany and Denmark. A potential reason for this observation could be that both the United States and Germany are large economies and, therefore, idiosyncratic developments can play an important role in the conduct of monetary policy. It should also be noted that U.S. household inflation expectations are fairly elevated during the entire post-crisis period, making it difficult to accurately explain the inflation dynamics at the end of the period. ${ }^{18}$

\subsubsection{Varying the Estimation Sample}

Finally, this subsection deals with the sensitivity of the results to the sample period and assesses the potential usefulness of the findings for forecasting future inflation. I first shorten the estimation sample and examine the stability of the coefficients in the augmented baseline specification. It should be noted, however, that the variables included in the augmented baseline specification were identified through a selection procedure based on the full sample. I re-estimate the augmented baseline specification over the following four periods, each time beginning in 1995q1 and ending in 2003q1, 2006q1, 2009q1 and 2012q1. Figure A15 shows the resulting fit for the full sample period in each of the four cases. It turns out that they all produce very similar results. This finding indicates that the coefficients of the augmented baseline specification are fairly stable over time, and thus it is less likely that omitted variables play an important role here. The next question of interest is how the actual selection of variables that are added to the baseline specification (and thus constitute the augmented baseline specification) changes over time. Figure A16 and Figure A17 illustrate the answer. Figure A16 presents the rank of the three additional variables (i.e., inflation expectations by European households for the next year, the government budget balance and energy-price growth) out of the 26 variables tested according to the MSE-minimizing selection procedure over time. As expected, it turns out that the household inflation expectations series shows the highest average rank among the three variables. Figure A16 also suggests that household inflation expectations are of less relevance during the years 2004-2010, which are characterized by a relatively constant inflation rate. However, when Figure A17 with the relative MSE is examined - i.e., the MSE of each of the three variables minus the MSE of the variable with the lowest MSE in each year - it turns out that the lower rankings of the household inflation expectations variable during the 2004-2010 period can be attributed to the high density of the MSE distribution. In addition, both figures suggest that the other two variables, the budget balance and the growth of energy prices, became more important during the crisis period, with mixed evidence in the post-crisis period.

\footnotetext{
${ }^{18}$ This problem is even more pronounced when only inflation expectations by households are included in the specification and inflation expectations by professional forecasters are left out.
} 


\section{Conclusion}

This paper has examined global inflation dynamics over the last two decades, with a specific focus on the post-crisis period following the global financial crisis. While global headline inflation in the pre-crisis period, as well as during the crisis itself, closely followed a standard Phillips curve relationship, post-crisis dynamics revealed two consecutive puzzles. First, global inflation rates between 2009 and 2011 were higher than predicted by economic theory. And second, from 2012 onwards, the trend reversed and global inflation rates were lower than expected.

By specifying a global Phillips curve that explains headline inflation using inflation expectations and a measure of economic slack at the global level, this paper reconciles the two puzzles and shows that all observations from $2009 \mathrm{q} 4$ onwards exhibit a different pattern than in the pre-crisis period or during the crisis itself. In the next step, a large set of potential explanatory variables is assessed in terms of their ability to improve the in-sample fit of the global Phillips curve. The analysis yields three main findings. First, the standard determinants can explain a sizable share of global inflation dynamics. Second, household inflation expectations are an important addition to the global Phillips curve. Furthermore, they are more volatile than inflation expectations by professional forecasters and most likely proxy for energy- and food-price dynamics. And third, the government budget balance seems to make an important contribution to the Phillips curve as well. When taking all three findings into account, it is possible to closely replicate global inflation dynamics over the post-crisis period.

The results therefore largely generalize to the global level the earlier finding by Coibion and Gorodnichenko (2013), who re-established the Phillips curve in the United States after replacing inflation expectations by professionals with inflation expectations by households. However, the findings of this paper indicate that a combination of both measures of inflation expectations rather than their substitution, maximizes the in-sample fit of the global Phillips curve. This paper also confirms the duality between household inflation expectations and commodity notably energy and food - prices. Although the literature has discussed such a relationship for the United States, it is not obvious that the results carry over to the global level. In fact, the results in this paper do suggest a more complex link. Finally, the additional role for the government budget balance in the Phillips curve is novel. I provide some initial evidence that is consistent with a direct link between the government budget balance and the inflation rate over and above the standard measure(s) of economic slack. However, more research will be required to determine whether there is indeed a direct link or whether the identified relationship proxies for another channel with similar dynamics.

The findings of this paper raise two important questions regarding the implementation of monetary policy. The first question is about the policy implications of the augmented Phillips curve specification obtained in this paper. While the definition and location of the two puzzles in Figure 3 suggested that post-crisis inflation showed a consistently different behavior, one might ask about the specific nature of the underlying forces. If they turn out to be temporary, the policy response might differ from that for a permanent change in the Phillips curve relationship. The global Phillips curve suggests that the last data points are at the intersection between the long-term and the post-crisis curves. Evidence on the importance of adding household inflation expectations to the global Phillips curve - in combination with similar findings in the recent literature - further suggests that central banks should monitor a portfolio of inflation expectations in order to track diverging patterns ahead of time. Although differences in normal times might be negligible, the higher volatility in household inflation expectations might contain useful predictive information, especially in times of crisis. 
A second question deals with the implications of these findings for core inflation. While central banks may look through shocks in headline inflation when conducting monetary policy, the results of this paper also affect the dynamics of core inflation. Although the most important items in headline inflation, such as food and energy, are traded globally (and thus the prices adjust globally at a fairly high frequency), prices for most items in the measure of core inflation adjust at a much slower pace across countries. However, the significant roles of the unemployment rate and the government budget balance indicate that core inflation dynamics are also determined at the global level. 


\section{Appendix}

Figure A1: U.S. Household Inflation Expectations Added to the Baseline Specification

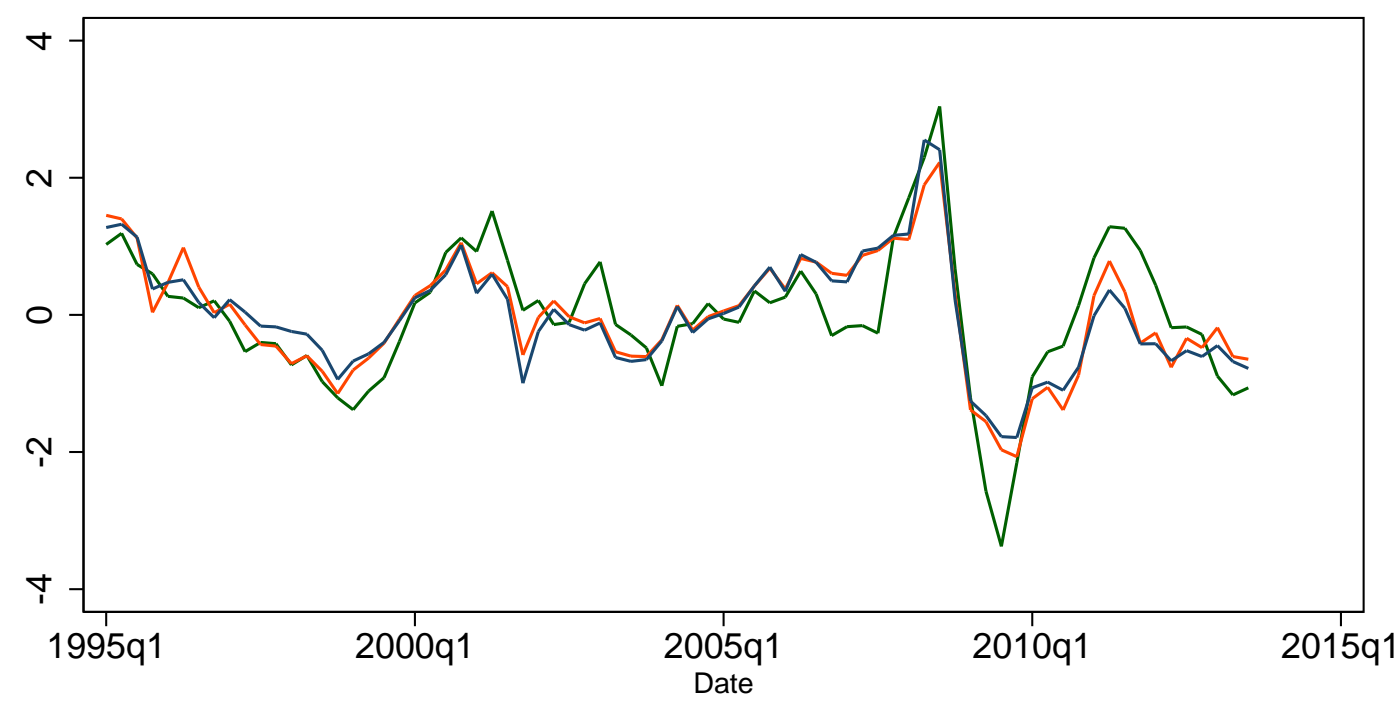

Actual Inflation

Baseline with US HH Exp. (Int.)

Baseline with US HH Exp. (No Int.)

Note: Actual Inflation = 1st factor of headline inflation. Baseline Specification = In-sample fit for the standard global Phillips curve specification, containing the unemployment rate and inflation expectations by professional forecasters. HH Exp. $=1 \mathrm{st}$ factor of inflation expectations by households over the next 12 months. Int. = Interaction terms between HH Exp. and the two standard determinants.

Figure A2: Adding More Variables to the Baseline Specification with Household Expectations

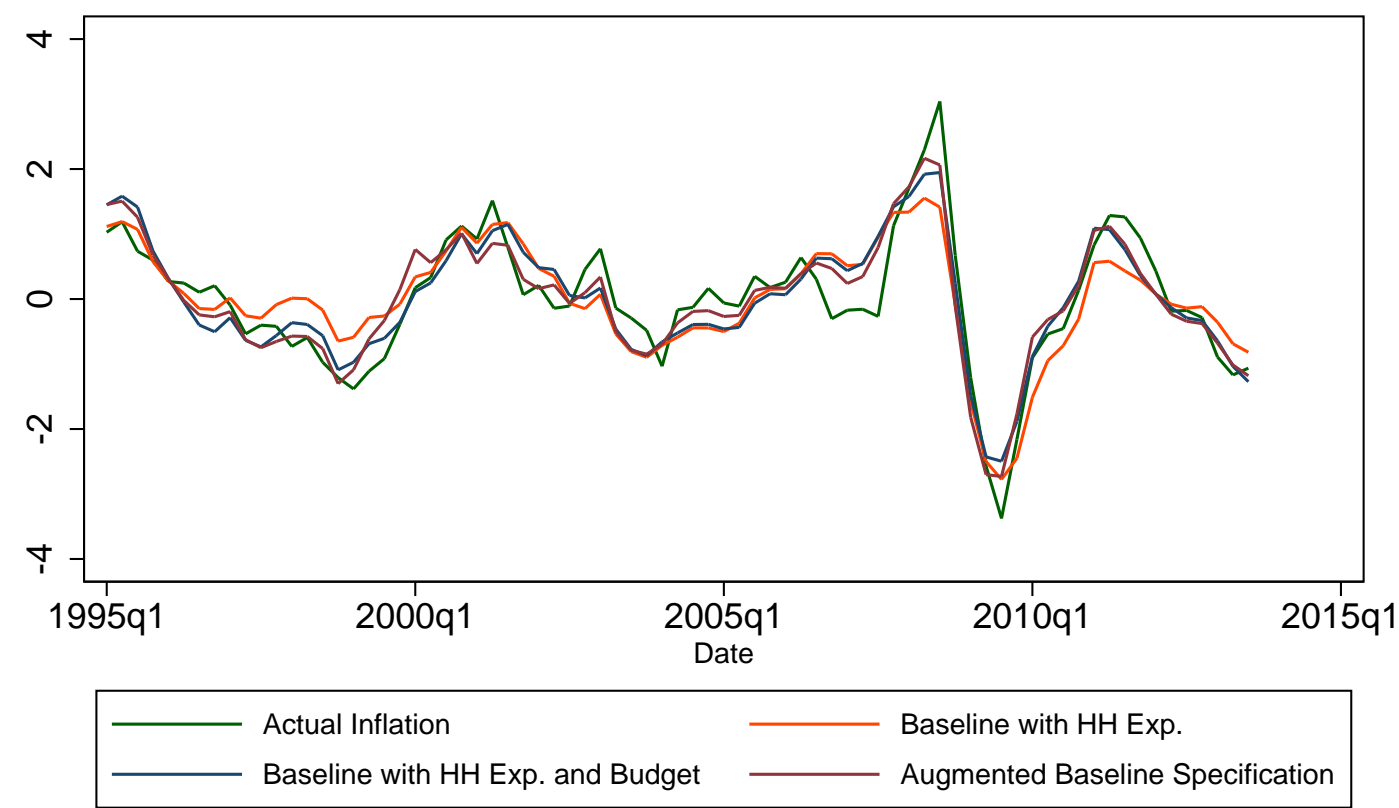

Note: Actual Inflation = 1st factor of headline inflation. Baseline Specification = In-sample fit for the standard global Phillips curve specification, containing the unemployment rate and inflation expectations by professional forecasters. Augmented Baseline Specification = Baseline specification plus the following three variables: household inflation expectations (HH Exp.), the budget balance in percent of GDP (Budget) and energy price growth - all global and without interactions. 
Figure A3: Robustness: Excluding the Two Standard Determinants from the Baseline Specification

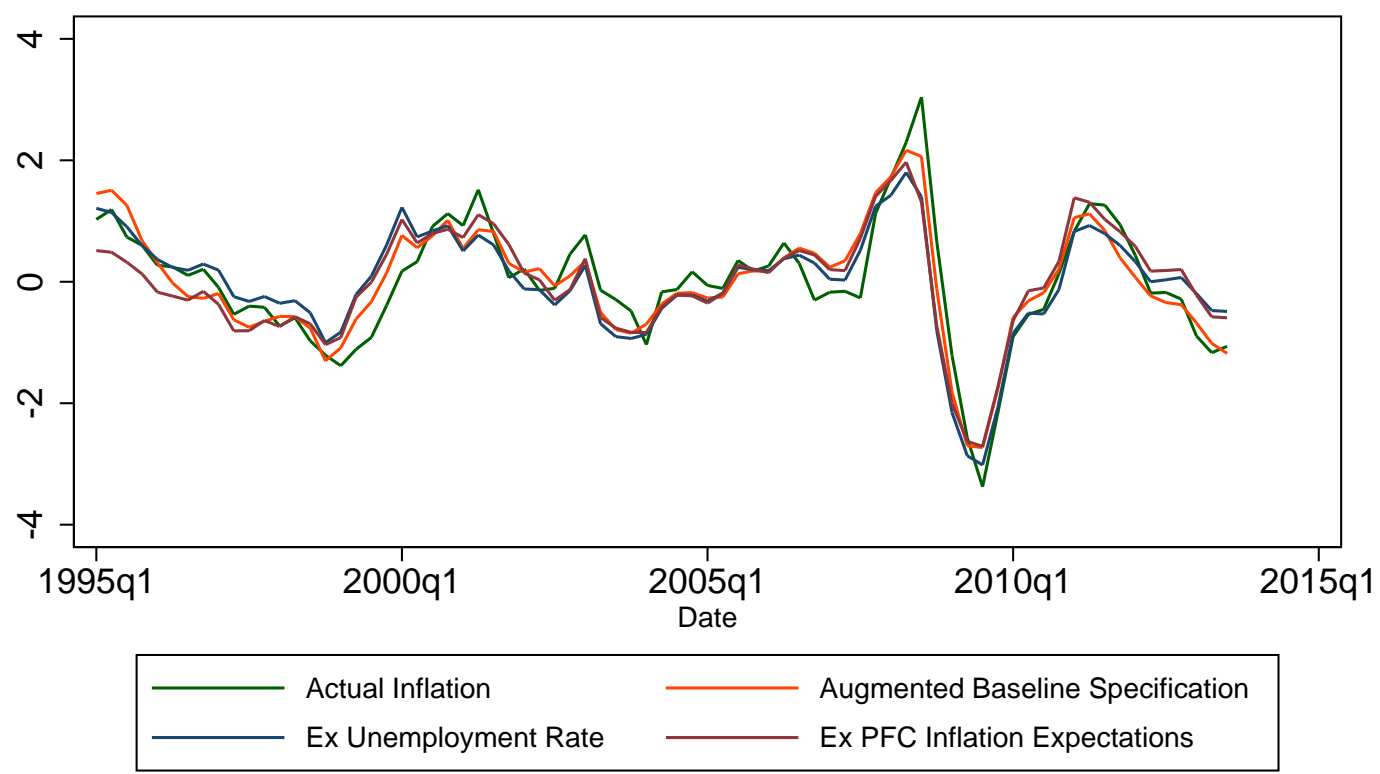

Note: Actual Inflation = 1st factor of headline inflation. Augmented Baseline Specification = In-sample fit for the standard global Phillips curve specification, containing the unemployment rate and inflation expectations by professional forecasters, plus the following three variables: household inflation expectations, the budget balance in percent of GDP and energy price growth - all global and without interactions. Ex Unemployment Rate = Excluding the Unemployment Rate. Ex PFC Inflation Expectations = Excluding inflation expectations by professional forecasters.

Figure A4: Inflation Expectations by Professional Forecasters and Households over Time

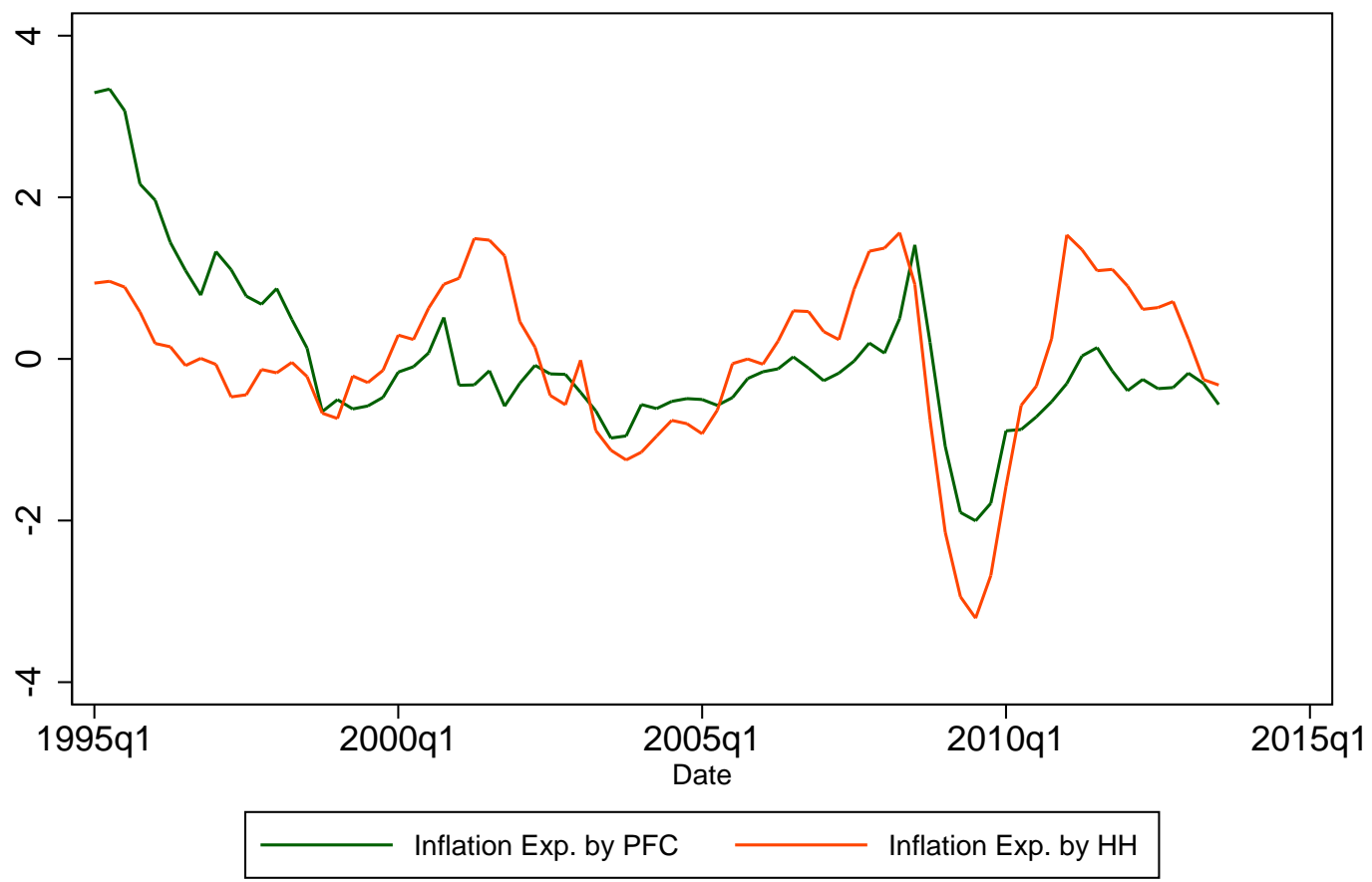

Note: Inflation expectations of households $(\mathrm{HH})$ refer to the next 12 months. Inflation expectations by professional forecasters (PFC) refer to the next calendar year. 
Figure A5: The In-Sample Fit Excluding Household Inflation Expectations but Adding Commodity Prices

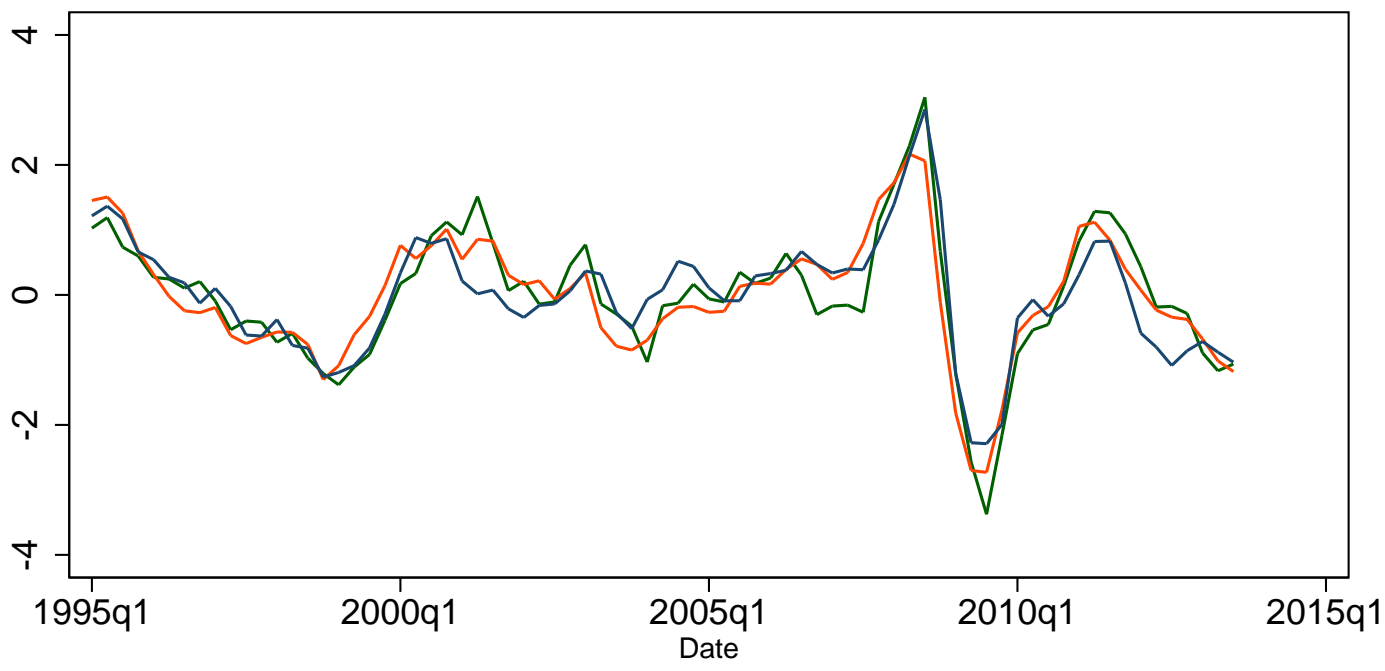

Actual Inflation

Augmented Baseline Specification

Repl. HH Infl. Exp. with FPG

Note: $\mathrm{HH}$ Infl. Exp. $=$ Household Inflation Expectations. FPG $=$ Food Price Growth. Actual Inflation $=$ 1st factor of headline inflation. Augmented Baseline Specification = In-sample fit for the standard global Phillips curve specification, containing the unemployment rate and inflation expectations by professional forecasters, plus the following three variables: household inflation expectations, the budget balance in \% of GDP (Budget) and energy price growth - all global and without interactions.

Figure A6: Inflation Expectations and the Budget Balance

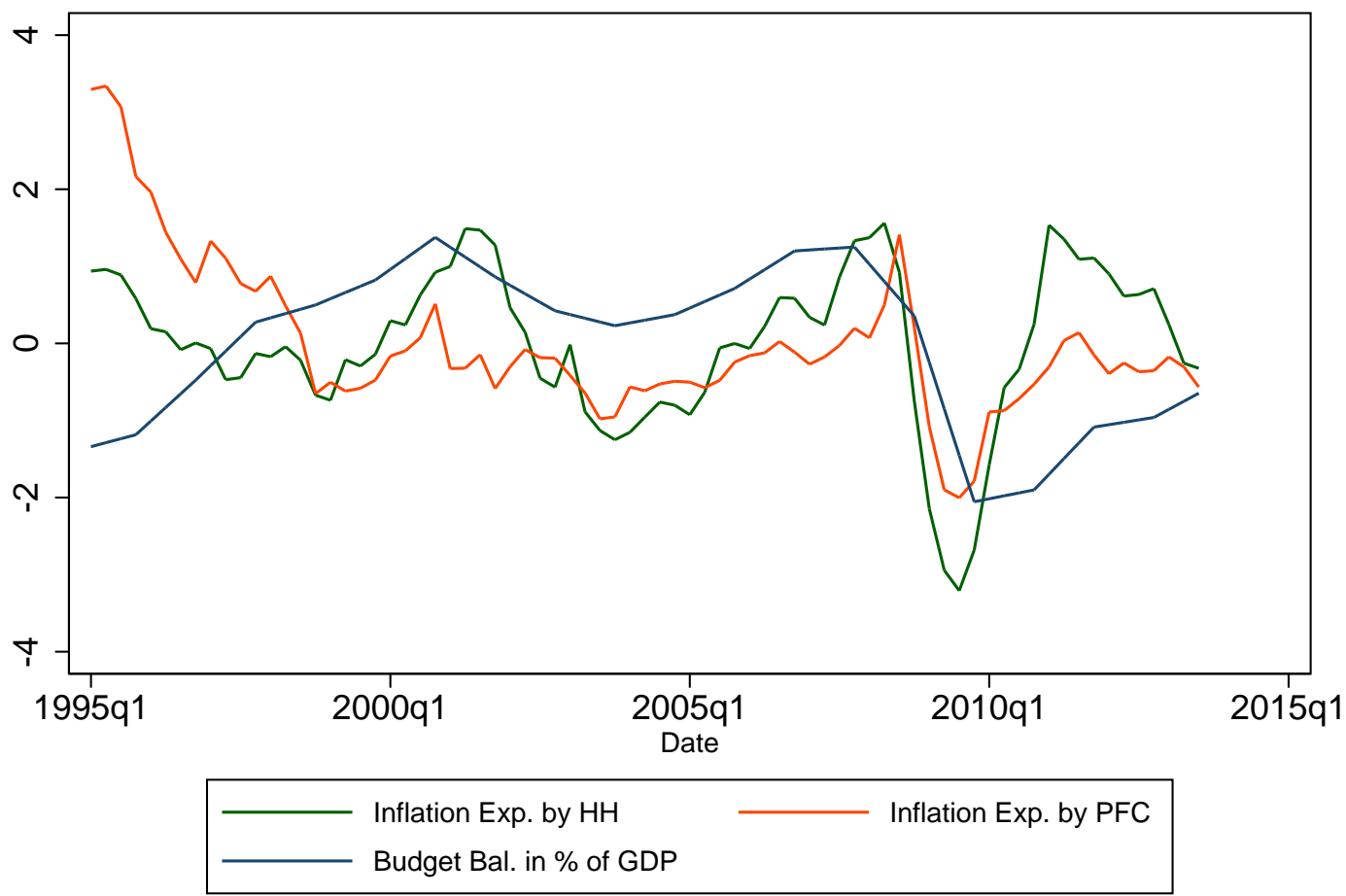

Note: $\mathrm{HH}=$ Households. PFC $=$ Professional Forecasters. 
Figure A7: Robustness: Main In-Sample Predictions Based on the First Factor (Memorandum)

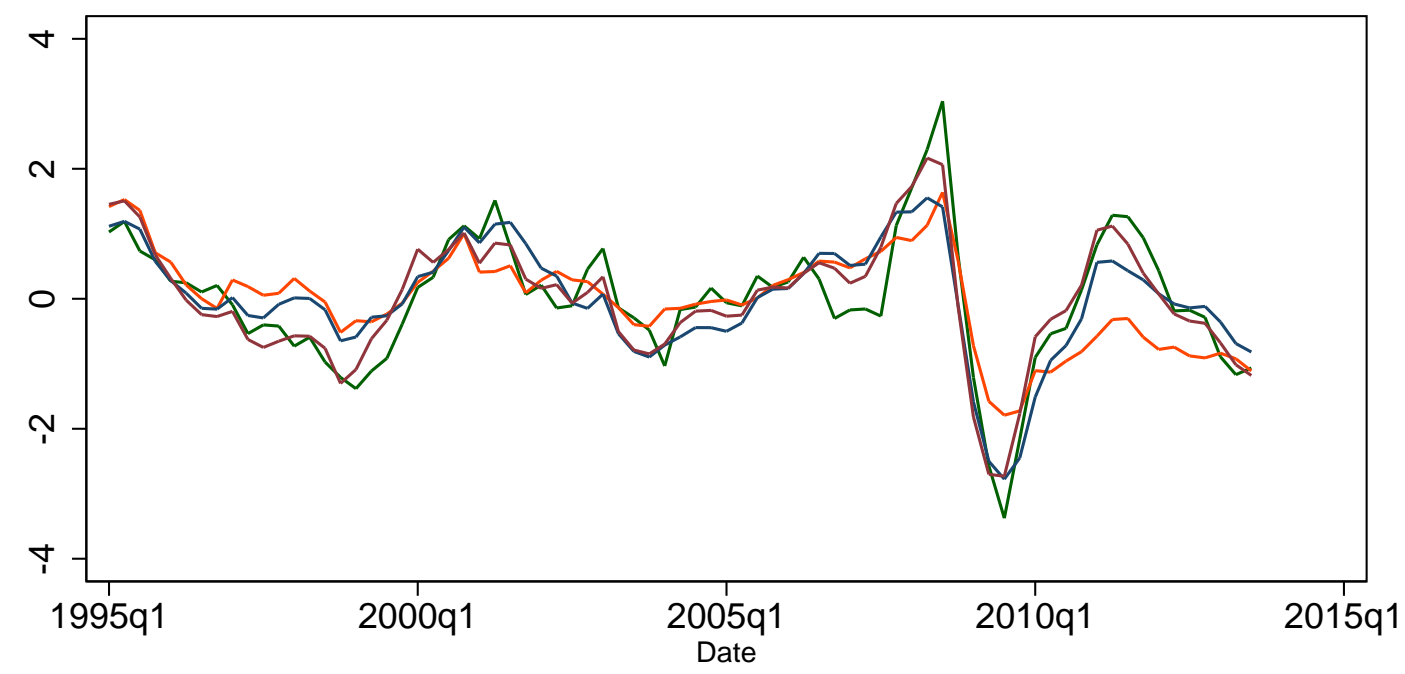

$$
\begin{aligned}
& \text { Actual Inflation } \\
& \text { Baseline Specification with HH Exp. }
\end{aligned}
$$

Note: Global aggregation is based on 1st factor. Actual Inflation = Global headline inflation. Augmented Baseline Specification = In-sample fit for the standard global Phillips curve specification, containing the unemployment rate and inflation expectations by professional forecasters, plus the following three variables: household inflation expectations, the budget balance in percent of GDP and energy price growth - all global and without interactions.

Figure A8: Robustness: Main In-Sample Predictions Based on an Unweighted Average

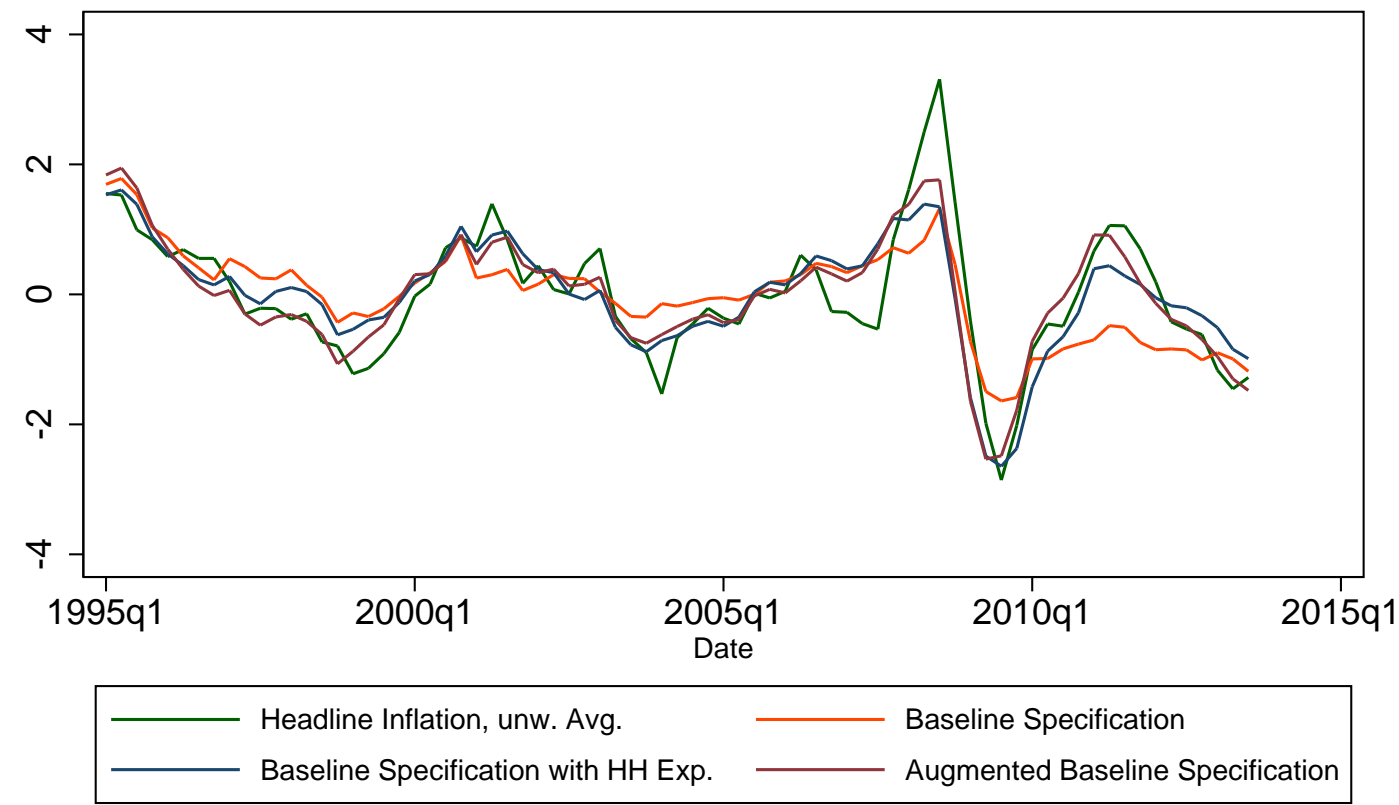

Note: Global aggregation is based on an unweighted average. Actual Inflation = Global headline inflation. Augmented Baseline Specification = In-sample fit for the standard global Phillips curve specification, containing the unemployment rate and inflation expectations by professional forecasters, plus the following three variables: household inflation expectations, the budget balance in percent of GDP and energy price growth - all global and without interactions. 
Figure A9: Robustness: Main In-Sample Predictions Based on a Weighted Average

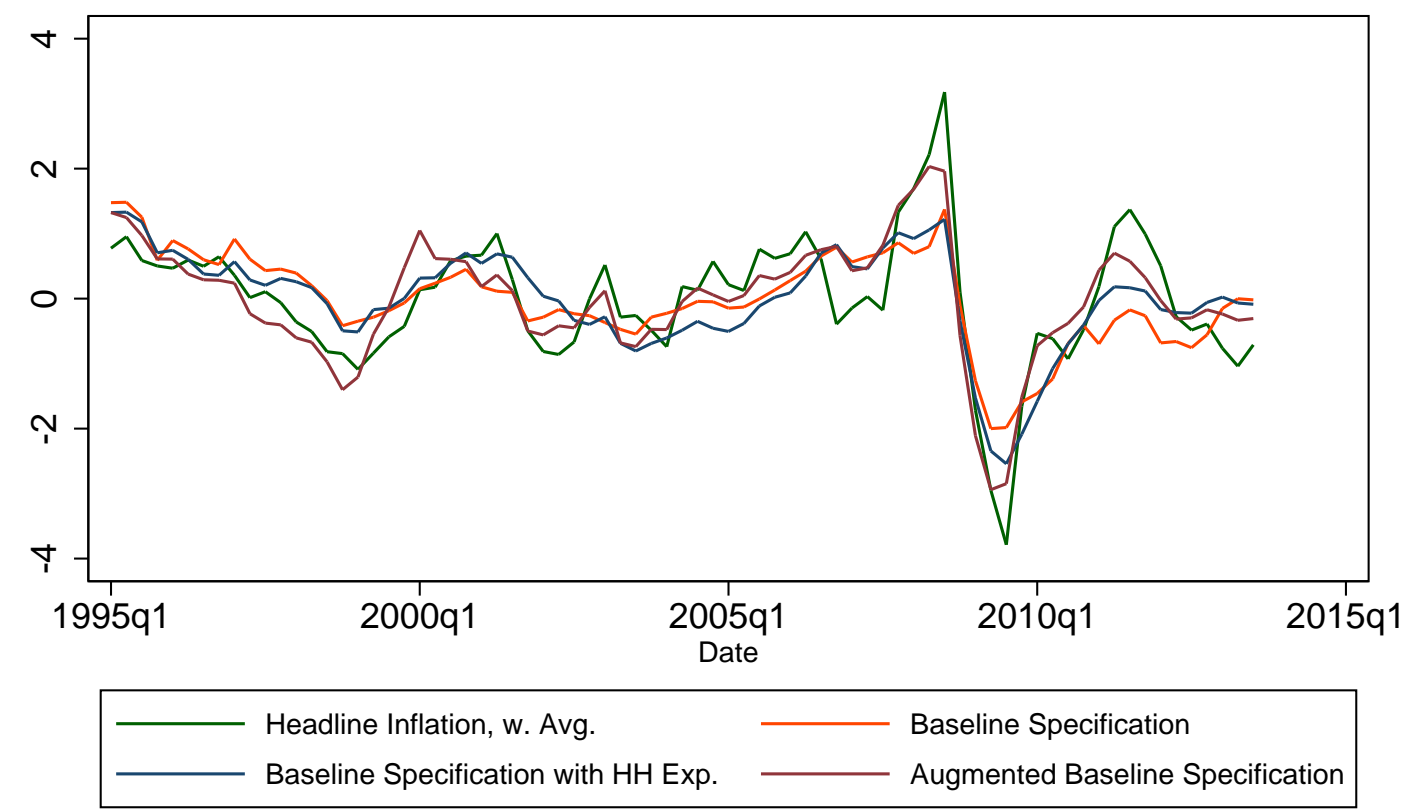

Note: Global aggregation is based on an weighted average. Actual Inflation = Global headline inflation. Augmented Baseline Specification = In-sample fit for the standard global Phillips curve specification, containing the unemployment rate and inflation expectations by professional forecasters, plus the following three variables: household inflation expectations, the budget balance in percent of GDP and energy price growth - all global and without interactions.

Figure A10: Robustness: In-Sample Fit of Key Specifications in a Constant Country Sample

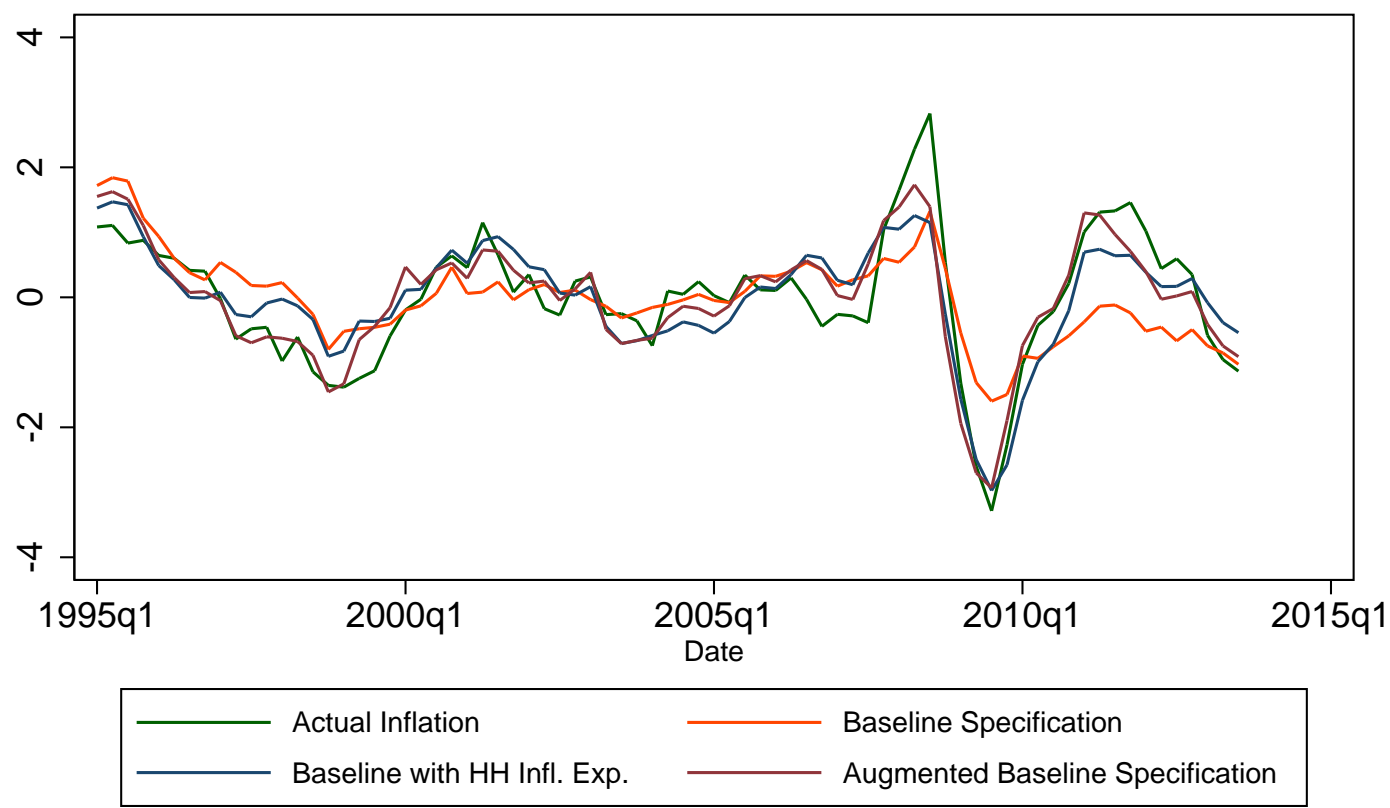

Note: Actual Inflation = 1st factor of headline inflation. Baseline Specification = In-sample fit for the standard global Phillips curve specification, containing the unemployment rate and inflation expectations by professional forecasters. Augmented Baseline Specification = Baseline specification plus the following three variables: household inflation expectations (HH Exp.), the budget balance in percent of GDP (Budget) and energy price growth - all global and without interactions. 
Figure A11: Robustness: Historical Contributions in a Constant Country Sample

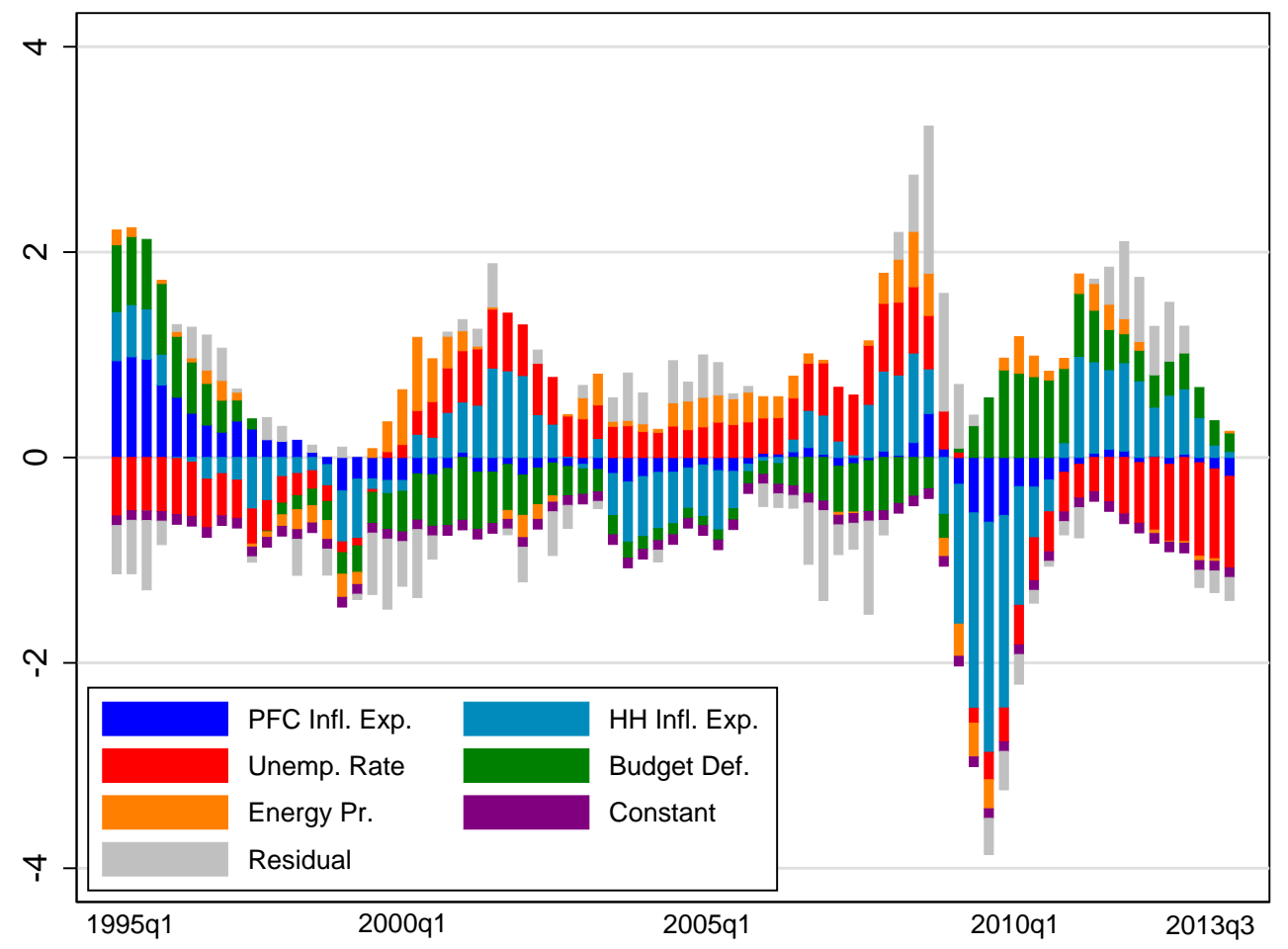

Figure A12: Robustness: Country-by-Country Results I
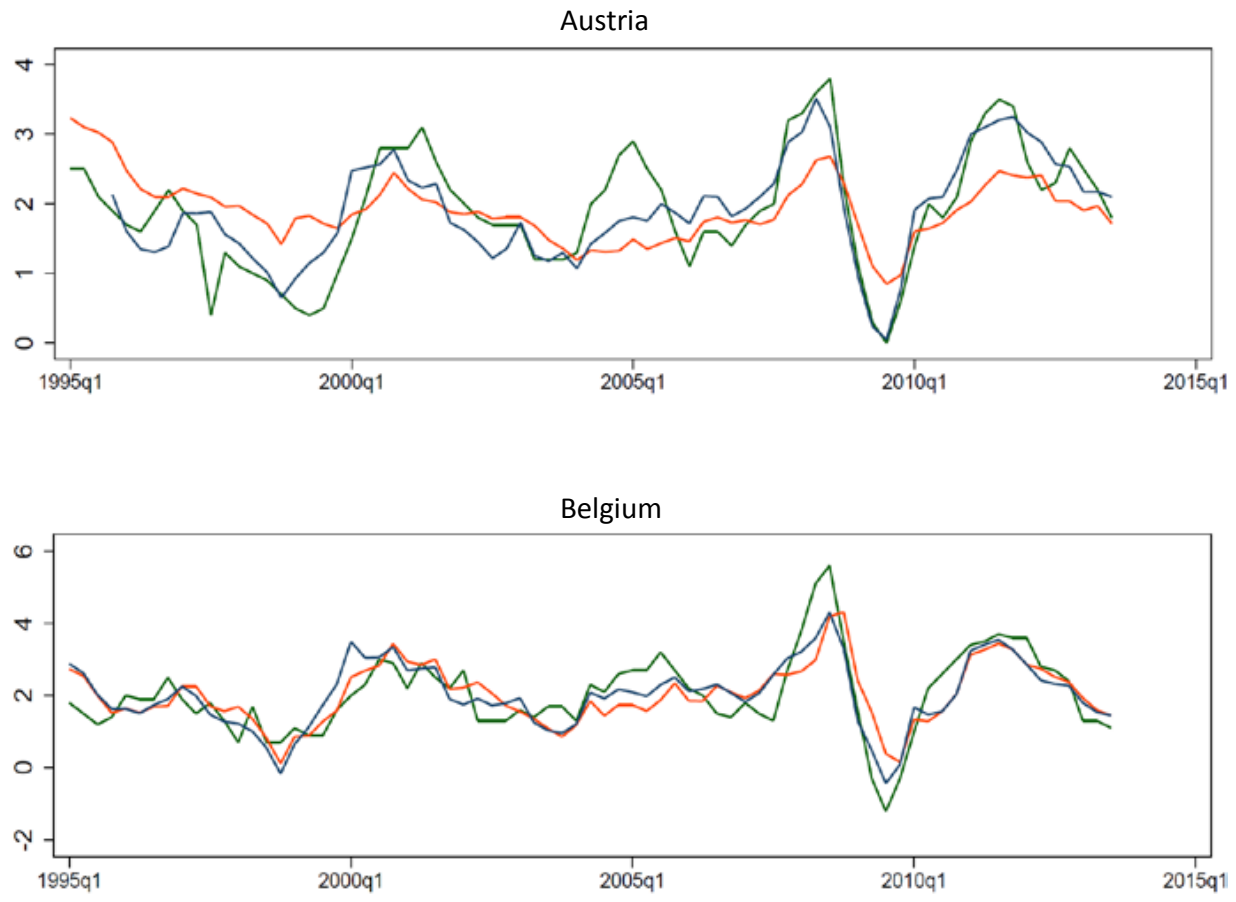

Note: Green Line $=$ Actual Inflation, Red Line $=$ Baseline Specification, Blue Line $=$ Augmented Baseline Specification. The same color scheme applies to the following two figures. 
Figure A13: Robustness: Country-by-Country Results II

Denmark

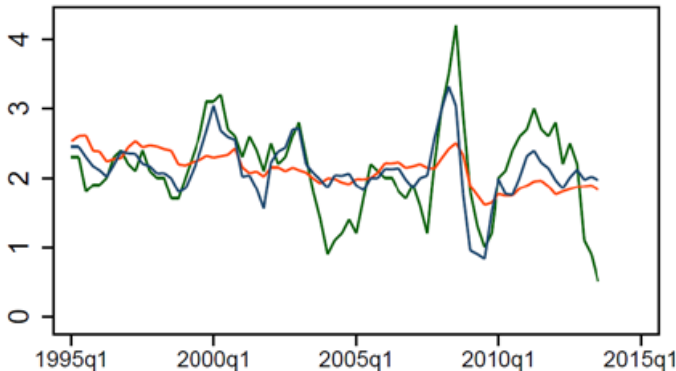

Germany

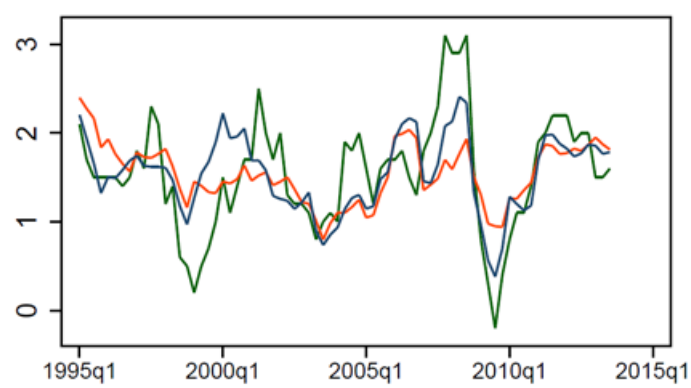

France

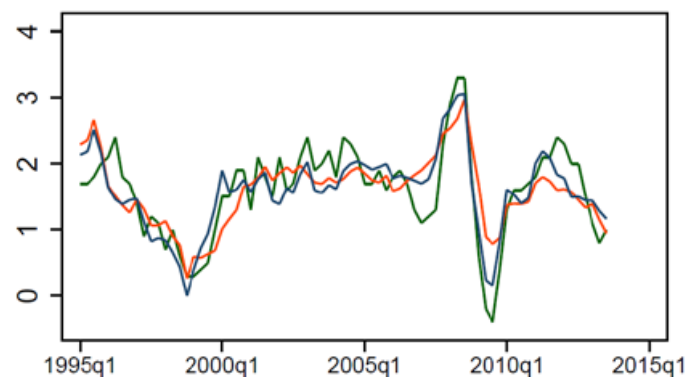

Italy

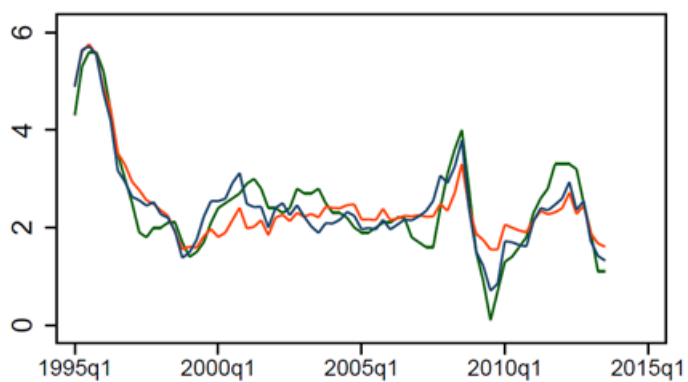

Figure A14: Robustness: Country-by-Country Results III

Portugal

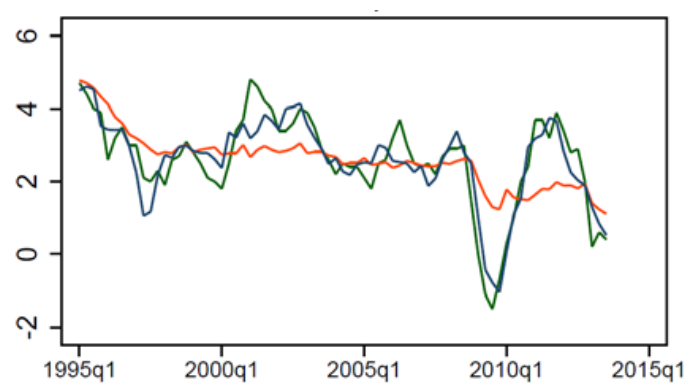

United Kingdom

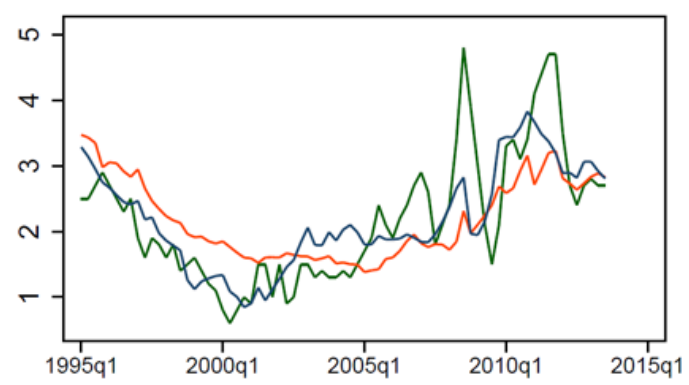

Spain

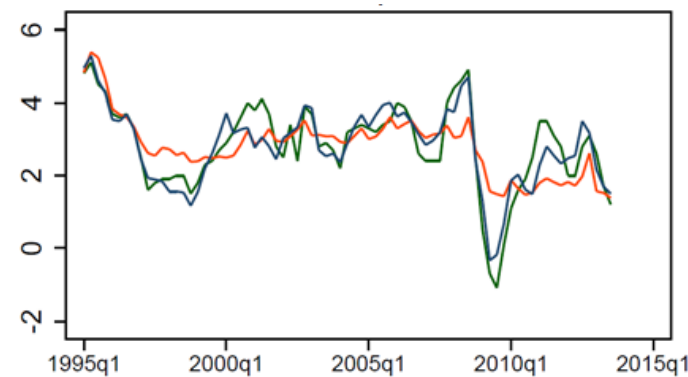

United States

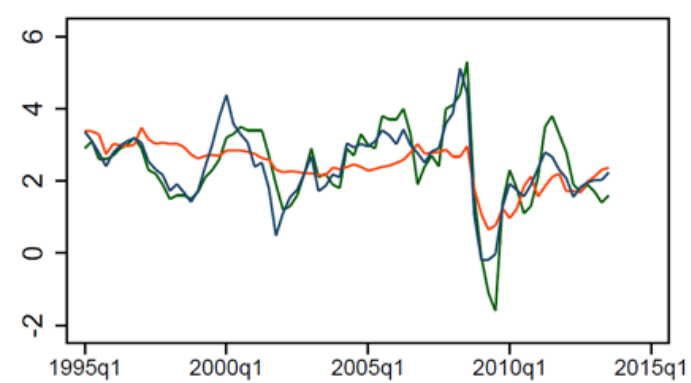


Figure A15: The Augmented Baseline Specification with Shorter Estimation Samples
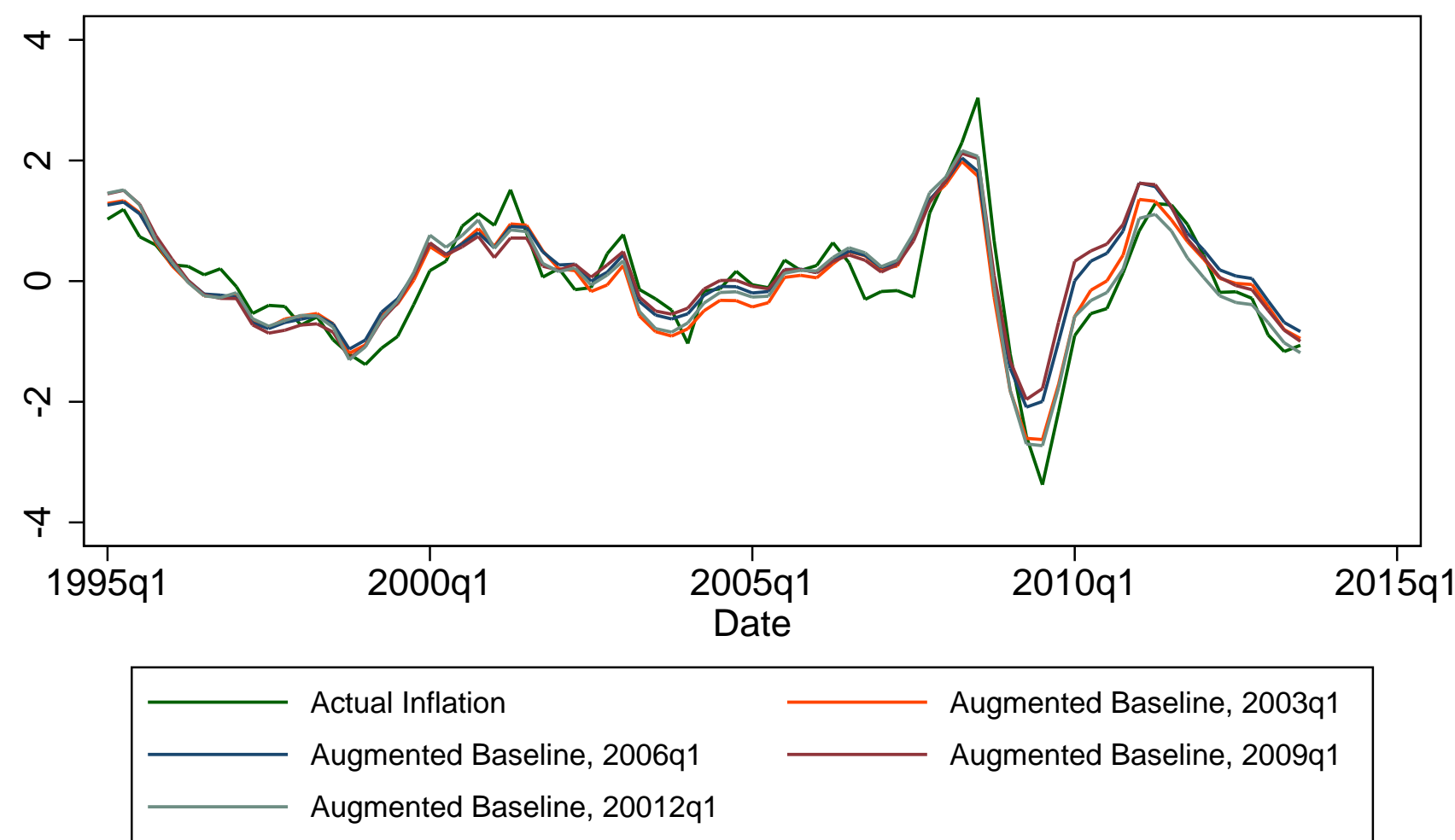

Note: Actual Inflation = 1st factor of headline inflation. Augmented Baseline Specification = In-sample fit for the standard global Phillips curve specification, containing the unemployment rate and inflation expectations by professional forecasters, plus the following three variables: household inflation expectations, the budget balance in percent of GDP and energy price growth - all global and without interactions. Dates indicates the end of the estimation sample. Starting date is $1995 \mathrm{q} 1$ in all cases. 
Figure A16: Repeating the First Selection Procedure at Different Points in Time - Rank

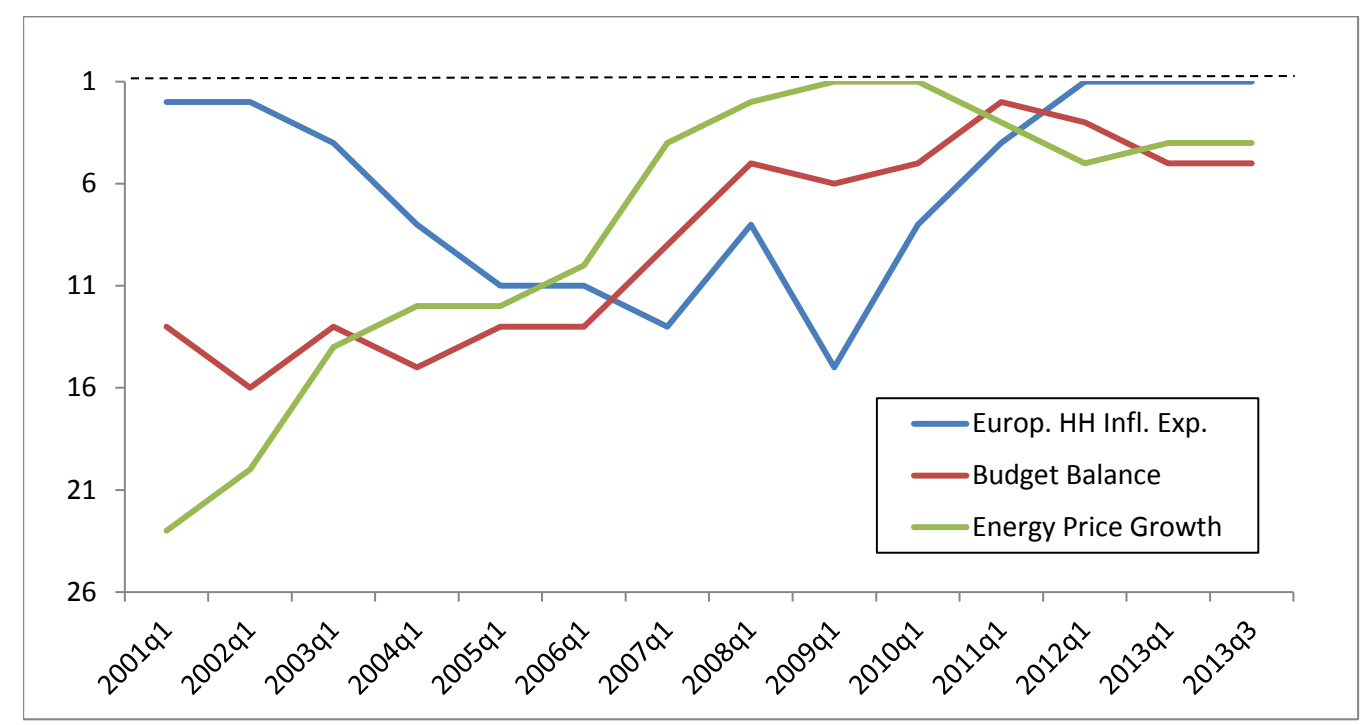

Note: This figure shows the time-varying rank (out of all 26 tested variables) for the following variables: European Household Inflation Expectations, Budget Balance in \% of GDP, and Energy-Price Growth, obtained from running the MSE-minimizing selection procedure at different points in time. Starting point of the selection procedure is 1995q1 in all cases. The baseline specification to which the third variable is added contains inflation expectations by professional forecasters for the next calendar year and the unemployment rate; i.e., no interaction terms.

Figure A17: Repeating the First Selection Procedure at Different Points in Time - Relative MSE

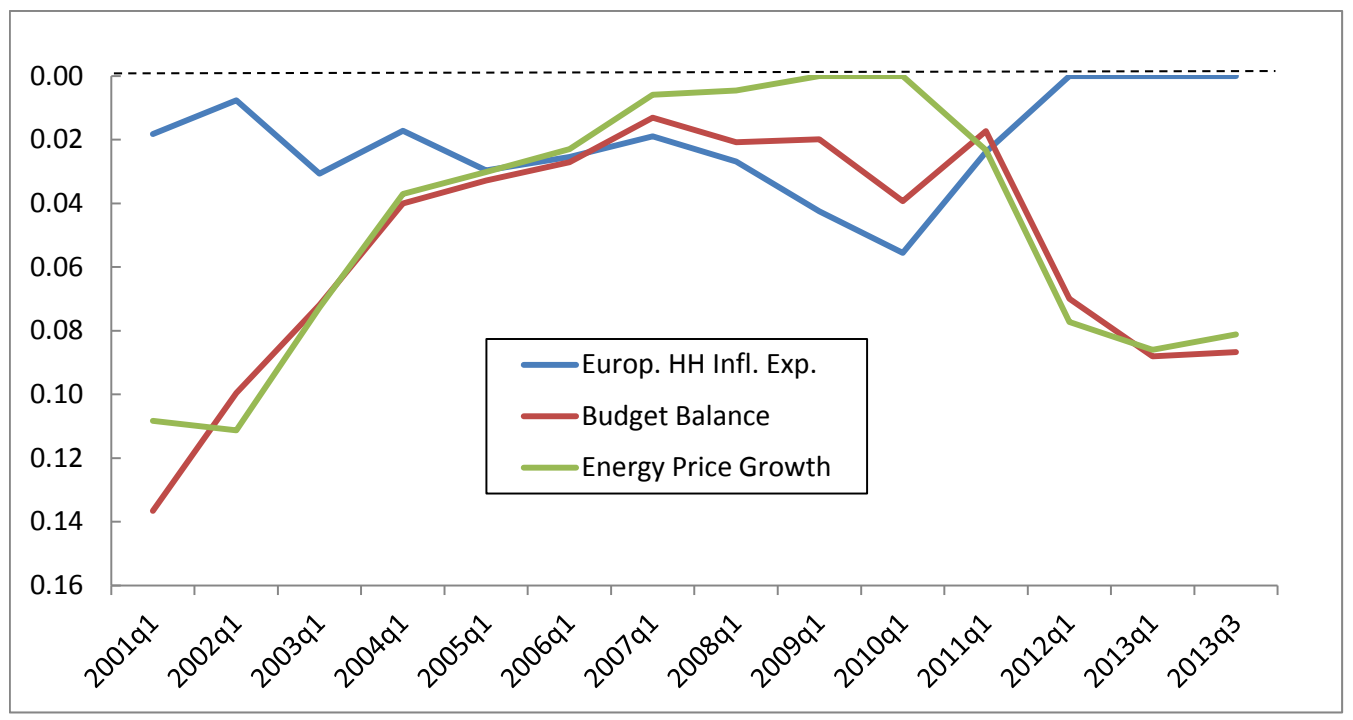

Note: This figure shows the time-varying relative MSE (= MSE - MSE of the variable with the lowest MSE) for the variables European Household Inflation Expectations, Budget Balance in \% of GDP, and Energy-Price Growth obtained from running the MSE-minimizing selection procedure at different points in time. Starting point of the selection procedure is 1995q1 in all cases. The baseline specification to which the third variable is added contains inflation expectations by professional forecasters for the next calendar year and the unemployment rate in levels; i.e., no interaction terms. 
Table A1: Literature on Global Inflation Dynamics and Their Determinants

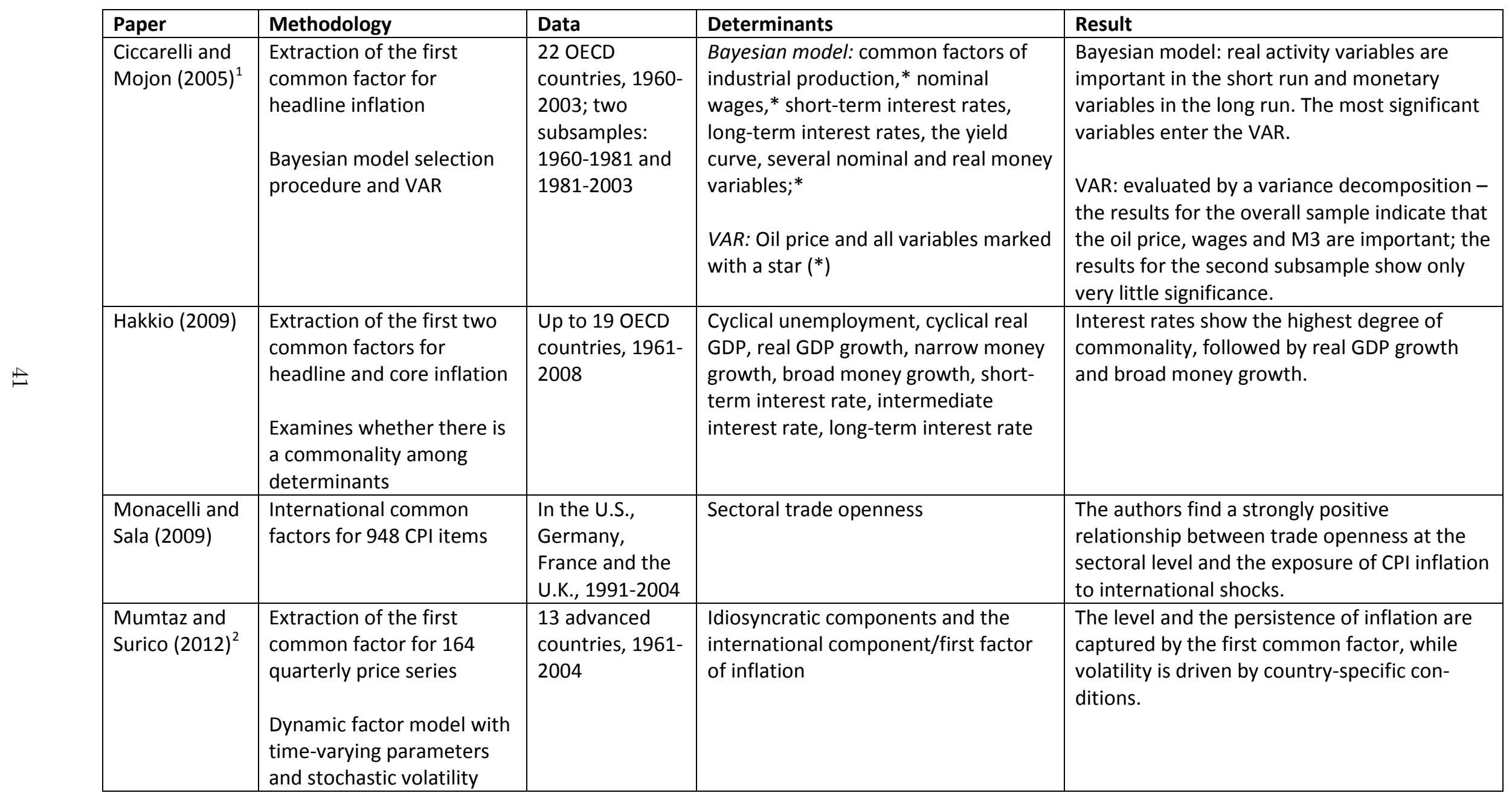

\footnotetext{
${ }^{1}$ Summary is based on the working paper version. The paper has been published with a slightly different focus in 2010.

${ }^{2}$ Summary is based on 2007 WP version.
} 
Table A2: Global Variables

Inflation

Headline Inflation

$\begin{array}{lllllllllllllllllllllllllll}25 & \mathrm{x} & \mathrm{x} & \mathrm{x} & \mathrm{x} & \mathrm{x} & \mathrm{x} & \mathrm{x} & \mathrm{x} & \mathrm{x} & \mathrm{x} & \mathrm{x} & \mathrm{x} & \mathrm{x} & \mathrm{x} & \mathrm{x} & \mathrm{x} & \mathrm{x} & \mathrm{x} & \mathrm{x} & \mathrm{x} & \mathrm{x} & \mathrm{x} & \mathrm{x} & \mathrm{x} & \mathrm{x} \\ 25 & \mathrm{x} & \mathrm{x} & \mathrm{x} & \mathrm{x} & \mathrm{x} & \mathrm{x} & \mathrm{x} & \mathrm{x} & \mathrm{x} & \mathrm{x} & \mathrm{x} & \mathrm{x} & \mathrm{x} & \mathrm{x} & \mathrm{x} & \mathrm{x} & \mathrm{x} & \mathrm{x} & \mathrm{x} & \mathrm{x} & \mathrm{x} & \mathrm{x} & \mathrm{x} & \mathrm{x} & \mathrm{x}\end{array}$

Inflation Expectations

Headline Inflation, backward-looking

Core Inflation, backward-looking

US Households, 1 year-ahead

US Households, $5+$ years-ahead

OECD Households, 1 year-ahead

Professional Forecasters, next year

Professional Forecasters, 5 years from now

Professional Forecasters, 10 years from now

Market-based, over the next 5 years

Market-based, over the next 10+ years

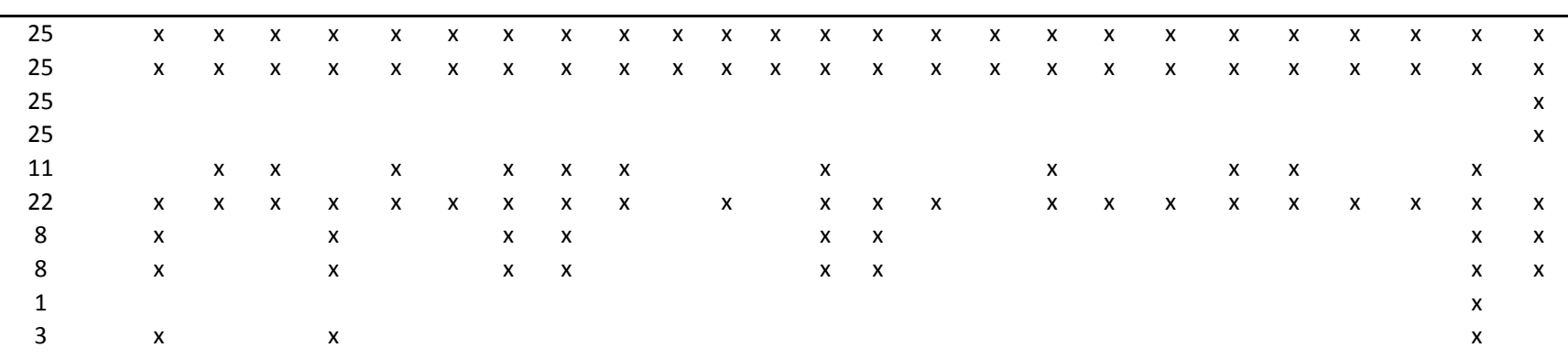

Measures of Economic Slack

\begin{tabular}{|c|c|c|c|c|c|c|c|c|c|c|c|c|c|c|c|c|c|c|c|c|c|c|c|c|c|}
\hline \multirow{2}{*}{$\begin{array}{l}\text { Unemployment Rate } \\
\text { Output Gap }\end{array}$} & 21 & $\mathrm{x}$ & $\mathrm{x}$ & $\mathrm{x}$ & $\mathrm{x}$ & $\mathrm{x}$ & $\mathrm{x}$ & $\mathrm{x}$ & $\mathrm{x}$ & & \multirow[b]{2}{*}{$\mathrm{x}$} & \multicolumn{2}{|l|}{$\mathrm{x}$} & \multirow{2}{*}{$\begin{array}{l}x \\
x\end{array}$} & \multirow{2}{*}{$\begin{array}{l}x \\
x\end{array}$} & \multirow{2}{*}{$\begin{array}{l}x \\
x\end{array}$} & \multirow[t]{2}{*}{$\mathrm{x}$} & \multirow{2}{*}{$\begin{array}{l}x \\
x\end{array}$} & \multirow{2}{*}{$\begin{array}{l}x \\
x\end{array}$} & \multirow{2}{*}{$\begin{array}{l}x \\
x\end{array}$} & \multirow{2}{*}{$\begin{array}{l}x \\
x\end{array}$} & $\mathrm{x}$ & \multicolumn{2}{|c|}{$\mathrm{x}$} & \multirow{2}{*}{$\begin{array}{l}x \\
x\end{array}$} \\
\hline & 22 & $\mathrm{x}$ & $x$ & $x$ & $\mathrm{x}$ & $\mathrm{x}$ & $\mathrm{x}$ & $\mathrm{x}$ & $x$ & & & $x$ & & & & & & & & & & $x$ & $\mathrm{x}$ & $\mathrm{x}$ & \\
\hline Unemployment Gap & 21 & $\mathrm{x}$ & $\mathrm{x}$ & $\mathrm{x}$ & $\mathrm{x}$ & $\mathrm{x}$ & $\mathrm{x}$ & $x$ & $x$ & & & $\mathrm{x}$ & & $\mathrm{x}$ & $\mathrm{x}$ & $\mathrm{x}$ & $\mathrm{x}$ & $\mathrm{x}$ & $\mathrm{x}$ & $\mathrm{x}$ & $\mathrm{x}$ & $\mathrm{x}$ & $\mathrm{x}$ & & $\mathrm{x}$ \\
\hline Real GDP Gap & 22 & $\mathrm{x}$ & $\mathrm{x}$ & $\mathrm{x}$ & $\mathrm{x}$ & $\mathrm{x}$ & $\mathrm{x}$ & $\mathrm{x}$ & $x$ & $\mathrm{x}$ & & & $\mathrm{x}$ & $\mathrm{x}$ & $\mathrm{x}$ & $\mathrm{x}$ & $\mathrm{x}$ & $\mathrm{x}$ & $\mathrm{x}$ & $\mathrm{x}$ & $\mathrm{x}$ & & $\mathrm{x}$ & $\mathrm{x}$ & $\mathrm{x}$ \\
\hline Industry Production Gap & 24 & $\mathrm{x}$ & $\mathrm{x}$ & $x$ & $\mathrm{x}$ & $\mathrm{x}$ & $x$ & $x$ & $\mathrm{x}$ & $\mathrm{x}$ & & $\mathrm{x}$ & $x$ & $\mathrm{x}$ & $\mathrm{x}$ & $\mathrm{x}$ & $\mathrm{x}$ & $\mathrm{x}$ & $\mathrm{x}$ & $\mathrm{x}$ & $\mathrm{x}$ & $x$ & $\mathrm{x}$ & $\mathrm{x}$ & $\mathrm{x}$ \\
\hline Industry Production Growth & 24 & $\mathrm{x}$ & $\mathrm{x}$ & $x$ & $\mathrm{x}$ & $\mathrm{x}$ & $\mathrm{x}$ & $x$ & $\mathrm{x}$ & $\mathrm{x}$ & & $\mathrm{x}$ & $\mathrm{x}$ & $\mathrm{x}$ & $\mathrm{x}$ & $\mathrm{x}$ & $\mathrm{x}$ & $\mathrm{x}$ & $\mathrm{x}$ & $\mathrm{x}$ & $\mathrm{x}$ & $\mathrm{x}$ & $\mathrm{x}$ & $\mathrm{x}$ & $\mathrm{x}$ \\
\hline Unit Labor Cost Growth & 12 & $\mathrm{x}$ & & & $\mathrm{x}$ & $\mathrm{x}$ & $x$ & $x$ & $x$ & & & & & $\mathrm{x}$ & $\mathrm{x}$ & $\mathrm{x}$ & & & & & & & $\mathrm{x}$ & & $\mathrm{x}$ \\
\hline Labor Compensation Growth & 14 & $\mathrm{x}$ & & & $\mathrm{x}$ & $\mathrm{x}$ & $x$ & $\mathrm{x}$ & $x$ & & & & & $\mathrm{x}$ & $\mathrm{x}$ & $x$ & & & $\mathrm{x}$ & & & $\mathrm{x}$ & $x$ & & $\mathrm{x}$ \\
\hline
\end{tabular}

\section{Other Variables}

\section{Gov. Budget Balance}

11

Growth of QE-Quantities

Inflation Expectations Uncertainty

Financial Market Uncertainty

Credit Growth

Real Estate Price Growth

\begin{tabular}{|c|c|c|c|c|c|c|c|c|c|c|c|c|c|c|c|c|c|c|c|c|c|c|c|}
\hline 21 & $x$ & $x$ & $x$ & $x$ & $x$ & $x$ & $x$ & $x$ & $x$ & $x$ & $x$ & $x$ & $x$ & & & $x$ & $x$ & $x$ & $x$ & $x$ & $x$ & $x$ & $x$ \\
\hline 1 & & & & & & & & & & & & & & & & & & & & & & & $x$ \\
\hline 14 & $x$ & & & $x$ & & & $x$ & $x$ & & & & $x$ & $x$ & $x$ & $x$ & $x$ & & & $x$ & $x$ & $x$ & $x$ & $\begin{array}{l}x \\
x\end{array}$ \\
\hline 20 & $x$ & $x$ & $x$ & $x$ & $x$ & $x$ & $x$ & $x$ & $x$ & & $x$ & $x$ & $x$ & & $x$ & & $x$ & $x$ & $x$ & $x$ & $x$ & $x$ & $x$ \\
\hline 11 & $x$ & & $x$ & $x$ & & & & & & & & & & $x$ & $x$ & $x$ & $x$ & $x$ & $x$ & & $x$ & & $x$ \\
\hline
\end{tabular}

Note: Stock Market, Oil, Energy, and Food Prices are all based on global indices. "x" indicates that data are available. 
Table A3: Summary Statistics for all Potential Explanatory Variables

\begin{tabular}{lrrrrr} 
Variable & Obs & Mean & Std. & Min & Max \\
\hline \hline Professional Forecasters, next year & 75 & 0 & 1.0 & -2.0 & 3.3 \\
Unemployment Rate & 75 & 0 & 1.0 & -1.6 & 1.7 \\
US Households, 1 year-ahead & 75 & 0 & 1.0 & -3.0 & 3.9 \\
US Households, 5+ years-ahead & 75 & 0 & 1.0 & -1.6 & 2.7 \\
OECD Households, 1 year-ahead & 75 & 0 & 1.0 & -3.2 & 1.6 \\
Professional Forecasters, 5 years from now & 75 & 0 & 1.0 & -1.1 & 3.7 \\
Professional Forecasters, 10 years from now & 75 & 0 & 1.0 & -1.2 & 3.5 \\
Market-based, over the next 5 years & 75 & 0 & 1.0 & -3.6 & 2.9 \\
Market-based, over the next 10+ years & 75 & 0 & 1.0 & -1.7 & 3.3 \\
Output Gaps & 75 & 0 & 1.0 & -1.7 & 2.2 \\
Industry Production Growth & 75 & 0 & 1.0 & -4.0 & 1.6 \\
Unit Labor Cost Growth & 75 & 0 & 1.0 & -2.1 & 3.9 \\
Labor Compensation Growth & 75 & 0 & 1.0 & -2.7 & 1.8 \\
Gov. Budget Balance & 75 & 0 & 1.0 & -2.1 & 1.4 \\
Inflation Expectations Uncertainty & 75 & 0 & 1.0 & -1.6 & 2.8 \\
Headline Inflation, backward-looking & 71 & 0 & 1.0 & -2.8 & 2.5 \\
Core Inflation, backward-looking & 71 & 0 & 1.0 & -1.6 & 3.1 \\
Real GDP Gap & 75 & 0 & 0.1 & -0.3 & 0.3 \\
Unemployment Gap & 75 & 0 & 0.4 & -0.8 & 0.9 \\
Industry Production Gap & 75 & 0 & 0.3 & -1.0 & 0.6 \\
Food Price Growth & 75 & 0.0 & 0.1 & -0.2 & 0.5 \\
Energy Price Growth & 75 & 0.1 & 0.3 & -0.5 & 1.1 \\
Oil Price Growth & 75 & 0.2 & 0.3 & -0.5 & 1.3 \\
Stock Market Price Growth & 75 & 0.1 & 0.2 & -0.4 & 0.4 \\
Growth of QE-Quantities & 74 & 0.3 & 1.1 & -0.1 & 7.0 \\
Real Estate Price Growth & 71 & -0.1 & 1.4 & -8.8 & 5.2 \\
Credit Growth & 71 & 0.1 & 1.1 & -3.6 & 6.0 \\
Financial Market Uncertainty & 75 & 21.2 & 7.9 & 11.0 & 58.6 \\
\hline \hline & & & & & \\
\hline
\end{tabular}

Note: National variables are generally standardized (Mean $=0$, Std. $=1$ ) owing to the computation of the first factor and are present for 75 observations (1995q1-2013q3). However, when a global variable does not enter in levels (e.g., as gap measure or as growth rate) or a variable is global by definition (e.g., prices), mean, standard deviation and observations can differ slightly. 
Table A4: Selected Specifications to Support the Overall Robustness

\begin{tabular}{|c|c|c|c|c|c|}
\hline $\begin{array}{l}\text { Dependent Variable: } \\
\text { Headline Inflation }\end{array}$ & (1) & (2) & (3) & (4) & (5) \\
\hline Unemployment Rate & $\begin{array}{c}-0.63 * * * \\
(0.00)\end{array}$ & $\begin{array}{c}-0.53^{* * *} \\
(0.00)\end{array}$ & & $\begin{array}{c}-0.30 * * \\
(0.03)\end{array}$ & $\begin{array}{c}-0.59 * * * \\
(0.00)\end{array}$ \\
\hline Inflation Expectations by PFC, next year & $\begin{array}{c}0.56^{* * *} \\
(0.00)\end{array}$ & $\begin{array}{c}0.58^{* * *} \\
(0.00)\end{array}$ & $\begin{array}{c}0.21 * * * \\
(0.00)\end{array}$ & & \\
\hline Inflation Expectations by US HH, 12 months & $\begin{array}{c}0.52^{* * *} \\
(0.00)\end{array}$ & $\begin{array}{c}0.39 * * * \\
(0.00)\end{array}$ & & & \\
\hline Unemp. Rate x Infl. Exp. by US HH & $\begin{array}{c}0.24 * * * \\
(0.00)\end{array}$ & & & & \\
\hline Infl. Exp. by PFC x Infl. Exp. by US HH & $\begin{array}{c}0.04 \\
(0.69)\end{array}$ & & & & \\
\hline Inflation Expectations by $\mathrm{HH}, 12$ months & & & $\begin{array}{c}0.58^{* * *} \\
(0.00)\end{array}$ & $\begin{array}{c}0.72^{* * *} \\
(0.00)\end{array}$ & \\
\hline Budget Bal. in \% of GDP & & & $\begin{array}{l}0.09 * \\
(0.07)\end{array}$ & $\begin{array}{l}-0.21 * \\
(0.07)\end{array}$ & $\begin{array}{c}-0.27^{* *} \\
(0.01)\end{array}$ \\
\hline GR of World Energy Prices & & & $\begin{array}{c}1.07^{* * *} \\
(0.00)\end{array}$ & $\begin{array}{c}0.86 * * * \\
(0.00)\end{array}$ & \\
\hline GR of World Energy Prices, 1st lag & & & & & $\begin{array}{c}0.85 * * * \\
(0.00)\end{array}$ \\
\hline GR of World Food Prices, 1st lag & & & & & $\begin{array}{c}2.15^{* * *} \\
(0.00) \\
\end{array}$ \\
\hline Observations & 75 & 75 & 75 & 75 & 75 \\
\hline R-squared & 0.70 & 0.66 & 0.76 & 0.75 & 0.79 \\
\hline
\end{tabular}

Note: P-Values in Parentheses. Constant not reported. 
Table A5: Varying Global Aggregation Techniques: All Key Specifications

\begin{tabular}{|c|c|c|c|}
\hline \multirow{2}{*}{$\begin{array}{l}\text { Dependent Variable: } \\
\text { First Factor }\end{array}$} & \multicolumn{3}{|c|}{ Headline Inflation } \\
\hline & $(1)$ & $(2)$ & (3) \\
\hline Unemployment Rate & $\begin{array}{c}-0.54^{* * *} \\
(0.00)\end{array}$ & $\begin{array}{c}-0.33^{* * *} \\
(0.00)\end{array}$ & $\begin{array}{c}-0.75^{* * *} \\
(0.00)\end{array}$ \\
\hline Inflation Expectations by HH, 12 months & & $\begin{array}{c}0.58^{* * *} \\
(0.00)\end{array}$ & $\begin{array}{c}0.49 * * * \\
(0.00)\end{array}$ \\
\hline Inflation Expectations by PFC, next year & $\begin{array}{c}0.71 * * * \\
(0.00)\end{array}$ & $\begin{array}{c}0.34 * * * \\
(0.00)\end{array}$ & $\begin{array}{c}0.47^{* * *} \\
(0.00)\end{array}$ \\
\hline Budget Bal. in \% of GDP & & & $\begin{array}{c}-0.50^{* * *} \\
(0.00)\end{array}$ \\
\hline GR of World Energy Prices & & & $\begin{array}{c}0.70 * * * \\
(0.00) \\
\end{array}$ \\
\hline Observations & 75 & 75 & 75 \\
\hline R-squared & 0.52 & 0.74 & 0.86 \\
\hline Unweighted Avg. & $(1)$ & $(2)$ & (3) \\
\hline Unemployment Rate & $\begin{array}{c}-0.36^{* * *} \\
(0.00)\end{array}$ & $\begin{array}{c}-0.21 * * * \\
(0.01)\end{array}$ & $\begin{array}{c}-0.71^{* * *} \\
(0.00)\end{array}$ \\
\hline Inflation Expectations by HH, 12 months & & $\begin{array}{c}0.52^{* * *} \\
(0.00)\end{array}$ & $\begin{array}{c}0.48^{* * *} \\
(0.00)\end{array}$ \\
\hline Inflation Expectations by PFC, next year & $\begin{array}{c}0.67^{* * *} \\
(0.00)\end{array}$ & $\begin{array}{c}0.42^{* * *} \\
(0.00)\end{array}$ & $\begin{array}{c}0.50 * * * \\
(0.00)\end{array}$ \\
\hline Budget Bal. in \% of GDP & & & $\begin{array}{c}-0.57^{* * *} \\
(0.00)\end{array}$ \\
\hline GR of World Energy Prices & & & $\begin{array}{c}0.26 \\
(0.27) \\
\end{array}$ \\
\hline 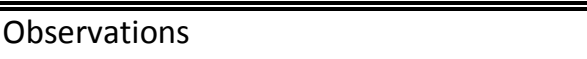 & 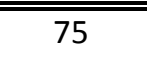 & 75 & 75 \\
\hline R-squared & 0.51 & 0.71 & 0.79 \\
\hline Weighted Avg. & (1) & (2) & (3) \\
\hline$\overline{\text { Unemployment Rate }}$ & $\begin{array}{c}-0.49^{* * *} \\
(0.00)\end{array}$ & $\begin{array}{c}-0.33^{* * *} \\
(0.00)\end{array}$ & $\begin{array}{c}-0.81^{* * *} \\
(0.00)\end{array}$ \\
\hline Inflation Expectations by HH, 12 months & & $\begin{array}{c}0.38^{* * *} \\
(0.00)\end{array}$ & $\begin{array}{c}0.35^{* * *} \\
(0.00)\end{array}$ \\
\hline Inflation Expectations by PFC, next year & $\begin{array}{c}0.58^{* * *} \\
(0.00)\end{array}$ & $\begin{array}{c}0.36^{* * *} \\
(0.00)\end{array}$ & $\begin{array}{c}0.34^{* * *} \\
(0.00)\end{array}$ \\
\hline Budget Bal. in \% of GDP & & & $\begin{array}{c}-0.60 * * * \\
(0.01)\end{array}$ \\
\hline GR of World Energy Prices & & & $\begin{array}{c}1.06 * * * \\
(0.00) \\
\end{array}$ \\
\hline Observations & 75 & 75 & 75 \\
\hline R-squared & 0.50 & 0.59 & 0.79 \\
\hline
\end{tabular}

Note: P-Values in Parentheses. Constant not reported. 
Table A6: Constant Country Sample: Baseline Specification and Post-Crisis Dummy

\begin{tabular}{|c|c|c|c|c|c|}
\hline $\begin{array}{l}\text { Dependent Variable: } \\
\text { Headline Inflation } \\
\end{array}$ & (1) & (2) & (3) & (4) & (5) \\
\hline Unemployment Rate & $\begin{array}{c}-0.32^{* * *} \\
(0.00)\end{array}$ & $\begin{array}{c}-0.40^{* * *} \\
(0.00)\end{array}$ & $\begin{array}{c}-0.96^{* * *} \\
(0.00)\end{array}$ & $\begin{array}{c}-0.97^{* * *} \\
(0.00)\end{array}$ & $\begin{array}{c}-0.91^{* * *} \\
(0.00)\end{array}$ \\
\hline Inflation Expectations by PFC, next year & $\begin{array}{c}0.67^{* * *} \\
(0.00)\end{array}$ & $\begin{array}{l}1.00 \\
(.)\end{array}$ & $\begin{array}{c}0.99 * * * \\
(0.00)\end{array}$ & $\begin{array}{l}1.00 \\
(.)\end{array}$ & $\begin{array}{c}0.91^{* * *} \\
(0.00)\end{array}$ \\
\hline Post-Crisis Dummy & & & $\begin{array}{c}1.75^{* * *} \\
(0.00)\end{array}$ & $\begin{array}{c}1.76^{* * *} \\
(0.00)\end{array}$ & $\begin{array}{c}2.47^{* * *} \\
(0.00)\end{array}$ \\
\hline Unemployment Rate x Post-Crisis Dummy & & & $\begin{array}{c}0.26 \\
(0.41)\end{array}$ & $\begin{array}{c}0.26 \\
(0.40)\end{array}$ & $\begin{array}{l}-0.13 \\
(0.50)\end{array}$ \\
\hline Infl. Exp. By PFC x Post-Crisis Dummy & & & & & $\begin{array}{c}0.98^{* * *} \\
(0.00) \\
\end{array}$ \\
\hline Observations & 75 & 75 & 75 & 75 & 75 \\
\hline R-squared & 0.44 & & 0.76 & & 0.81 \\
\hline
\end{tabular}

Note: P-Values in Parentheses. Constant not reported.

Table A7: Constant Country Sample: Construction of the Augmented Baseline Specification

\begin{tabular}{|c|c|c|c|c|}
\hline $\begin{array}{l}\text { Dependent Variable: } \\
\text { Headline Inflation }\end{array}$ & (1) & (2) & (3) & (4) \\
\hline Unemployment Rate & $\begin{array}{c}-0.25 * * * \\
(0.00)\end{array}$ & $\begin{array}{c}-0.19^{* *} \\
(0.01)\end{array}$ & $\begin{array}{c}-0.57^{* * *} \\
(0.00)\end{array}$ & $\begin{array}{c}-0.46^{* * *} \\
(0.00)\end{array}$ \\
\hline Inflation Expectations by PFC, next year & $\begin{array}{c}0.36^{* * *} \\
(0.00)\end{array}$ & $\begin{array}{c}0.37^{* * *} \\
(0.00)\end{array}$ & $\begin{array}{c}0.29 * * * \\
(0.00)\end{array}$ & $\begin{array}{c}0.30^{* * *} \\
(0.00)\end{array}$ \\
\hline Inflation Expectations by HH, 12 months & $\begin{array}{c}0.62^{* * *} \\
(0.00)\end{array}$ & $\begin{array}{c}0.60 * * * \\
(0.00)\end{array}$ & $\begin{array}{c}0.72^{* * *} \\
(0.00)\end{array}$ & $\begin{array}{c}0.65^{* * *} \\
(0.00)\end{array}$ \\
\hline Unemp. Rate x Infl. Exp. by HH & $\begin{array}{c}0.12 \\
(0.18)\end{array}$ & & & \\
\hline Infl. Exp. By PFC x Infl. Exp. by HH & $\begin{array}{l}0.04 \\
(0.49)\end{array}$ & & & \\
\hline Budget Bal. in \% of GDP & & & $\begin{array}{c}-0.50 * * * \\
(0.00)\end{array}$ & $\begin{array}{c}-0.42^{* * *} \\
(0.00)\end{array}$ \\
\hline GR of World Energy Prices & & & & $\begin{array}{c}0.66^{* * *} \\
(0.00) \\
\end{array}$ \\
\hline Observations & 75 & 75 & 75 & 75 \\
\hline R-squared & 0.73 & 0.72 & 0.79 & 0.82 \\
\hline
\end{tabular}

Note: P-Values in Parentheses. Constant not reported. 


\section{$7 \quad$ References}

Aizenman, J. and N. Marion, 2011. "Using inflation to erode the US public debt," Journal of Macroeconomics, 33(4), pp. 524-541.

Ball, L. and S. Mazumder, 2011. "Inflation Dynamics and the Great Recession," Brookings Papers on Economic Activity, 42(1), pp. 337-405.

Borio, C., P. Disyatat, and M. Juselius, 2013. "Rethinking potential output: Embedding information about the finanical cycle," BIS Working Papers, No. 404.

Christiano, L. J., M. Eichenbaum, and M. Trabandt, 2014. "Understanding the Great Recession," NBER Working Papers, No. 20040.

Ciccarelli, M. and B. Mojon, 2005. "Global Inflation," ECB Working Paper \#0537. The paper has been published with a slightly different focus in 2010 in The Review of Economics and Statistics, 92(3), pp. 524-535.

Coibion, O. and Y. Gorodnichenko, 2013. "Is The Phillips Curve Alive and Well After All? Inflation Expectations and the Missing Disinflation," mimeo. Forthcoming in Gertler, 2014. "Lessons from the Financial Crisis for Monetary Policy."

Dahlhaus, T., K. Hess, and A. Reza, 2014. "International Transmission Channels of US Quantiative Easing: Evidence from Canada," mimeo.

Del Negro, M., M. P. Giannoni, and F. Schorfheide, 2014. "Inflation in the Great Recession and New Keynesian Models," NY FED Staff Report, No. 618.

Ehrmann, M., D. Pfajfar and E. Santoro, 2014. "Consumer Attitudes and the Epidemiology of Inflation Expectations," Bank of Canada Working Paper, No. 28.

Eickmeier, S. and K. Pijenburg, 2013. "The Global Dimension of Inflation - Evidence from Factor-Agumented Phillips Curves," Oxford Bulletin of Economics and Statistics, 75(1), pp. 103-122.

Ferroni, F. and B. Mojon 2014. "Domestic and Global Inflation," mimeo.

Gilchrist, S., R. Schoenle, J. W. Sim, and E. Zakrajšsek, 2014. "Inflation Dynamics During the Financial Crisis," mimeo.

Gordon, R., 2013. "The Phillips Curve is Alive and Well: Inflation and the NAIRU During the Slow Recovery," NBER Working Paper, No. 19390.

Hakkio, C., 2009. "Global Inflation Dynamics," Federal Reserve Bank of Kansas City Working Paper.

Hall, R., 2011. "The Long Slump," American Economic Review, 101(2), pp. 431-69. 
King, R. G. and M. W. Watson, 2012. "Inflation and Unit Labor Cost," Journal of Money, Credit and Banking, 44, pp. 111-149.

Lagarde, C., 2014. "The Global Economy in 2014," Speech at the National Press Club, Washington D.C., January 15, 2014.

Leheyda, N. and F. Verboven, 2013. "Scrapping Subsidies during the Financial Crisis - Evidence from the Europe", KU Leuven Discussion Paper Series, No. 13.

Medel, C., M. Pedersen, and Pincheira, 2014. "The Elusive Predictive Ability of Global Inflation," Bank of Chile Working Paper, No. 725.

Monacelli, T. and L. Sala, 2009. "The International Dimension of Inflation: Evidence from Disaggregated Consumer Price Data," Journal of Money, Credit and Banking, 41(s1), pp. 101-120.

Mumtaz, H. and P. Surico, 2012. "Evolving International Inflation Dynamics: World And Country-Specific Factors," Journal of the European Economic Association, 10(4), pp. 716-734.

Murphy, R., 2014. "Explaining inflation in the aftermath of the Great Recession," Journal of Macroeconomics, 40, pp. 228-244.

Svensson, L., 2013. "The Possible Unemployment Cost of Average INflation Below A Credible Target," mimeo.

WEO, 2013. "The dog that didnt bark: Has inflation been muzzled or was it just sleeping?," World Economic Outlook, Chatper 3.

Williams, J., 2010. "Sailing into Headwinds: The Uncertain Outlook for the U.S. Economy," Presentation to a Joint Meeting of the San Francisco and Salt Lake City Branch Boards of Directors, Salt Lake City, Utah. 